RISK PREFERENCES IN SMALL AND LARGE STAKES:

EVIDENCE FROM INSURANCE CONTRACT DECISIONS

Benjamin L. Collier

Daniel Schwartz

Howard C. Kunreuther

Erwann O. Michel-Kerjan

WORKING PAPER 23579 
NBER WORKING PAPER SERIES

\title{
RISK PREFERENCES IN SMALL AND LARGE STAKES: EVIDENCE FROM INSURANCE CONTRACT DECISIONS
}

\author{
Benjamin L. Collier \\ Daniel Schwartz \\ Howard C. Kunreuther \\ Erwann O. Michel-Kerjan \\ Working Paper 23579 \\ http://www.nber.org/papers/w23579
NATIONAL BUREAU OF ECONOMIC RESEARCH
1050 Massachusetts Avenue \\ Cambridge, MA 02138 \\ July 2017, Revised March 2018
}

\begin{abstract}
We thank Levon Barseghyan, Georges Dionne, Glenn Harrison, Johannes Jasperson, Dylan Small and seminar participants in the National Bureau of Economic Research Insurance Workshop, Risk Theory Society, American Risk and Insurance Association, and Society for Judgment and Decision Making for their guidance and insightful comments. We thank Juan Zhang for her research assistance. This work is partially supported by the Zurich Insurance Foundation, the Center for Risk and Economic Analysis of Terrorism Events (CREATE) at the University of Southern California (U.S. Department of Homeland Security's Center of Excellence), the Travelers-Wharton Partnership for Risk Management Fund, and the Wharton Risk Management and Decision Processes Center. D. Schwartz was supported by the Complex Engineering Systems Institute (CONICYT - PIA - FB0816; ICM P-05-004-F). The views expressed herein are those of the authors and do not necessarily reflect the views of the National Bureau of Economic Research.
\end{abstract}

NBER working papers are circulated for discussion and comment purposes. They have not been peer-reviewed or been subject to the review by the NBER Board of Directors that accompanies official NBER publications.

(C) 2017 by Benjamin L. Collier, Daniel Schwartz, Howard C. Kunreuther, and Erwann O. Michel-Kerjan. All rights reserved. Short sections of text, not to exceed two paragraphs, may be quoted without explicit permission provided that full credit, including $(\odot)$ notice, is given to the source. 
Risk Preferences in Small and Large Stakes: Evidence from Insurance Contract Decisions Benjamin L. Collier, Daniel Schwartz, Howard C. Kunreuther, and Erwann O. Michel-Kerjan NBER Working Paper No. 23579

July 2017, Revised March 2018

JEL No. D12,D81,H42,Q54

\begin{abstract}
We examine risk preferences using the flood insurance decisions of over 100,000 households. In each contract, households make a small stakes decision, the deductible, and a large stakes one, the coverage limit. Over 94 percent of household choose one of the two lowest deductibles out of six options, and 77 percent fully insure, select a coverage limit of at least their home's replacement cost. Households must be extremely risk averse to explain each of these choices with standard expected utility models. Households' deductible choices imply a median relative risk aversion of 108. Households' coverage limit choices require a median relative risk aversion of at least 112. Their substantial risk aversion over large stakes is due to households' tendency to fully insure despite paying premiums well above their contracts' expected value. Allowing for probability distortions improves our models and explains the small and large decisions of most households in our data. Assessing rank dependent utility models, we find that households follow two tenets of prospect theory: overestimation of small probabilities and diminishing sensitivity to losses.
\end{abstract}

\author{
Benjamin L. Collier \\ Department of Risk, Insurance, \\ and Healthcare Management \\ Fox School of Business \\ 1801 Liacouras Walk \\ Philadelphia, PA 19122 \\ collier@temple.edu \\ Daniel Schwartz \\ Department of Industrial Engineering \\ University of Chile \\ Republica 701 \\ Santiago, Chile \\ daschwar@dii.uchile.cl
}

\author{
Howard C. Kunreuther \\ Operations and Information Management \\ The Wharton School \\ University of Pennsylvania \\ 3730 Walnut Street, 500 JMHH \\ Philadelphia, PA 19104-6366 \\ and NBER \\ kunreuther@wharton.upenn.edu \\ Erwann O. Michel-Kerjan \\ The Wharton School \\ University of Pennsylvania \\ Center for Risk Management \\ 3730 Walnut Street, 556 JMHH \\ Philadelphia, PA 19104-6340 \\ erwannmichelkerjan@hotmail.com
}




\section{Introduction}

We analyze the risk preferences implied by the flood insurance decisions of over 100,000 households in flood-prone areas of the United States. These households purchase insurance from the National Flood Insurance Program (NFIP) to protect their homes. Households make two choices along a continuum of potential losses when purchasing flood insurance: the deductible represents a small stakes decision and the coverage limit (i.e., the maximum an insurance claim would pay) a large stakes decision.

Several papers show that households' small stakes decisions, including their deductible choices, can be difficult to reconcile with expected utility models (e.g., Rabin, 2000; Sydnor, 2010; Barseghyan, Prince, and Teitelbaum, 2011). Yet even its critics often concede that "expected utility theory certainly captures some of the intuition for risk aversion over very large stakes" (Rabin and Thaler, 2001, p. 224). Economists may justifiably embrace expected utility theory if it describes households' most economically important choices.

We start by assessing whether households' small and large stakes insurance decisions align with standard formulations of expected utility theory. We model households as constant relative risk aversion (CRRA) expected utility maximizers, and we identify the coefficient of relative risk aversion $\rho$ that best explains households' deductible choices and the coefficient that best explains their coverage limit choices. ${ }^{2}$ We also examine other expected utility models such as using constant absolute risk aversion (CARA). We use three approaches in our analysis. First, we estimate a structural random utility model (McFadden, 1974) assuming that risk preferences are similar across households. This model assumes that differences in household's premium loads (the ratio of premiums to a contract's expected value) explain differences in choices. Second, we estimate a structural random utility model that allows preferences to vary across households, modeling risk aversion as a function of variables that have been shown to influence individuals' risky decisions (e.g., cultural differences across regions). This model assumes that differences in households' insurance choices may be due to a combination of preference heterogeneity and premium loads. Finally, we conduct a non-econometric analysis in which we identify the range of relative risk aversion values that could explain a household's deductible choice and the range that could explain its coverage limit, which we call a "boundary analysis."

\footnotetext{
${ }^{2}$ CRRA utility is "the most widely used parametric family for fitting utility functions to data" (Wakker, 2008, p.1329).
} 
Standard calibrations of relative risk aversion (e.g., $\rho=1$, Arrow, 1971; Chetty, 2006; Gourinchas and Parker, 2002) predict that households would choose high deductibles and low coverage limits, but households typically do neither. Over 94 percent of households choose one of the two lowest deductible options in our data, and 77 percent fully insure, select a coverage limit of at least their home's replacement cost. We show that for households to make these two choices they must be extremely risk averse.

Regarding deductibles, our findings follow Rabin (2000) and Sydnor (2010): households' preference for low deductibles requires triple-digit relative risk aversion in each of our estimation strategies. For example, we find a median relative risk aversion $\rho=108$ from households' deductible choices in our structural econometric model with heterogeneous preferences, which correctly predicts 47 percent of households' deductibles.

Regarding coverage limits, we also find that households' choices imply triple-digit relative risk aversion. Our boundary analysis shows that the median household must have a relative risk aversion of at least 112 to explain its coverage limit. This very high risk aversion arises from a well-known theoretical result (Mossin, 1968): individuals offered insurance with premiums priced above the contract's expected value will partially insure (select a coverage limit below their replacement cost in our setting) unless they are extremely risk averse. ${ }^{3}$ Thus, theory suggests that households would fully insure rarely, but 77 percent actually do. ${ }^{4}$

Next, we assess whether households distort probabilities following rank dependent utility (Quiggin, 1982). Substantial evidence indicates that individuals misweight and/or misperceive probabilities when making decisions under risk (e.g., Preston and Baratta, 1948; Prelec, 1998). Rank dependent utility greatly improves our ability to explain households' insurance choices for

\footnotetext{
${ }^{3}$ Almost all (97 percent) of the households in our data pay premiums that exceed the expected value. This is nearly always the case in private insurance markets due to a positive loading factor (e.g., for administrative costs).

${ }^{4}$ The results of the structural random utility models of the coverage limit decision raise doubts that these models characterize households' decision making. While expected utility predicts that a household's coverage limit should be decreasing in premium loads, most households fully insure and pay higher loads when they buy more coverage. These models must then reconcile the behavior of three-quarters of households who fully insure, and require extreme risk aversion, with the 12 percent of households who choose low coverage limits, implying low relative risk aversion. Ultimately, the structural models estimate that relative risk aversion is about 3 (e.g., a median of 2.8 in the model with heterogeneous preferences), but cannot explain the coverage limits that most households select, under-predicting the average ratio of coverage relative to the replacement cost by 34 percentage points. A richer set of explanatory variables in our structural models that differentiate partial and full insurers might help generate the triple-digit risk aversion needed to explain fully insuring. But this solution attributes the distribution of choices to innate differences in households rather than a behavioral model in which households compare tradeoffs between premium and coverage.
} 
small stakes (as shown by Barseghyan et al., 2013), but also for large stakes. The CRRA rank dependent utility model correctly predicts 66 percent of households' deductible choices and overpredicts households' coverage limit ratios (coverage relative to the replacement cost) by 2 percentage points, on average (versus an under-prediction of 34 percentage points for CRRA expected utility).

Households insure in our rank dependent utility models because they overweight small probabilities. For example, households overweight the median annual likelihood of a flood, 1.33 percent, acting as if it occurs with a 10 percent probability when choosing a deductible, and 3.3 percent probability when choosing a coverage limit. Using CRRA rank dependent utility, we find small and large stakes preferences that are consistent with two tenets of prospect theory: households 1) overweight small probabilities, and 2) demonstrate diminishing sensitivity to losses (Kahneman and Tversky, 1979). The latter indicates that absolute differences matter less as the stakes increase - thus, households perceive the difference between a $\$ 1,000$ loss and $\$ 2,000$ loss as greater than that between an \$11,000 and \$12,000 loss. Given these findings, we examine the predictions of cumulative prospect theory. The Tversky and Kahneman (1992) parameters, derived from lotteries in the lab, correctly predict 56 percent of households' deductibles, and underestimate coverage limits by 16 percentage points on average. We conclude that cumulative prospect theory is a useful starting point for understanding households' insurance decisions in our data.

Our data overcomes several constraints that typically challenge one's ability to examine large stakes preferences with insurance choices. First, a household's maximum flood exposure is clearly defined. The potential maximum loss is limited by the value of the home structure, and the flood insurance program provides a specific estimate of that value to households during the application process. Second, households have greater flexibility in selecting a coverage limit than is typical of property insurance as the flood insurance program does not maintain a coinsurance clause. ${ }^{5}$ Third, the insurance covers a single hazard, flood. Finally, almost all (96 percent) of residential flood insurance policies in the U.S. are purchased through this program (Dixon et al., 2006, p.19). All households that we study have the same deductible and contract limit choices and their premiums are priced using the same rules. This structure reduces the endogenous selection problems that can

\footnotetext{
5 Private homeowners' policies normally includes a clause requiring that policyholders select a coverage limit of at least 80 percent of the replacement cost to be fully reimbursed for damages.
} 
arise from studying the policies of private insurers whose pricing and contracts may differ from their competitors.

The paper proceeds as follows. We discuss relevant research (Section 2), describe the setting and data (Section 1), provide our decision models and estimation (Section 4), and evaluate our expected utility models (Section 5) and rank dependent utility models (Section 6). In Section 7, we examine the robustness of our results and alternative explanations. For example, our findings do not change by modeling households with CARA preferences, changing the wealth assumptions in our CRRA models, or examining the choices of households in a zone with higher flood probabilities. Also, our findings do not seem to result from specific considerations relevant to flood risk or program features. Section 8 concludes and discussed implications of our research.

\section{Relevant Research}

Our research benefits from a large literature estimating risk preferences in lab settings (see Harrison and Rutström, 2008, for a review). Lab experiments are often characterized by strong internal validity and clearly defined choice sets, e.g., asking individuals to select a lottery among several alternatives. Experiments also demonstrate that participants can be highly influenced by the choice environment and context effects, as the same individual can demonstrate risk aversion or risk seeking depending on the task (e.g., Berg, Dickhaut, and McCabe, 2005).

A second literature has inferred risk aversion from individuals' major decisions, for example, through consideration of the equity premium puzzle (e.g., Barro and Jin, 2011), consumption over the life cycle (Gourinchas and Parket, 2002), and labor supply (Chetty, 2006). These studies often assume CRRA expected utility preferences and find a relative risk aversion coefficient around 1 or a little higher. These choices are undoubtedly consequential, but involve more complex decisions than the clearly defined lotteries posed in experimental settings. ${ }^{6}$

Insurance contract choices represent a third alternative, which Cohen and Einav (2007) call “(almost) an ideal setting for estimating risk aversion" (p. 745) as it mirrors the well-defined financial lotteries used in experimental settings. They examine the distribution of risk aversion

\footnotetext{
${ }^{6}$ For example, a households' labor supply decision might include working more at the same job, taking a second job, working less to seek education, etc., and the choice set differs across households. Without the ability to identify a household's choice set, it is difficult to assess how well derived risk aversion explains a household's decision among its alternatives.
} 
implied by individual's auto deductibles selections, and find substantial heterogeneity in risk preferences (e.g., a median relative risk aversion of 0.5 but an average of 44). Barseghyan et al. (2013) use random utility models to analyze households' home and auto deductible decisions and find that households overweight small claims risks. Sydnor (2010) examines the lower and upper bounds of risk aversion implied by a household's homeowners insurance deductible choice. Over 80 percent of households select a low deductible, and he finds that their deductibles often imply extremely high risk aversion (e.g., coefficients of relative risk aversion in the hundreds or thousands). He shows that cumulative prospect theory can more plausibly explain households' deductible choices. ${ }^{7}$ Our work extends previous research on risk preferences by using natural, consequential choices in the field and examining both small and large stakes insurance decisions.

\section{The Setting and Data}

Homeowners insurance in the U.S. typically does not cover flood risk. Protection against floodrelated damage can be purchased as a standalone contract from the federally-run National Flood Insurance Program (NFIP), which is overseen by the Federal Emergency Management Agency (FEMA). Households buy flood insurance from an authorized insurer or insurance agent who receives a commission intended to cover its origination and administrative costs. At the end of 2017, 5 million NFIP policies were in force for a total insured value about \$1.3 trillion (FEMA, 2017).

We examine contracts that insure single family residential structures against flood risk. ${ }^{8}$ Our data include all policies for single-family dwellings from 2001 to 2009 insured by the NFIP and all its claims from 1982 to 2009 , resulting in 16,349,345 policy observations and 635,220 claims observations for these households. We use these data to model flood risk for each policyholder, estimating the probability of a claim and the distribution of losses given a claim. In Section 3.2,

\footnotetext{
7 Also noteworthy, Baresghyan, Prince, and Teitelbaum (2011) and Einav et al. (2012) examine the extent to which households' risk preferences are consistent across domains. The former finds that households' preferences are inconsistent when comparing their homeowners, auto liability and auto comprehensive insurance deductibles. The latter examine individuals' insurance coverages (e.g., health, short-term disability) and 401(k) investment decisions and find that individuals making riskier decisions in one domain are more likely to do so in another. We complement their research by examining two decisions along the continuum of a single loss distribution for each household.

${ }^{8}$ Additionally, households can purchase flood coverage for the contents of their homes, which we do not examine. Contents coverage has its own premium, deductible, and coverage limit.
} 
we describe our baseline sample, a subset of policies that we use in our risk preference models, which includes 103,080 observations. Reported summary statistics are for this baseline sample.

Households in our primary analyses reside in areas that FEMA estimates have at least a one percent annual flood risk probability but are not prone to coastal storm surge (FEMA designates this "Zone A"). This is by far the largest risk category in the program, accounting for 47 percent (or 2.1 million) of all policies for single-dwelling homes in 2012. In Section 7, we exploit distinct features of two other zones to examine the robustness of our results: (1) homes with a higher likelihood of a claim due to storm surge, and (2) homes with less than a one percent annual flood probability, which are subject to different program requirements. The flood insurance program also treats homes differently depending on whether they were built before or after flood maps were developed; we discuss specific differences below.

Our data include the contract selected by the policyholder and the characteristics of the insured home needed to calculate premiums for any potential policy available to a household. Households can select one out of six deductible options ranging from $\$ 500, \$ 1,000$ up to $\$ 5,000$, in $\$ 1,000$ increments, and could purchase property coverage limits up to $\$ 250,000$ in $\$ 100$ increments. The selected limit can cover up to the home's replacement cost (i.e., the cost to rebuild the home using similar materials if it is destroyed). Homeowners are provided their home's replacement cost when they select an insurance policy (NFIP, 2006b, p. 4_175). In the event of a claim, the NFIP measures flood losses as a percent of the home's property value, which is assessed onsite at the time of a claim. The claims payment is then made based on the replacement cost of the loss.

\subsection{Flood Risk}

We estimate households' claim rates and loss distributions based on the characteristics of the home that the flood insurance program uses to set premium rates. Here, we provide an overview of our methodology for modeling flood risk and summary statistics on claim rates and loss distributions. Online Appendix A.1 offers a detailed explanation and additional modeling.

We model flood risk in two parts: the likelihood of a flood and given a flood, the distribution of losses. We model the claim rate as an approximation of the probability that a policyholder incurs any flood loss. ${ }^{9}$ We estimate the likelihood of a flood claim using a random effects panel logit

\footnotetext{
${ }^{9} \mathrm{We}$ assume that all flood losses are reported. While other forms of insurance create a disincentive to report small losses as it may increase future premiums (Braun et al., 2006), this flood insurance motivates reporting even minor
} 
model with policies and claims data from 2001 to 2009, which includes 16,349,345 policies. We use detailed information regarding the insured home and its vulnerability as explanatory variables. Table 1 provides summary statistics for the baseline sample; the estimated average annual flood claim probability is 1.33 percent.

We also estimate loss distributions for each household in the program using all flood claims from 1982 to 2009 , a total of 635,220 . We model losses as a percent of the property value and estimate their probability at each percentile. We find that losses follow a censored lognormal distribution and model the two parameters of this distribution, $\mu$ and $\sigma$. Losses are top-censored as all floods beyond a certain severity lead to a full loss of the home. ${ }^{10}$ Table 1 provides summary statistics for the loss distribution. The expected damage is 20.3 percent of the home's value; however, the median damage is 9 percent.

We compare this parametric approach to several nonparametric. The distribution of potential property losses is influenced by the type of event that occurs; events that affect many households (e.g., a severe storm) result in larger expected losses for each household. We account for this process in our parametric models with fixed effects that group events by their number of claims and, in our nonparametric models, by weighing observations using the number of claims for the event. Figure 1 depicts a parametric, weighted nonparametric, and unweighted nonparametric loss distribution for households in the baseline sample whose homes were built before flood maps were developed. The parametric distribution uses the median parameter values of $\mu$ and $\sigma$, and tends to fall between the weighted and unweighted nonparametric distributions. We use the probability estimates from the parametric approach in our risk preference models. Our estimates of risk are

\footnotetext{
damage so that an adjuster determines if damages exceed the deductible. For example, 2.5 percent of flood insurance claims in our data are for losses below the minimum deductible of $\$ 500$, which did not result in a claims payment. If this assumption were violated, it could be that low-value losses are under-reported, especially for households with large losses. Thus, we also examined our risk preference models using flood risk estimates that include a household's deductible as an explanatory variable. This approach leads to similar results.

${ }^{10}$ For example, suppose that a storm with 35 in. of rainfall would destroy the home. More severe storms, with rainfall exceeding 35 in., would also destroy the home, leading to the top censoring. Since we model losses in the claims data as a portion of the home's property value, all losses are on the unit interval and so we might consider a distribution that more closely matches this support (e.g., beta, logit-normal) rather than the log-normal, with support $x \in(0, \infty)$. However, our loss generating process seems to align with a censored log-normal distribution: losses are increasing in flood severity, but are capped at the full loss of the home, leading to a probability density mass at a full loss (Figure 1, see Online Appendix A.1.2 for more details).
} 
similar to those of Kousky and Michel-Kerjan (2015) who use flood insurance policies from 1980 to $2012 .{ }^{11}$

Table 1 Policy Summary Statistics

Percentiles

\begin{tabular}{lccccccc}
\cline { 5 - 7 } & Mean & St. Dev. & $1 \%$ & $10 \%$ & $50 \%$ & $90 \%$ & $99 \%$ \\
\hline Claim Rate & $1.33 \%$ & $0.56 \%$ & $0.29 \%$ & $0.70 \%$ & $1.33 \%$ & $1.56 \%$ & $3.24 \%$ \\
Loss Given a Claim & $20.3 \%$ & $26.0 \%$ & $0.4 \%$ & $1.5 \%$ & $9 \%$ & $59 \%$ & $100 \%$ \\
Premium (\$) & 540 & 326 & 147 & 219 & 490 & 932 & 1675 \\
Load & 3.22 & 2.84 & 0.76 & 1.37 & 2.69 & 5.25 & 12.17 \\
Property Value (\$) & 112,387 & 51,138 & 16,399 & 51,325 & 105,325 & 186,335 & 242,196 \\
Replacement Cost $(\$)$ & 107,177 & 57,779 & 13,300 & 41,000 & 96,300 & 195,000 & 250,000 \\
\hline
\end{tabular}

Note: "Loss given a claim" reports the median loss as a percent of a home's property value for each percentile across policyholders. Load describes a contract's ratio of premiums to expected value. Replacement cost provides the amount needed to rebuild the current structure using similar materials. We derive these claim rate and loss estimates from our flood models described in Section 3.1. Baseline sample of 103,080 policies.

\subsection{Baseline Sample}

In contrast to our flood models which use all of our data, we use a subset of the data in our risk preferences models, which includes 103,080 observations. These are policies with claims between 2003 and 2008. We focus on these years because we can replicate households' observed premiums using the program's pricing formulas well during this time. We examine households with claims because the policy and claim databases each contain distinct variables that are important to estimating preferences (e.g., our flood loss models use a home's property value which is only included in the claims database). In our baseline sample, we include only a policyholders' first claim so that each insured household is represented once in the analysis (we do not include this restriction in our flood models) to reduce potential learning effects on contract selections. Because there is a maximum coverage limit of $\$ 250.000$, we examine only homes with replacement costs up to this value so that all households in the analyses could select a coverage limit to protect the full replacement cost of their home. ${ }^{12}$

\footnotetext{
${ }^{11}$ They find an average annual claim rate of 1.45 percent versus our estimate of 1.33 . We include our corresponding estimate in brackets in the following excerpt from their paper: "half of claims [55 percent] are for less than 10 percent of the value of the building, roughly 15 percent [10 percent] of claims exceed 50 percent of the building's value, and approximately 7 percent [6 percent] exceed 75 percent of building value" (p.13).

${ }_{12}$ Ninety-five percent of all insuring households have home replacement costs of $\$ 250,000$ or less during the studied time period, 2003 to 2008.
} 


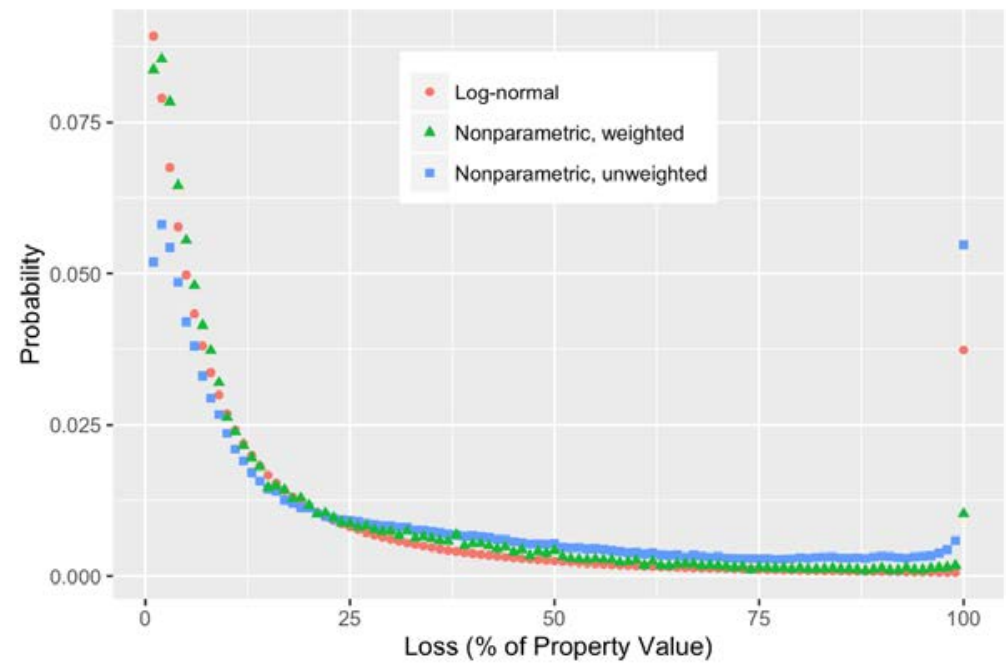

\section{Figure 1 Distribution of Losses Given a Claim}

Note: Loss distribution estimates for households in the baseline sample whose homes were built before flood maps were developed. The squares and triangles show flood loss distributions at the aggregate level in our data. The squares weight all observations equally. The triangles weight observations by the severity of the event. Events that affect many households (e.g., a severe storm) result in larger expected losses for each household. We estimate the parameters of the log-normal distribution for each household using the households' characteristics and fixed effects that account for event severity. The circles in the figure show the log-normal distribution using the median parameter estimates, $\mu=$ -2.49 and $\sigma=1.40$, for these households.

\subsection{Insurance Premiums}

Households pay a mean (median) annual premium of $\$ 540$ (\$490, Table 1$)$ that depend on the home's characteristics and the selected coverage limit and deductible. The average household pays about 72 cents for each $\$ 100$ of coverage limit up to $\$ 50,000$ and 30 cents for each $\$ 100$ above $\$ 50,000$. The deductible acts as a multiplier on the coverage limit premium. ${ }^{13}$ Table 2 provides an illustrative pricing menu, showing a subset of coverage limits for convenience. Each cell shows the median premium that a household would pay. Online Appendix A.2 provides the specific formula and additional discussion of the premium.

Table 1 includes statistics on premium loads, the ratio of a contract's premium (determined by the NFIP) relative to its expected value (determined by our flood models). Ninety-seven percent of policyholders in our baseline sample have a premium load greater than 1 (i.e., premiums above the contract's expected value). The median contract load in our baseline sample is 2.7. Loads in

13 Thus, the premium depends on $\delta p_{c}$ where e.g., $p_{c}$ is the coverage limit premium and $\delta$ the deductible multiplier. Aa household choosing between a $\$ 1,000$ and $\$ 5,000$ deductible may have a 1.0 multiplier versus 0.785 , respectively. 
our baseline sample tend to be higher than those for the program, but are within the range of other private catastrophe insurance markets (Kunreuther et al., 1995) and previous estimates of subpopulations in the NFIP (Michel-Kerjan, 2010).

Figure 2 shows the median premium loads across the deductible and coverage limit menus. Comparing loads may clarify patterns of choices in the data. For example, households with low risk aversion may not typically select a low deductible if they were maximizing their expected utility, but might do so if the premium loadings were much lower for this option. For deductible loads, we use the household's selected coverage limit and vary the deductible, and vice versa for the coverage limit choice. We observe that the median load is similar across deductible options: it is lowest (2.67) for the $\$ 1,000$ deductible and highest (2.77) for the $\$ 5,000$ deductible. For the coverage limit graph, we show coverage limits as a percent of the home's replacement cost and exclude all coverage limits above the replacement cost. The median premium loads tend to increase in the percent of the replacement cost insured, from a minimum of 1.3 to a maximum of $2.4 .{ }^{14}$ In summary at the median, contract options are priced above the expected value, and premium loads are similar across deductibles but are increasing in the coverage limit ratio. We revisit premium loads when discussing households' choices.

\section{Table 2 Illustrative Pricing Menu}

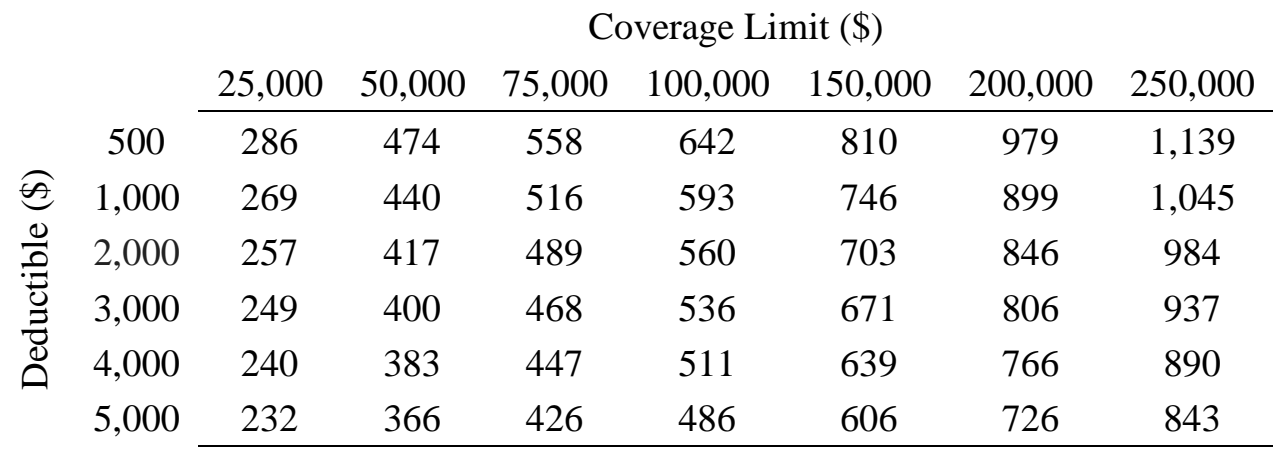

Note: Menu provides median premium values for the households in the baseline sample for different deductible and coverage limit combinations. The table shows the six deductible options. Households may select a coverage limit of up to $\$ 250,000$ with choices in $\$ 100$ increments.

\footnotetext{
${ }^{14}$ Median premium loads are lower in the coverage limit graph than the deductible graph because they exclude coverage limits that exceed the replacement cost. Some households select a larger limit, which is reflected in the deductible graph.
} 

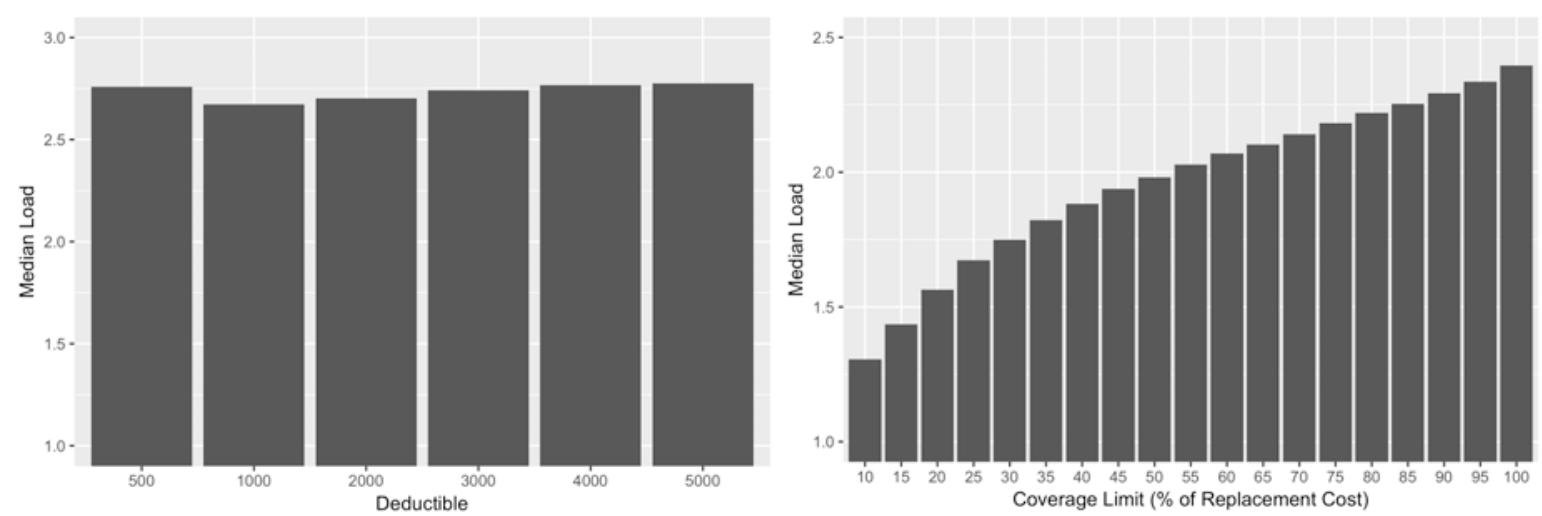

Figure 2 Median Premium Loads for Baseline Sample

Note: Figures show median premium loads for the baseline sample across the deductible and coverage limit menus. For the deductible graph, we use each household's selected coverage limit in calculating premium loads and vary the deductible, and vice versa for the coverage limit figure. We scale the coverage limit as a percent of the home's replacement cost. The histogram bins coverage limits in 5 percentage point increments such that the 100 percent bin includes limits greater than 95 percent and less than or equal to 100 percent.

\subsection{Selected Contracts}

Households overwhelmingly select low deductibles for their flood insurance, as shown in Table 3. Ninety-four percent of households selected one of the two lowest deductible choices available. The flood insurance program offers two default deductible options, depending on whether the insured home was built before federal flood maps were developed for its location: $\$ 500$ if before and $\$ 1,000$ if after). All households in our data are free to choose any of the six available options in the deductible menu, regardless of their default. ${ }^{15}$

\section{Table 3 Policyholder Deductible Selection}

\begin{tabular}{lcccccc} 
Deductible & $\$ 500$ & $\$ 1,000$ & $\$ 2,000$ & $\$ 3,000$ & $\$ 4,000$ & $\$ 5,000$ \\
\hline Policyholders $(\%)$ & 46.6 & 47.4 & 1.4 & 0.5 & 0.2 & 3.8 \\
\hline
\end{tabular}

Note: Baseline sample of 103,080 policies.

Figure 3 shows the coverage limits selected as a proportion of the home's replacement cost separately for households selecting the $\$ 500, \$ 1,000$, and $\$ 5,000$ deductibles. Households most commonly select a coverage limit equal to their replacement cost; 42 percent of all policyholders do this. About a third of households select a coverage limit that exceeds the replacement cost, even

\footnotetext{
${ }^{15}$ Seventy-two percent of households with a $\$ 1,000$ default keep this deductible, 19 percent select the $\$ 500$, and about 9 percent choose a higher deductible. Eighty-two percent of households with a $\$ 500$ default keep this deductible, 15 percent select the $\$ 1,000$ deductible, and 3 percent choose a higher deductible. We explore the effects of deductible defaults in Section 7.
} 
though they cannot receive a payment greater than this amount. Mossin (1968) explains this behavior: "there may be some uncertainty as to what will be the actual evaluation of the property in case of damage. We have not taken this kind of randomness into account in our theory, but it seems a perfectly reasonable hypothesis that it will lead to a number of observed cases of full (or over-) insurance" (p. 558). ${ }^{16}$ We conclude that households who insure at or above the replacement cost of their home intend to fully insure. In Online Appendix A.7.8, we exclude households that over-insure and retest our models, finding that their exclusion does not qualitatively change our main findings. Figure 3 also shows that households who select a higher deductible are more likely to select lower coverage limits, with a Spearman rank correlation of $0.14, p<0.01 .^{17}$

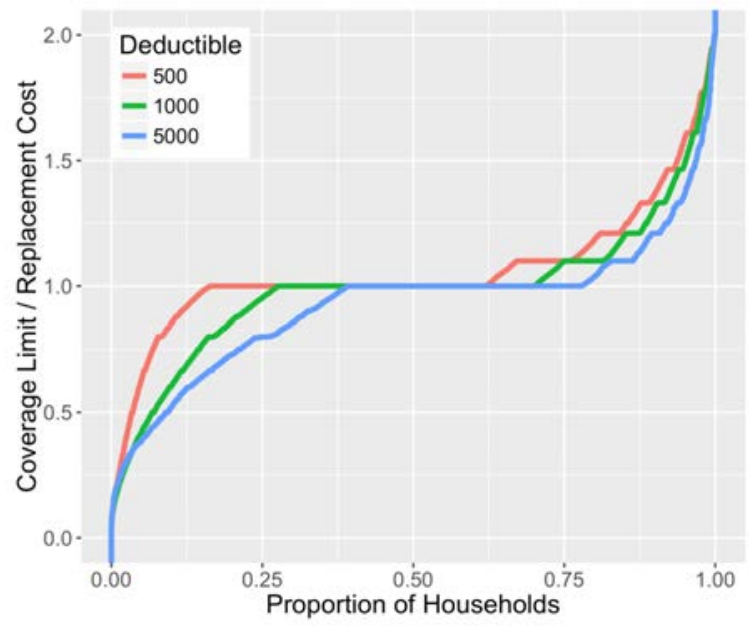

\section{Figure 3 Household Coverage Limit Selections}

Note: The figure provides household coverage limit selections as a proportion of the replacement costs of their homes separately for households selecting the $\$ 500, \$ 1,000$, and $\$ 5,000$ deductibles. Households cannot receive an insurance payout that exceeds their replacement cost. Baseline sample of 103,080 policies.

Table 4 compares several characteristics of insured homes across the most common deductible choices and divides coverage limits into households that select coverage limits less than their replacement cost ("Partial"), at the replacement cost ("Full"), and above the replacement cost

\footnotetext{
${ }^{16}$ Households whose property values are larger than their replacement cost are twice as likely to over-insure. About 43 percent of households who do not over-insure have a property value that exceeds the replacement cost while 72 percent of over-insurers do. These households may approach the insurance decision with an estimate of their property value, receive a lower replacement cost from their insurance agent, and buy a coverage limit above the replacement cost to make certain that their coverage is sufficient.

${ }^{17}$ This pattern could be explained by risk aversion: less risk averse households purchase higher deductibles and lower coverage limits than more risk averse households. This correlation across choices is similar to Einav et al. (2012), who find an average Spearman rank correlation of 0.19 across insurance coverages.
} 
("Over"). It shows that households choosing the $\$ 5,000$ deductible tend to have higher claim rates, higher premiums, homes at lower elevation, older homes, and homes that were built before flood maps were developed. Partially insuring households tend to have homes at lower elevation, with lower property values, and that were built before flood maps were developed.

\section{Table 4 Contract Choices and Descriptive Statistics}

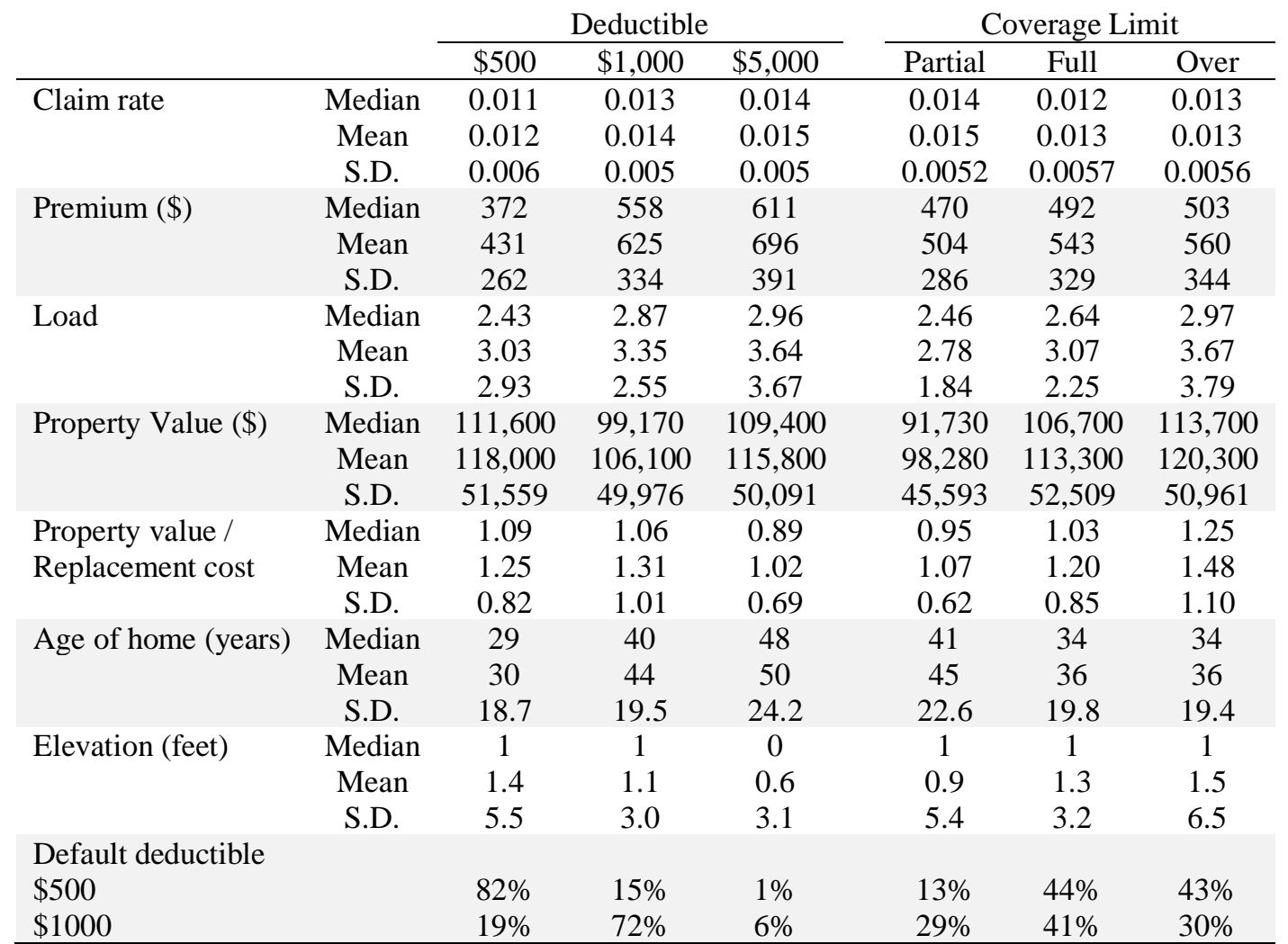

Note: Home characteristics and households' deductible and coverage limit selections. For the deductible, we show the three most commonly selected deductibles. For coverage limits, we divide households into those that select limits below ("Partial"), at ("Full"), and above ("Over") the replacement cost. Load describes a contract's ratio of premiums to expected value. Elevation is relative to the 100-year flood plain. Baseline sample of 103,080 policies.

The premium loads in Table 4 are noteworthy. Households choosing the $\$ 5,000$ deductible tend to have higher premium loads than those choosing lower deductibles; however, fully insuring households tend to have higher premium loads than partially insuring households. ${ }^{18}$ If we assume that households have similar risk preferences, we would expect to see the former pattern, households with higher premium loads choose higher deductibles, but not the latter. However, our

\footnotetext{
${ }^{18}$ Excluding households who over-insure, we find a Spearman rank correlation between a household's premium load and its coverage limit ratio of $0.08, p<0.01$. These households have a rank correlation of $0.12, p<0.01$, between their premium load and deductible choice.
} 
structural models can capture differences not shown in these summary statistics and so we return to this point in Section 5 .

\section{Modeling Households' Preferences}

\subsection{Insurance Decisions}

Our analyses of risk preferences begin with expected utility models. We present this model, but extend it to include rank dependent utility below (Section 4.2.2). We assume that households' deductible selection problem is

$$
\max _{d \in\left\{d_{1}, d_{2}, \ldots, d_{n}\right\}} \int_{0}^{d} u(w-p(d)-l) \pi(l)+\int_{d}^{c^{*}} u(w-p(d)-d) \pi(l)+\int_{c^{*}}^{h} u\left(w-p(d)-d-l+c^{*}\right) \pi(l) \quad d l
$$

where $u(x)$ represents standard utility (i.e., monotonically increasing in $x$, at least twice differentiable, etc.), $d$ is the deductible, $c^{*}$ the coverage limit that the household selects, $h$ the total replacement cost of the home, $p$ the premium, $w$ wealth, and $l$ losses with $l \in[0, h]$, which occur with probability $\pi(l)$. The first integrand accounts for flood losses less than the deductible, the second accounts for losses above the deductible but less than the coverage limit, and the third accounts for losses greater than the coverage limit selected by the household. Similarly, the households' coverage limit decision is

$$
\max _{c \in[\underline{c}, \bar{c}]} \int_{0}^{d^{*}} u(w-p(c)-l) \pi(l)+\int_{d^{*}}^{c} u\left(w-p(c)-d^{*}\right) \pi(l)+\int_{c}^{h} u\left(w-p(c)-d^{*}-l+c\right) \pi(l) d l
$$

where $d^{*}$ is the deductible that the household selects.

As we describe in Section 1, the data provide each household's deductible and coverage limit choices, $d^{*}$ and $c^{*}$, the pricing schedule that allows us to determine the premium $p$ for any contract, and the home's replacement $\operatorname{cost} h$. The claims data allows us to estimate flood probabilities $\pi(l)$ for each household. We apply these probabilities to a household's replacement cost, and assume the household's wealth $w$ is its home's replacement cost. ${ }^{19}$ We test our results with other wealth assumptions including using the property value as wealth (Section 7).

As shown in Equations 1 and 2, we assume that a household compares deductible options while holding its selected coverage limit constant, and vice versa for the coverage limit decision.

\footnotetext{
${ }^{19}$ The implicit assumption we make is that if a home is damaged by flood, the household will replace what was damaged. An alternative would be to measure losses in terms of the property value instead of the replacement cost. This modeling choice regarding losses seems to align with households' decisions as households most commonly select a coverage limit that equals their replacement cost (Section 3.4).
} 
This approach allows for risk attitudes to differ across deductible and coverage limit decisions; however, it can lead to similar parameters for each choice if households' preferences are similar for these decisions. This type of analysis, examining a specific choice while holding all other decisions constant, is a ubiquitous feature of decision making models. For example, analyses of auto or homeowners insurance deductibles tend to abstract away from other contract features such as liability limits (e.g., Cohen and Einav, 2007; Sydnor, 2010). ${ }^{20}$

We model households with CRRA utility:

$$
u(x)= \begin{cases}\frac{1}{1-\rho} x^{1-\rho} & \rho \neq 1 \\ \ln (x) & \rho=1\end{cases}
$$

$$
\text { s. t. , } x>0
$$

where $\rho$ is the Arrow-Pratt coefficient of relative risk aversion and impose a minimum such that final wealth never falls below $\$ 1$.

We follow several assumptions commonly used in the literature estimating preferences from households' insurance decisions (e.g., Cohen and Einav, 2007; Sydnor, 2010; Barseghyan et al., 2013). They are that households know the contract options available to them, their contracts reflect their preferences (e.g., that households compare the contract alternatives and select the observed deductible and coverage limit), the contract choice does not alter the households' loss probabilities (i.e., no moral hazard), households know their loss probabilities, and they face at most one flood loss during the year. A key difference from previous research is that our models require that households have more detailed knowledge of their loss probabilities. The papers above examine deductible choices only and so assume that households know their claim rates; our examination of coverage limits leads us to assume that households understand their flood loss distributions. In

\footnotetext{
${ }^{20}$ Our deductible problem reduces to the one studied by Sydnor if we assume that all households select a coverage limit that equals the replacement cost (see Sydnor, 2010, p. 188).

We also estimated the joint optimization problem in which households select among all possible combinations of the deductible and coverage limit

$$
\max _{d \in\left\{d_{1}, d_{2}, \ldots, d_{n}, c \in[c, c]\right.} \int_{0}^{d} u(w-p(c)-l) \pi(l)+\int_{d}^{c} u(w-p(c)-d) \pi(l)+\int_{c}^{h} u(w-p(c)-d-l+c) \pi(l) d l .
$$

As two contract choices fit one risk aversion parameter, this model is over-identified and so we include it here with caution as a potentially useful reference. We find a similar risk aversion estimate to that of the modeled coverage limit problem (where $\rho=2.7$ versus 2.9 for the joint problem), suggesting that the coverage limit decision largely determines the estimate from the joint problem.
} 
Section 6, we consider whether households' decisions suggest that they distort objective probabilities (e.g., by misestimating flood risks).

\subsection{Estimation}

\subsubsection{Flood Probabilities}

Here, we discuss our flood models, presented in Section 3.1, in the context of estimating risk preferences. We estimate the likelihood of a flood for household $i, \gamma_{i}$, using a random effects panel logit. Random effects account for the possibility of unobserved heterogeneity in flood rates across households. Our models estimate the two parameters of a censored log-normal distribution for each household, conditioning on the household's characteristics. Let $G_{i}$ represent the cumulative, log-normal loss distribution for household $i$. A household's cumulative distribution of flood losses $l$ is

$$
\Pi_{i}(l)=\left\{\begin{array}{cc}
1-\gamma_{i} & \text { if } l=0 \\
\gamma_{i} G_{i}(l) & \text { if } l>0
\end{array}\right.
$$

We discretize the state space, considering each percentage point loss from 0 to 100 percent of the home's replacement cost value $h$ such that the household's possible losses are a $1 \times 101$ vector, $\left\{0,0.01 h_{i}, 0.02 h_{i}, \ldots, h_{i}\right\}$. We take first differences of the cumulative distribution to create the household's probability density function, $\pi_{i}$ (e.g., $\left.\pi_{i}\left(h_{i}\right)=\Pi_{i}\left(h_{i}\right)-\Pi_{i}\left(0.99 h_{i}\right)\right)$. Thus, the calculated expected utility of household $i$, given its contract choices, is

$$
v_{i}=\sum_{l \in\left\{0,0.01 h_{i}, \ldots, h_{i}\right\}} \pi_{i}(l) u_{i}(l)=\sum_{l} \pi_{i}(l) u_{i}(w-p-\min (d, l)+\min (0, c-l)) .
$$

\subsubsection{Risk Preferences, Structural Estimates}

We adopt a random utility framework (McFadden, 1974) and fit value function parameters using maximum likelihood estimation. For household $i$, let

$$
g_{i}(k ; \boldsymbol{\theta}, \sigma) \equiv v_{i}(k ; \boldsymbol{\theta})+\epsilon_{i}(k ; \sigma)
$$

where $v$ represents the household's probability-weighted value function, a specific contract $k \in$ $K, \theta$ vector of value function parameters such as relative risk aversion (and probability weights for rank dependent utility models), and $\epsilon_{k}$ an i.i.d. error component, which is assumed to be distributed type 1 extreme value with scale parameter $\sigma$. Thus, households' utility $g$ comprises two additively separable components, a deterministic part $v$ and a random part $\epsilon$, which is jointly 
distributed across the choice set $K$. Parameter $\sigma$ is a transformation of the variance of the error term such that larger values indicate more unexplained variation in the choice. The probability that a household chooses contract $k$ is

$$
\operatorname{Pr}\left(k_{i} ; \theta, \sigma\right)=\operatorname{Pr}\left(\epsilon_{i k^{\prime}}-\epsilon_{i k}<v_{i k}-v_{i k^{\prime}} \forall k \neq k^{\prime}\right)=\frac{\exp \left(v_{i}(k ; \boldsymbol{\theta}) / \sigma\right)}{\sum_{k^{\prime} \in K} \exp \left(v_{i}\left(k^{\prime} ; \boldsymbol{\theta}\right) / \sigma\right)} .
$$

Our estimation strategy solves the log-likelihood problem

$$
\underset{\boldsymbol{\theta}, \sigma}{\operatorname{argmax}} \sum_{i=1}^{N} \sum_{k=1}^{K} y_{i k} \ln \operatorname{Pr}\left(k_{i} ; \theta, \sigma\right)
$$

where $y_{i k}=1$ if household $i$ chooses contract $k$ and 0 otherwise (Cameron and Trivedi, 2005, Chapter 15). We model households' deductible choices using the six available options: $\$ 500$, $\$ 1,000, \$ 2,000 \ldots \$ 5,000$. We model households' coverage limits from $\$ 10,000$ to $\$ 250,000$ in $\$ 10,000$ increments. ${ }^{21}$ Throughout, we estimate the parameters from households' deductible decisions and from their coverage limit decisions and compare these parameters.

Expected utility models. In Section 5.2, we model households as expected utility maximizers and estimate $\rho$ and $\sigma$. Thus, in this model, we assume that households have similar preferences and that their choices vary due to differences in their premium loads (or due to choice errors $\epsilon$ ). Parameter $\rho$ is the risk aversion that best explains households' contract choices and so is akin to research that characterizes a population's risk aversion.

${ }^{21}$ McFadden's random utility model cannot always differentiate between similar choices (e.g., Cameron and Trivedi, 2005, Chapter 15); a menu with many similar options can reduce the sensitivity of choice probabilities to model parameters, complicating the maximum likelihood estimation (MLE). Our preferred model with $\$ 10,000$ increments, which leads to 25 coverage limit options, might create too many similar options. We also modelled households' coverage limits in increments of $\$ 25,000$ and of $\$ 1,000$ and derived similar preference estimates to estimated using our preferred model in each case.

Apestugiua and Ballester (2016) find that for random utility models, the likelihood of choosing riskier lotteries can be non-monotonic, decreasing then increasing in risk aversion for CRRA and CARA models. This pattern can occur because the differences between the expected utility derived from two contract choices (e.g., $v_{i k}$ and $v_{i k^{\prime}}$ in Equation 6) decreases as risk aversion grows and so model errors $\left(\epsilon_{i k}\right.$ and $\left.\epsilon_{i k^{\prime}}\right)$ can play a more prominent role in influencing the choice probabilities. Barseghyan et al. (2016) note that, for models of homogeneous preferences, jointly estimating the scale parameter $\sigma$ and the preference parameters (which we do) reduces this problem by allowing the distribution of errors to adjust with the preference parameters. The problem may be greater for models with heterogeneous preferences as the same scale parameter is used for households along a distribution of risk aversion. We compare our models assuming heterogeneous preferences with other estimation strategies with this in mind.

We jointly estimate the scale parameter $\sigma$ with preference parameters $\theta$. As is typical, we normalize a household's utility to facilitate joint estimation of the scale and preference parameters (Train, 2009, Chapter 2). We apply an affine transformation, using the difference in the maximum and minimum $v_{i}$ in the choice set, $v_{i}^{n}(k ; \theta)=$ $\left(v_{i}(k ; \theta)-v_{i}\left(k_{\min } ; \theta\right)\right) /\left(v_{i}\left(k_{\max } ; \theta\right)-v_{i}\left(k_{\min } ; \theta\right)\right)$, where $k_{\max }$ and $k_{\min }$ are the contracts resulting in the maximum and minimum $v_{i}$, respectively, given preference parameters $\theta$. We implement the MLE in $\mathrm{R}$ using differential evolution algorithms for the optimization (Ardia et al., 2016). 
Section 5.3 allows risk aversion to vary across households. Thus, in this model, we assume that choices may also differ across households due to differences in risk aversion. We model risk aversion as a function of the characteristics of the household and the home that have been shown to influence individuals' decisions under risk, such as recent severe events (Gallagher, 2014), culture or region (Harrison, Humphrey, and Verschoor, 2010), proxies for income and wealth (Cohen and Einav, 2007), and menu default options (Johnson et al., 1993). Specifically, we model

$$
\rho_{i}=\lambda_{j}+\delta_{t}+\eta_{1} \text { PropertyValue }_{i}+\eta_{2} \text { Age }_{i}+\eta_{3} I\left(\text { DefaultDeductible }_{i}=\$ 1,000\right)
$$

where $\lambda_{j}$ and $\delta_{t}$ are respectively region, using the nine U.S. Census Bureau divisions, and year fixed effects. Age is the age of the home. The property value serves as a proxy for income and other aspects such as educational attainment that may affect its risk preferences but are not included in the utility function. DefaultDeductible is indicator for whether the household has a $\$ 500$ or $\$ 1,000$ default. The identifying assumption is that households' risk aversion as indicated by their contract choices is a function of these characteristics. ${ }^{22}$ Thus, these structural models for the deductible and coverage limit decisions each estimate a $1 \times 17$ parameter vector $\left\{\lambda_{j}, \delta_{t}, \eta, \sigma\right\}$.

Rank dependent utility models. In Section 6, we model households as rank dependent utility maximizers, allowing for distortions on the cumulative probability distribution following Quiggin (1982). First, we construct the cumulative distribution in which outcomes and their probabilities are ordered from "worst to best," which we denote $\Pi_{i}^{\prime}$. In our setting, the worst outcome is a flood that destroys the home completely and the best is no flood event. Second, apply probability weights to the ranked cumulative (e.g., the weighting function of Prelec, 1998), which we denote $\Omega\left(\Pi_{i}^{\prime}\right)$. We apply the constraints that the transformed probabilities are between zero and one and sum to one. Thus, a net overweighting of flood probabilities results in an underweighting of the outcome in which no flood occurs and vice versa. Third, we take first differences of the weighted cumulative distribution to create the household's weighted probability density function, $\omega\left(\pi_{i}^{\prime}\right)$. The rank dependent utility of household $i$, given its contract choices, is

$$
v_{i}^{R D U}=\sum_{l \in\left\{0,0.01 h_{i}, \ldots, h_{i}\right\}} \omega_{i}(l) u_{i}(l) .
$$

\footnotetext{
${ }^{22}$ Standard conceptualizations of risk aversion would follow the null hypothesis that a household's default deductible (and perhaps other explanatory variables here) should not affect its optimal choice. Including the default deductible not only examines this prediction, but shows the effect of the default on estimated risk aversion.
} 
While a variety of probability distortion models have been proposed (e.g., Tversky and Kahneman, 1992; Prelec, 1998), the probabilities in our data are small relative to the values typically tested in previous studies. We take a flexible approach, estimating probability weights using a polynomial approximation (Barseghyan et al., 2013). In Online Appendix A.4, we model probability weighting in households' insurance decisions using Chebyshev polynomials and CRRA utility. We find that a second-degree polynomial best approximates households' deductible decision, which we can write as $\Omega_{\mathrm{i}}=\beta_{0}+\beta_{1} \Pi_{\mathrm{i}}^{\prime}+\beta_{2} \Pi_{i}^{\prime 2}$ where $\Pi_{\mathrm{i}}^{\prime}$ is the rank-ordered cumulative flood loss probabilities of household $i$. If households do not distort probabilities, we would find $\beta_{0}, \beta_{2}=0$ and $\beta_{1}=1$, which would provide support for expected utility. We find that a firstdegree polynomial best approximates probability weighting in households' coverage limit decisions such that $\Omega_{\mathrm{i}}=\beta_{0}+\beta_{1} \Pi_{\mathrm{i}}^{\prime}$.

Using Chebyshev polynomials, we estimate a model in which we assume that households are risk neutral but may distort probabilities (Yaari, 1987) in Section 6.1. For these models, we report parameters $\left\{\beta_{0}, \beta_{1}, \beta_{2}, \sigma\right\}$ for the deductible model and $\left\{\beta_{0}, \beta_{1}, \sigma\right\}$ for the coverage limit model. Thus, in these models, we assume that households distort probabilities similarly and that their choices vary due to differences in their flood probabilities (or due to choice errors $\varepsilon$ ). In Section 6.2, we estimate both a CRRA value function and probability distortion parameters and so report $\left\{\rho, \beta_{0}, \beta_{1}, \beta_{2}, \sigma\right\}$ for the deductible model and $\left\{\rho, \beta_{0}, \beta_{1}, \sigma\right\}$ for the coverage limit model. Finally, we compare our findings in which we model distortions with Chebyshev polynomials to those using probability weighting functions from Prelec (1998) and Wu and Gonzalez (1996) in Section A.6. Prelec's function is $\Omega_{I}=\exp \left(-v\left(-\ln \left(\Pi_{\mathrm{i}}^{\prime}\right)\right)^{\psi}\right)$ where $v$ and $\psi$ are model parameters. The Wu-Gonzalez weighting function is $\Omega_{i}=\delta \Pi_{i}^{\prime \gamma} /\left(\delta \Pi_{i}^{\prime \gamma}+\left(1-\Pi_{i}^{\prime}\right)^{\gamma}\right)$. We estimate parameters $\{\rho, v, \psi, \sigma\}$ in the CRRA models with Prelec distortions, and $\{\rho, \delta, \gamma, \sigma\}$ in the CRRA models with Wu-Gonzalez distortions.

\subsubsection{Risk Preferences, Boundary Analysis}

For comparison with the expected utility structural econometric estimates of risk aversion, we also use a non-econometric approach in which we find the minimum and maximum level of risk aversion that would motivate a CRRA expected utility household to select its chosen deductible rather than an alternative, following Sydnor (2010). We similarly calculate the lower and upper 
bound coefficient of relative risk aversion for each household required to explain its coverage limit decision. For example, the lower bound risk aversion for the deductible $\rho_{d, i}^{-}$makes the household indifferent between its selected deductible $d_{i}$ and the next highest deductible $d_{i}^{+}$, $v\left(d_{i}, \rho_{\bar{d}, i}^{-}\right) \sim v\left(d_{i}^{+}, \rho_{d, i}^{-}\right)$.

This approach differs from our structural estimation strategy. First, it does not allow for point identification of risk aversion, but indicates a range of potential values. Second, it does not assume choice errors and so is deterministic, does not allow for statistical hypothesis testing, and does not impose a parametric distribution on risk aversion. Finally, unlike our structural models that examine heterogeneity in risk aversion, this approach does not require explanatory variables that meaningfully relate to a household's risk preferences to model risk aversion.

\subsection{Identification of Model Parameters}

We provide the intuition regarding how variation in our data allows us to estimate model parameters. It follows from a large literature on identifying individuals' risk attitudes from their lab choices or insurance choices (e.g., Hey and Orme, 1994; Holt and Laury, 2002; Cohen and Einav, 2007; Ericson et al., 2016; see reviews from Harrison and Rutström, 2008, and Barseghyan et al., 2016).

Expected utility models estimate risk aversion by examining households' willingness to pay for insurance as revealed by their contract choices. The problem is akin to identifying an individual's certainty equivalent for a lottery in a lab setting. Suppose a household is choosing between two insurance contracts $k$ and $k^{\prime}$ where $k^{\prime}$ reduces uncertainty in final wealth relative to $k$ (e.g., through a higher coverage limit). The magnitude of the premium relative to the contract's expected value that the household is willing to pay determines the level of risk aversion (e.g., for CRRA, it determines the curvature of the value function, described by $\rho$ ). Given the elements required to populate a household's decision problem (e.g., loss probabilities, menu options, etc.), variation in premiums and selected contracts (selected coverage limits or deductibles) across households allows for identification of risk aversion in random utility models.

Rank dependent utility models differentiate risk aversion and probability weighting in the spirit of Jensen's inequality. Probability weighting (parameters outside the utility function, $u_{i}$ in Equation 7) affects willingness to pay differently than risk aversion (parameters inside the utility function). Consider a risk-neutral household who distorts probabilities using a probability 
weighting function. Its willingness to pay for insurance increases proportionally with its probability weights - ceteris paribus, willingness to pay doubles if the weighted probability of a claim doubles. In contrast, the willingness to pay of an expected utility maximizer is nonlinear in risk aversion (Ericson et al., 2016). Households' selections across a menu of insurance contract options (e.g., more than two deductible options) allows for differentiation between curvature in the value function and probability distortions as our data include both exogenous variation in the risk of loss and premiums (Section 3).

In addition, we assume that any unobserved heterogeneity in households' flood risk is independent of their contract choices. Several studies consider the joint distribution of risk and risk preferences (see Einav, Finklestein, and Levin, 2010, for a review). That research tends to focus on adverse selection and examines settings in which policyholders may be especially likely to have private information about their risk such as auto insurance and annuity. The typical concern is that the econometrician's preference estimates may be biased if they do not account for the effects of private information on households' decisions. ${ }^{23}$

Our assumption is convenient: jointly estimating risk and risk preference would create a substantial computational challenge in our setting as we evaluate a large state space by modeling the flood loss distribution of each household. However, we also believe that households do not tend to have an informational advantage regarding their flood risk. The primary source of public data on flood risk is the flood maps developed by FEMA and the loss statistics reported by the NFIP (2018). We use this information in our probability models. As an additional precaution, we examine only a household's contract choices at the time of its policy's first flood claim in our risk preference models. Thus, the decisions of households who have learned from their previous flood claims and possibly obtained private information are omitted from our risk preferences analyses.

\footnotetext{
${ }^{23}$ Note that the consideration here is the information available to the econometrician versus the household, which we might denote "econometric adverse selection." Flood insurance premium loads differ across households because of policy-related program rules (Section 3.3). It is not problematic for our analysis if households who are charged low premium loads buy more insurance ("program adverse selection") as variation in premiums relative to risk helps our identification. Evidence on program adverse selection in insurance markets differs across settings, typically with no or small effects in property insurance markets (Cohen and Siegelman, 2010).
} 


\section{Expected Utility}

We examine households' small and large stakes decisions in the context of expected utility. We use CRRA utility because of its prevalence (Wakker, 2008) and previous research indicating that risk preferences are approximately proportional in wealth (e.g., Friend and Blume, 1975), but we also examine CARA and expo-power utility functions (Section 7). Our primary analyses consider what coefficient of relative risk aversion best characterizes a decision in our data using MLE in the random utility model described in Section 4.2 and how well each model explains households' choices. ${ }^{24}$ We summarize the results at the end of this section.

\subsection{CRRA, Canonical Model}

We begin with a descriptive analysis to examine the choices that households would make if they were CRRA expected utility maximizers with a coefficient of relative risk aversion $\rho=1$, a canonical value from previous research (Arrow, 1971; Chetty, 2006; Gourinchas and Parker, 2002). Thus, we do not estimate structural parameters in this model, but include it as a reference for what we might expect a representative household to do.

The canonical model, CRRA expected utility with $\rho=1$, predicts that households would insure much less of their risk than they do. It predicts that households would select high deductibles and low coverage limits. Figure 4 provides households' deductible and coverage limit choices and those predicted by our models. "Actual" is the distribution of households" choices and "EUT CRRA, $\rho=1$ " describes the predictions of the canonical model. For the deductible, the model predicts that 92 percent of households would select the highest deductible $(\$ 5,000)$ while more than 90 percent select one of the lowest two deductible options ( $\$ 500$ and $\$ 1,000)$. In total, the model correctly predicts the deductibles selected by 8 percent of households. For the coverage limit, the model predicts that 85 percent of households would select a coverage limit of less than half of their replacement cost while only about 5 percent do. The low predicted coverage limits result from the contract loads. A risk averse household will tend to prefer increasingly larger deductibles as contract loads increase, reducing coverage for moderate stakes but maintaining it

\footnotetext{
${ }^{24}$ We report several measures to compare models such as the Akaike information criterion (AIC). Comparisons of model predictions and actual choices are not a suitable goodness-of-fit statistic as random utility models are probabilistic (Train, 2009, Chapter 3), but model predictions are an important consideration regarding whether the assumed model seems to characterize households' decisions.
} 
for large stakes. However, given the deductible options, the only way that households can reduce their insurance after selecting the $\$ 5,000$ deductible is by selecting a lower coverage limit, leading to the coverage limit predictions of the canonical model.

Table 5 Model Results, Maximum Likelihood Estimation

\begin{tabular}{|c|c|c|c|c|c|c|c|c|c|}
\hline & & $\rho$ & $\beta_{0}$ & $\beta_{1}$ & $\beta_{2}$ & $\sigma$ & $\begin{array}{c}\text { Log } \\
\text { Likelihood }\end{array}$ & AIC & BIC \\
\hline \multirow[t]{2}{*}{ EUT CRRA } & Deductible & $\begin{array}{c}139 \\
(0.85)\end{array}$ & & & & $\begin{array}{c}0.377 \\
(0.0031)\end{array}$ & $-168,942$ & 337,888 & 337,907 \\
\hline & $\begin{array}{c}\text { Coverage } \\
\text { Limit }\end{array}$ & $\begin{array}{c}2.72 \\
(0.0068)\end{array}$ & & & & $\begin{array}{c}0.191 \\
(0.0012)\end{array}$ & $-299,923$ & 599,850 & 599,869 \\
\hline \multirow[t]{2}{*}{$\begin{array}{l}\text { EUT CRRA, } \\
\text { heterogeneous }\end{array}$} & $\begin{array}{l}\text { Deductible } \\
\text { Mean } \\
\text { Median }\end{array}$ & $\begin{array}{l}113 \\
108\end{array}$ & & & & $\begin{array}{c}0.310 \\
(0.002)\end{array}$ & $-164,935$ & 329,908 & 330,090 \\
\hline & $\begin{array}{l}\text { Cov. Limit } \\
\text { Mean } \\
\text { Median }\end{array}$ & $\begin{array}{l}2.81 \\
2.78\end{array}$ & & & & $\begin{array}{c}0.184 \\
(0.001)\end{array}$ & $-297,756$ & 859,549 & 595,730 \\
\hline \multirow[t]{2}{*}{ RDU Yaari } & Deductible & & $\begin{array}{c}0.023 \\
(0.0016)\end{array}$ & $\begin{array}{c}5.80 \\
(0.045)\end{array}$ & $\begin{array}{c}-0.228 \\
(0.0016)\end{array}$ & $\begin{array}{c}0.175 \\
(0.0007)\end{array}$ & $-104,378$ & 208,764 & 208,802 \\
\hline & $\begin{array}{l}\text { Coverage } \\
\text { Limit }\end{array}$ & & $\begin{array}{c}0.00711 \\
(0.000031)\end{array}$ & $\begin{array}{c}1.49 \\
(0.024)\end{array}$ & & $\begin{array}{c}0.120 \\
(0.00048)\end{array}$ & $-245,684$ & 491,374 & 491,403 \\
\hline \multirow[t]{2}{*}{ RDU CRRA } & Deductible & $\begin{array}{c}-4.08 \\
(0.059)\end{array}$ & $\begin{array}{c}0.029 \\
(0.014)\end{array}$ & $\begin{array}{c}6.03 \\
(0.023)\end{array}$ & $\begin{array}{l}-59.14 \\
(0.014)\end{array}$ & $\begin{array}{c}0.186 \\
(0.000074)\end{array}$ & $-103,865$ & 207,740 & 207,788 \\
\hline & $\begin{array}{l}\text { Coverage } \\
\text { Limit }\end{array}$ & $\begin{array}{c}-0.767 \\
(0.0088) \\
\end{array}$ & $\begin{array}{c}0.00774 \\
(0.000034) \\
\end{array}$ & $\begin{array}{c}3.64 \\
(0.027) \\
\end{array}$ & & $\begin{array}{c}0.125 \\
(0.00049)\end{array}$ & $-244,469$ & 488,946 & 488,984 \\
\hline
\end{tabular}

Note: Standard errors are in parentheses. Table compares utility models describing households' deductible and coverage limit decisions, using the Akaike information criterion (AIC) and Bayesian information criterion (BIC). Lower values indicate better fit for the AIC and BIC. The parameter $\sigma$ describes the scale of errors in the random utility model. The EUT CRRA heterogeneous model estimates risk aversion as a function of the household's characteristics. We allow for probability distortions using rank dependent utility (RDU, Quiggin, 1982). Parameters $\beta$ show probability distortions $\Omega=\beta_{0}+\beta_{1} \Pi^{\prime}+\beta_{2} \Pi^{\prime 2}$ where $\Pi^{\prime}$ is the rank-ordered cumulative objective probability. Expected utility theory (EUT) assumes that households weight outcomes based on their objective probabilities and so these models fix $\beta_{0}, \beta_{2}=0$ and $\beta_{1}=1$. Yaari (1987) assumes that households are risk neutral but may distort probabilities. Negative values of $\rho$ indicate diminishing sensitivity to losses. If a parameter is missing it is assumed to take the value $\rho, \beta_{0}, \beta_{2}=0$, and $\beta_{1}=1$. Baseline sample of 103,080 policies.

\subsection{Characterizing Preferences with CRRA, Homogeneous Risk Aversion}

Next, we use MLE to identify the risk aversion coefficients that characterize households' preferences for deductibles and coverage limits, labeled "EUT CRRA" in Figure 4 and Table 5. The EUT CRRA deductible model correctly describes 47 percent of households' deductible selections. It correctly describes the selections of 60 percent of households choosing the $\$ 500$ deductible, 38 percent of those choosing the $\$ 1,000$ deductible, but only 0.3 percent of those choosing the $\$ 5,000$ deductible.

The coefficient of relative risk aversion for the EUT CRRA deductible model is $\rho=139$. Like Sydnor (2010), we find three-digit relative risk aversion from households' insurance deductible choices. Our risk aversion estimate from the EUT CRRA coverage limit model is much 
lower, $\rho=2.7$, and more consistent with estimates found in other domains. For example, Barro and Jin (2011) estimate $\rho=3$ in their analyses of equity premiums.

The descriptive power of the EUT CRRA coverage limit model is quite poor. For example, the model indicates that only 10 percent of households would insure at least 90 percent of their replacement cost, but 83 percent do. On average, this model under-predicts households' coverage limit ratios by 34 percentage points $\left(\operatorname{mean}\left(\left(c_{i}-\widehat{c_{l}}\right) / r c_{i}\right)=0.34\right.$ where $c_{i}$ and $\widehat{c_{l}}$ are the selected and predicted coverage limits and $r c_{i}$ is the replacement cost for household $i$ ). While the predictions shown in Figure 4 would suggest that the average household's risk aversion is greater than 2.7, the coefficient estimate must balance the decisions of both full and partial insurers: larger coefficients of relative risk aversion would better explain the behavior of full insurers, but also lead to greater losses of utility for partial insurers.

\subsection{Allowing for Variation in Preferences, Heterogeneous Risk Aversion}

Aggregate estimates of relative risk aversion might mask important heterogeneity in households that explains their contract selections. To examine this possibility, we estimate risk aversion as a function of the households' characteristics, as described in Section 4.2.2. Namely, we model a household's risk aversion as a function of the region, contract year, property value, default deductible, and age of the home. According to likelihood ratio tests, the EUT CRRA heterogeneous preferences models fit the data significantly better, at the 1 percent level, than the EUT CRRA model with homogeneous preferences for both the deductible and coverage limit decisions. ${ }^{25}$

Table 6 reports summary statistics for the estimated distribution of relative risk aversion. The average relative risk aversion is 113 for the deductible model and 2.81 for the coverage limit model. In each case, the mean risk aversion of these models assuming heterogeneous preferences is within one standard deviation of the estimates from the models assuming homogeneous preferences (139 and 2.72, respectively).

\footnotetext{
${ }^{25}$ Table 5 reports the $\log$ likelihood for these models. For the deductible, the log likelihood ratio is $L L R=$ $2 \times(-164,935-(-168,042))=8,014$ with 17 degrees of freedom and assumed to be distributed $\chi^{2}$ (Cameron and Trivedi, 2005, Chapter 7). Similarly, the coverage limit model has an $L L R=4,334$ with 17 degrees of freedom.
} 
Panel A. Deductible Predictions

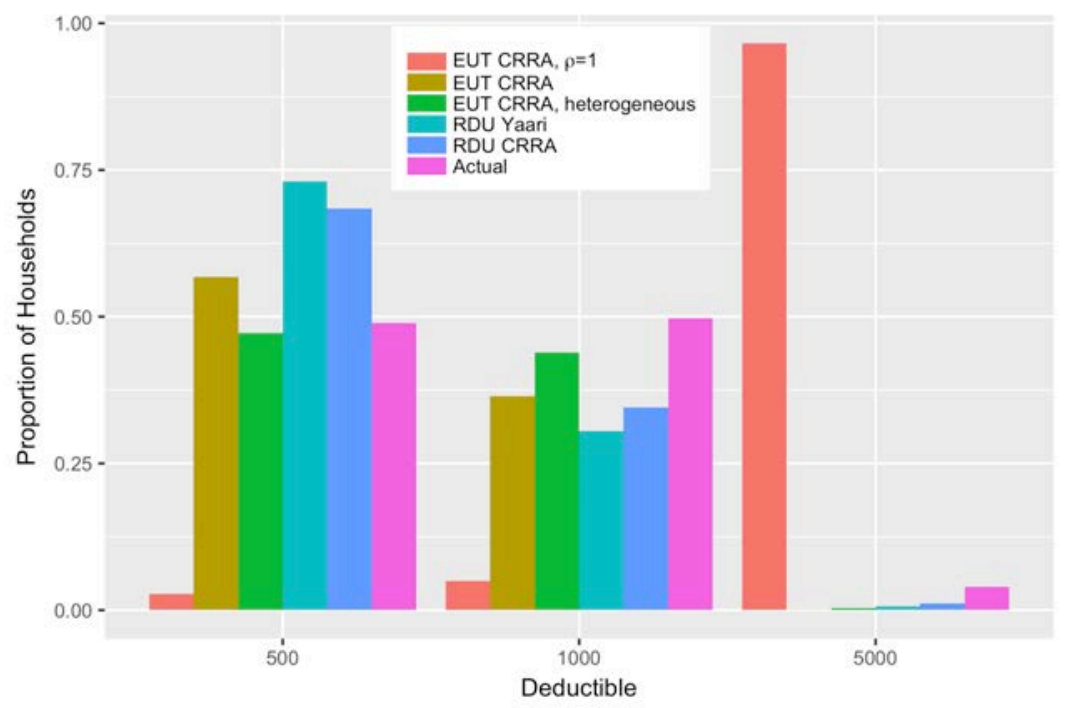

Panel B. Coverage Limit Predictions

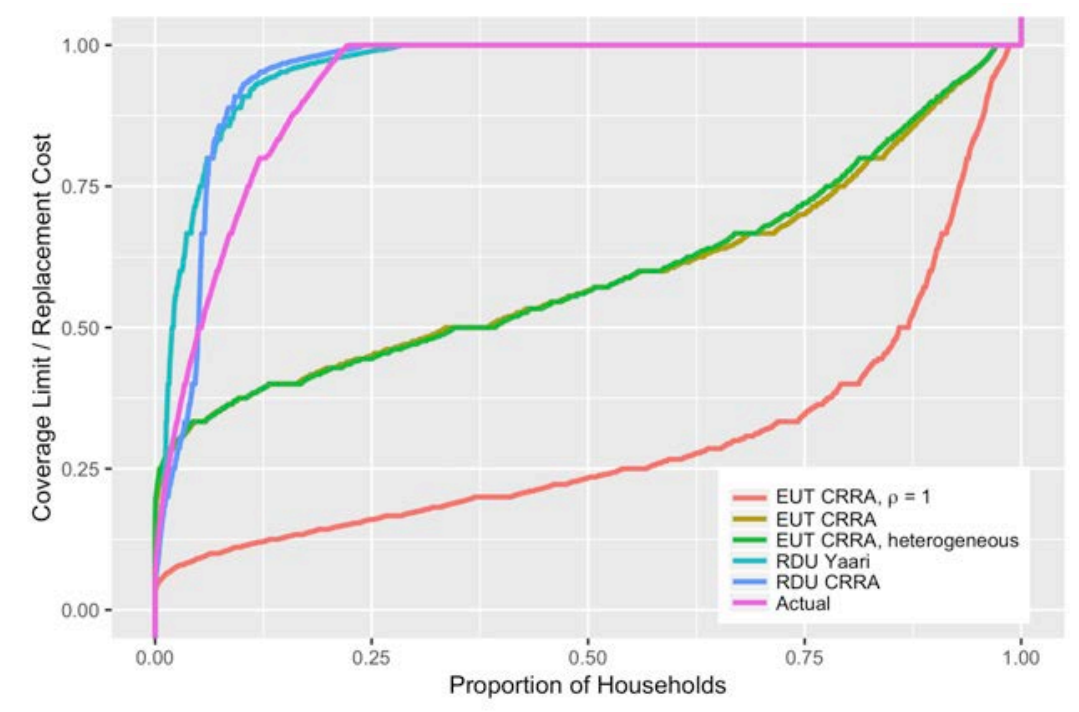

\section{Figure 4 Model Predictions}

Note: The graphs compare households' contract decisions (“Actual") with the predictions of several utility models. Panel A shows deductible predictions, showing the three most frequently chosen deductibles $(\$ 500, \$ 1,000, \$ 5,000)$, which are selected by 98 percent of households. Panel B shows the coverage limit relative to the home's replacement cost, imposing a maximum ratio value of 1 . "EUT CRRA, $\rho=1$ " uses a relative risk aversion coefficient commonly derived in previous research. The remaining models use maximum likelihood estimation to fit model parameters; Table 5 reports these parameter values. "EUT CRRA" models households as CRRA expected utility maximizers. "EUT CRRA, heterogeneous" models estimate risk aversion as a function of the household's characteristics. "RDU Yaari" models households as risk neutral, rank dependent utility maximizers; and "RDU CRRA" as CRRA rank dependent utility maximizers. Baseline sample of 103,080 policies. 
The distributions of risk aversion suggest that these models capture some of the differences in choices across households that the homogeneous preferences models of Section 5.2 could not. $^{26}$ The deductible model estimates a broad distribution of risk aversion with a standard deviation of 44.5 , a $1^{\text {st }}$ percentile of risk aversion in 27.5 , and $99^{\text {th }}$ percentile of 230 . The variation in risk aversion is much smaller in the coverage limit model with a standard deviation of 0.42 , a $1^{\text {st }}$ percentile of 1.99 , and $99^{\text {th }}$ percentile of 3.86. The coefficient of variation $((\operatorname{st} . \operatorname{dev} \cdot(\rho) / \operatorname{mean}(\rho)$ is 0.39 for the deductible model and 0.015 for the coverage limit model) also indicates more variation in risk aversion from the deductible model.

These models with heterogeneous preferences predict households' choices about as well the models assuming homogeneous preferences. The deductible model correctly predicts 47 percent of households' deductible decisions (versus 47 percent for the homogeneous model). It is slightly better at predicting higher deductibles (e.g., it correctly predicts 47 percent of households that selected the $\$ 1,000$ deductible versus 38 percent for the homogenous model), but correctly predicts households selecting the lowest deductible of $\$ 500$ at lower rates (52 percent versus 61 percent for the homogeneous model). The heterogeneous model underestimates coverage limit ratios by an average of 33.5 percentage points (versus 33.9 for the homogeneous model).

These models with heterogeneous risk preferences assume that households' risk aversion is a function of our included explanatory variables. Our results provide partial support for this assumption such as the improvement in model fit. However, we find important limitations of these models, especially for coverage limit decisions, which may emerge from the inability of these explanatory variables to differentiate households. Online Appendix A.3 provides additional details regarding model results.

\footnotetext{
${ }^{26}$ First, the magnitude of the scale parameter $\sigma$ is lower (e.g., for the deductible model, 0.310 versus 0.377 ), indicating a reduction in the unexplained variation of choices. Second, the models' regression coefficients are nonzero and so create a distribution of risk aversion across households. (In both deductible and coverage limit models, almost all regression coefficients are statistically significant, reported in the Online Appendix A.3.)
} 
Table 6 Risk Aversion for CRRA Expected Utility Model with Heterogeneous Preferences

\begin{tabular}{lccccccc} 
& & & \multicolumn{5}{c}{ Percentiles } \\
\cline { 4 - 8 } & Mean & St. Dev. & $1 \%$ & $10 \%$ & $50 \%$ & $90 \%$ & $99 \%$ \\
\hline Deductible & 113 & 44.5 & 27.5 & 61.3 & 108 & 176 & 230 \\
Coverage Limit & 2.81 & 0.42 & 1.99 & 2.28 & 2.78 & 3.38 & 3.86 \\
\hline
\end{tabular}

Note: Table provides the distribution of relative risk aversion for households' deductible and coverage limit decisions from a model in which households are assumed to be CRRA expected utility maximizers and relative risk aversion is a function of the household's characteristics.

\subsection{Boundary Analysis}

Given the difficulty of explaining households' choices with these structural, econometric models for the coverage limit, we take an alternative, deterministic approach to estimate household-level coefficients of relative risk aversion (Sydnor, 2010). We identify a lower and upper bound coefficient of relative risk aversion for each household given the contract choices that it made, using the methods outlined in Section 4.2.3. For example, the lower bound relative risk aversion for the coverage limit $\rho_{c, i}^{-}$makes the household indifferent between its choices and the next lowest coverage limit, $v\left(c_{i}, \rho_{c, i}^{-}\right) \sim v\left(c_{i}-\$ 100, \rho_{c, i}^{-}\right) .{ }^{27}$ In this model, no level of risk aversion could induce a household to select a coverage limit that exceeds its replacement cost and so we treat over-insuring households as if they selected a coverage limit that equals their replacement cost and charge them the associated premium for this contract.

Table 7 shows the minimum and maximum coefficients of risk aversion that would explain households' deductible and coverage limit decisions. Regarding the deductible, we cannot identify an upper bound risk aversion for households selecting the lowest deductible of $\$ 500-$ these households might have selected a lower deductible if it were available. Like our previous results, the average household selecting a $\$ 500$ deductible must have at least a triple-digit coefficient of relative risk aversion (a median coefficient of at least 104). Households selecting the $\$ 1,000$ deductible have a median lower bound risk aversion of 34 and upper bound of 144. On average, the difference between a household's lower and upper bounds is 150. This large range is due to the low dollar values and lumpiness of the deductible menu (e.g., choices in \$1,000 increments).

\footnotetext{
${ }^{27}$ We use $\$ 100$ coverage limit increments to match the menu available to households. Our random utility models allow us to adjust our choice set so that considering coverage limits in increments of $\$ 10,000$ (which we show above) and \$1,000 leads to similar estimates (see Train, 2009, Chapter 2, for more details on grouping menu options in these models). In the boundary analysis, the coverage limit increments affect our estimates of risk aversion for fully insuring. We examine how using other increments affects our results below.
} 
We do not identify a lower bound risk aversion for households selecting the highest deductible of $\$ 5,000$. At the median, households selecting a $\$ 5,000$ deductible cannot have a coefficient of relative risk aversion that exceeds 21 .

Regarding coverage limits, we cannot identify an upper bound for fully insuring households. Households who fully insure have a median risk aversion of at least 157. This risk aversion is so high because not only do households fully insure at actuarially unfair rates, but they choose to do so even though they could select a coverage limit of even $\$ 100$ less. ${ }^{28}$

Among households who partially insure, about half (45 percent) choose a coverage limit of at least 80 percent of their replacement cost. These households must have a median risk aversion of 15 to explain their coverage limit choices. Households insuring less than 80 percent of their replacement cost have a median relative risk aversion between 3 and 4. In total, partially insuring households have a median lower and upper bound risk aversion of 6 . About 40 percent of partially insuring households cannot have a risk aversion coefficient greater than 3. Two-thirds of partially insuring households require a single-digit upper bound for risk aversion. This result clarifies the risk aversion estimate of 2.7 from our structural model with homogeneous preferences (Section 5.2): while most households fully insure, the decision of partially insuring households typically requires only single-digit risk aversion to explain with expected utility.

\subsection{Summary of Expected Utility Results}

Our models of households as CRRA expected utility maximizers suggest that households are extremely risk averse. We begin this section with a canonical expected utility model, assuming $\rho=1$. This model predicts that households would select high deductible and low coverage limits. Instead, households choose the opposite.

Regarding deductible decisions, our findings are similar across estimation strategies. Our structural model with homogeneous preferences estimates $\rho=139$; our model with heterogeneous preferences estimates a mean (median) $\rho_{i}=113$ (108); and our boundary analysis

\footnotetext{
${ }^{28}$ We use coverage limit increments of $\$ 100$ to match the coverage limit menus available to households. If instead we use $\$ 1,000$ increments, and so solve the lower bound risk aversion problem $v\left(c, \rho^{-}\right) \sim v\left(c-\$ 1,000, \rho^{-}\right)$, fully insuring households have a mean (median), lower bound risk aversion of 126.3 (95). If we use $\$ 10,000$ increments, the estimate is 24.1 (17). Also, we assume that household's wealth is its replacement cost. As a sensitivity analysis, if we assume that wealth is $\$ 10,000$, the median lower bound risk aversion of full insurers is 18 . If instead, we assume wealth is $\$ 1$ million, the median is about 1,930 .
} 
indicates a mean (median) lower bound $\rho_{d, i}^{-}=103$ (62) and upper bound $\rho_{d, i}^{+}=199(119) .{ }^{29}$ While very high relative to the canonical model, these risk aversion estimates are consistent with other findings regarding small stakes preferences (e.g., Sydnor, 2010) and correctly predict about 47 percent of households' deductibles.

Table 7 Boundary Analysis of Relative Risk Aversion

\begin{tabular}{|c|c|c|c|c|c|c|c|c|c|c|}
\hline & \multirow[b]{2}{*}{ Obs. } & \multirow[b]{2}{*}{$\rho$} & \multirow[b]{2}{*}{ Mean } & \multirow[b]{2}{*}{ St. Dev. } & \multicolumn{5}{|c|}{ Percentiles } \\
\hline & & & & & & $1 \%$ & $10 \%$ & $50 \%$ & $90 \%$ & $99 \%$ \\
\hline \multirow[t]{6}{*}{ Deductible } & 500 & 48,077 & Min & 146.6 & 151.9 & -10 & 8 & 104 & 332 & 726 \\
\hline & & & Max & NA & NA & NA & NA & NA & NA & NA \\
\hline & 1,000 & 48,906 & Min & 62.4 & 70.6 & -10 & 3 & 39 & 161 & 307 \\
\hline & & & Max & 217.7 & 239.3 & 0 & 7 & 144 & 549 & 1,030 \\
\hline & 5,000 & 3,924 & Min & NA & NA & NA & NA & NA & NA & NA \\
\hline & & & $\operatorname{Max}$ & 29.6 & 29.0 & -8 & 2 & 21 & 74 & 111 \\
\hline \multirow[t]{6}{*}{ Coverage Limit } & Full & 80,145 & Min & 214.3 & 207.1 & -62 & 26 & 157 & 478 & 964 \\
\hline & & & Max & NA & NA & NA & NA & NA & NA & NA \\
\hline & Partial, $\geq 80 \%$ & 10,455 & Min & 27.1 & 45.7 & -6 & 4 & 15 & 58 & 211 \\
\hline & & & Max & 27.1 & 42.1 & -7 & 4 & 15 & 60 & 220 \\
\hline & Partial, $<80 \%$ & 12,480 & Min & 4.0 & 2.6 & -1 & 1 & 4 & 8 & 12 \\
\hline & & & Max & 3.9 & 2.6 & -1 & 1 & 3 & 7 & 12 \\
\hline
\end{tabular}

Notes: Table shows the minimum and maximum coefficients of risk aversion that would explain households' deductible and coverage limit decisions assuming that households are CRRA expected utility maximizers as we have described. For ease of exposition, we only show the three most commonly selected deductibles $(\$ 500, \$ 1,000$, and $\$ 5,000$ ); for coverage limits, households that choose a limit that is less than their replacement cost are considered "Partial" insurers, which we divide into those insuring at least 80 percent of their home's replacement cost and those insuring less. Households selecting a limit of at least their replacement cost are considered "Full" insurers.

Regarding coverage limit decisions, our boundary analysis shows that households' choices require a high level of risk aversion, a mean (median) lower bound $\rho_{c, i}^{-}=112$ (62). This level of risk aversion emerges because 77 percent of households choose to fully insure; in standard models of expected utility, households will partially insure when insurance is priced above the actuarially fair rate unless they extremely risk averse (Mossin, 1968). Our structural estimates of risk aversion are much lower than those required to explain households' coverage limit choices: our model with homogeneous preferences estimates $\rho=2.72$ and our model with heterogeneous preferences estimates a mean (median) $\rho_{i}=2.81$ (2.78). These structural estimates substantially underpredict households' coverage limits (Figure 4). Partially insuring and fully insuring households look similar in our data, and the decisions of partial insurers keep structural estimates of risk

\footnotetext{
${ }^{29}$ The lower (upper) bound mean and median exclude the 4 (47) percent of households selecting the highest deductible $\$ 5,000$ (\$500) as we do not observe their lower (upper) bound.
} 
aversion low. A richer set of explanatory variables might help generate triple-digit relative risk aversion for fully insuring households in our heterogeneous model. The key message from our structural models of the coverage limit is that explaining the decision of the typical household is difficult for these models.

The boundary analysis also illustrates the extreme nature of household's decisions: choosing a low deductible ( $\$ 500$ or $\$ 1,000$ ) or fully insuring their property typically requires high risk aversion. About 2 percent choose neither. In Online Appendix A.4, we examine whether the combination of a household's deductible and coverage limit choices appear consistent, if at least one value of relative risk aversion could explain both decisions. We might divide households into three groups. First, consider the "consistent extremists," the 39 percent of households who buy as much insurance possible, selecting a \$500 deductible and fully insuring. These households' deductible and coverage limit choices are internally consistent, but require a mean (median) relative risk aversion of at least 278 (211). Second, consider "intermittent extremists," the 46 percent of households who either select a deductible greater than $\$ 500$ but still fully insure or who select the $\$ 500$ deductible but partially insure. Sixty percent of these households make consistent choices, but those households require a mean (median) relative risk aversion of at least 201 (150). Finally, consider the "non-extremists," the 15 percent of households who select a deductible greater than $\$ 500$ and partially insure. Fourteen percent of these households make consistent choices. They have a median lower bound risk aversion of 3 and represent 2 percent of the households in the baseline sample. In total, 2.6 percent of households make consistent choices and have a relative risk aversion under 10.

The nature of households' insurance decisions would seem to challenge the usefulness of these CRRA expected utility models (e.g., as a tool for policy evaluation), especially for understanding households' coverage limit decisions. These expected utility models explain variation in households' choices in two ways: variation in premium loads and/or variation in risk aversion. For a given risk averse household, expected utility predicts that the optimal coverage limit is decreasing in response to the premium load. We observe that premium loads tend to increase in the coverage limit ratio (Section 3.3) and that fully insuring households pay higher loads than partially insuring ones (Section 3.4). Thus, the distribution of households' choices needs to be explained by very large variation in risk aversion. The coverage limit model does not illustrate an 
intuition for how households make large stakes insurance decisions, but attributes differences in choices to largely unobserved differences in preferences.

\section{Rank Dependent Utility}

Households' small and large stakes insurance decisions may be characterized by probability distortions. In assessing distortions, we cannot differentiate probability weighting and subjective beliefs in our data. We use the terms probability "distortions" and "weighting" broadly to include the possibility of subjective beliefs. The paragraphs dedicated to "rank dependent utility models" in Section 4.2.2 describe the estimation methods in detail.

\subsection{Risk-Neutral, Rank Dependent Utility (Yaari Model)}

We begin with an illustrative model that assumes that households are risk neutral but distort probabilities (Yaari, 1987) based on rank-ordered cumulative probabilities (Quiggin, 1982). According to a Vuong test, the Yaari models fit the data significantly better, at the 1 percent level, than the CRRA expected utility models with heterogeneous preferences for both the deductible and coverage limit decisions. The Yaari model correctly predicts 62 percent of households' deductible choices. It modestly over-predicts coverage limits, estimating that 90 percent of households would choose a coverage limit of at least 90 percent of their replacement cost while 83 percent do.

The Yaari model indicates that households overweight small probabilities in selecting both a deductible and coverage limit, as values for $\beta_{0}>0$ and $\beta_{1}>1$. For the deductible decision, we model probability distortions as $\Omega_{\mathrm{i}}=\beta_{0}+\beta_{1} \Pi_{\mathrm{i}}^{\prime}+\beta_{2}{\Pi_{i}^{\prime}}^{2}$ where $\Pi_{\mathrm{i}}^{\prime}$ is the rank-ordered cumulative flood loss probabilities of household $i$. For the coverage limit decision, the weighting function and parameters are $\Omega_{\mathrm{i}}=\beta_{0}+\beta_{1} \Pi_{\mathrm{i}}^{\prime}$. The derived probability parameters of the deductible model are $\left\{\beta_{0}, \beta_{1}, \beta_{2}\right\}=\{0.023,5.80,-0.228\}$, and for the coverage limit model, they are $\left\{\beta_{0}, \beta_{1}\right\}=\{0.0071,1.49\}$ (shown in Table 5). Figure 5 illustrates the probability weighting results. The horizontal axis shows flood damage as a percent of the home's replacement cost. Following the formulation of rank dependent utility (Quiggin, 1982), flood outcomes are ranked from worst (a full loss of the home) to best (no flood) on the horizontal axis. The lines illustrate the results using the flood probabilities for a specific representative household whose claim rate, loss distribution parameters, and replacement cost are approximately the sample medians. The red 
line shows the cumulative objective probabilities; the blue line shows the probability distortions derived from the deductible decision, and the green line shows the probability distortions derived from the coverage limit decision. On the far left, the annual objective probability of a full loss is 0.04 percent; however, the coverage limit model indicates that households act as if the probability of a full loss were 0.77 percent $(\Omega=0.0071+1.49 \times 0.0004=0.0077)$. On the right $($ Loss $=$ $1 \%$, the smallest loss in the model), this household's claim rate is 1.3 percent, but it acts as if it were 2.7 percent when selecting a coverage limit. Finally, the household underweights the likelihood of not incurring a flood (Loss $=0$ ). Its objective probability is 98.7 percent, but its weighted probability is 97.3 percent. $^{30}$

The (risk neutral) households in the Yaari model purchase insurance because they overweight small probabilities. While the premium load requires risk aversion to purchase insurance in expected utility models, probability weighting in Yaari models motivate risk neutral households to select the contracts that we observe. For example, the household described above has a $\$ 100,000$ replacement cost and selects a contract with a $\$ 1,000$ deductible and $\$ 100,000$ coverage limit. This contract has a premium load of 2.81; however, it has a probability-weighted premium load, the ratio of premiums to probability-weighted payouts, of 0.60 using the parameters of the Yaari coverage limit model. ${ }^{31}$ Thus, households' overweighting of flood probabilities makes this contract attractive to a risk neutral household.

\subsection{CRRA, Rank Dependent Utility}

We now fit a rank dependent utility model with a CRRA value function ("RDU CRRA"). This model jointly estimates probability distortion parameters $(\beta)$ and the coefficient of relative risk aversion $(\rho)$. CRRA expected utility requires diminishing marginal utility of wealth $(\rho>0)$ to explain households' willingness to pay premiums exceeding expected value; however, a combination of wealth effects and probability weighting can explain households' willingness to

\footnotetext{
${ }^{30}$ Like previous research (e.g., Khaneman and Tversky, 1979; Barseghyan et al., 2013), we find that distortions are larger for smaller probabilities. Returning to the coverage limit model example, for the probability of a full loss the ratio of distorted to objective probabilities is $19.25(0.0077 / 0.0004=19.25)$ while the ratio for the probability of any flood $($ Loss $=1 \%)$ is $2.07(0.027 / 0.14=2.07)$.

31 A risk neutral household who does not distort probabilities would have an expected utility of $v_{i}=$ $\sum_{l} \pi_{i}(l)(-p-\min (d, l)+\min (0, c-l))$, following Equation 4. This household would not insure if premiums exceed the contract's expected value. Consider, a risk neutral household who distorts probabilities and has a rank dependent utility $v_{i}=\sum_{l} \omega\left(\pi_{i}(l)\right)(-p-\min (d, l)+\min (0, c-l))$, following Equation 7 . This household would not insure if premiums exceed the contract's weighted value, which depends on $\omega$.
} 
pay in CRRA rank dependent utility. Prospect theory is likely the most common model combining changes in income/wealth and probability weighting. It posits that individuals exhibit diminishing sensitivity to losses, absolute differences matter less as losses increase. Diminishing sensitivity to losses requires $\rho<0$ in the CRRA value function and so is the opposite of typical expected utility calibrations of CRRA (where negative $\rho$ is called "risk seeking"). While standard expected utility value functions (e.g., CARA, CRRA) explain risk preferences using the marginal utility of wealth, the point that households' attitudes toward wealth may differ from their risk attitudes is well documented (e.g., Dyer and Sarin, 1982; Yaari, 1987; Rabin, 2000). ${ }^{32}$

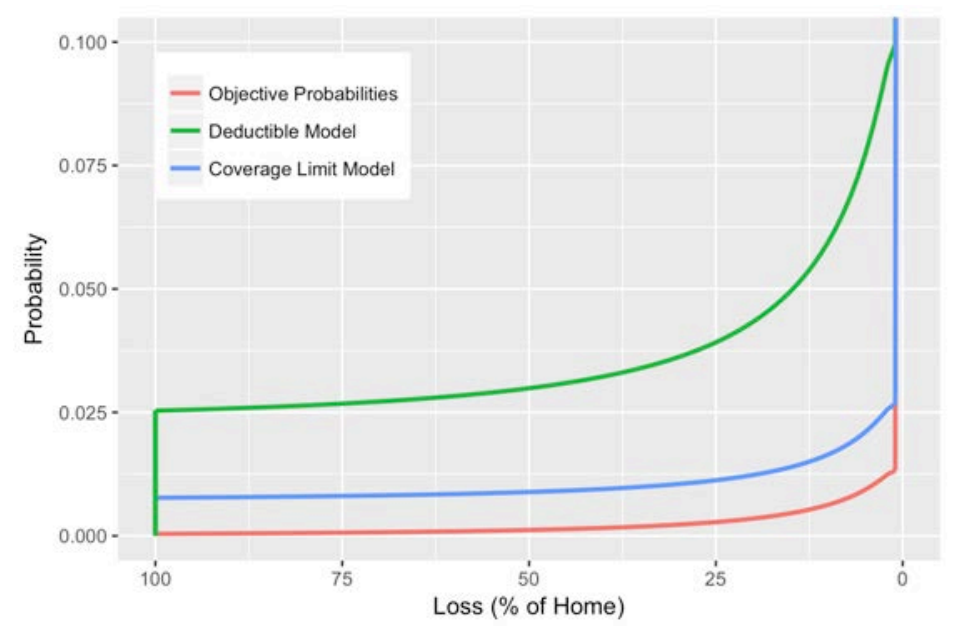

\section{Figure 5 Probability Weighting for the Yaari Model}

Note: Figure illustrates the Yaari model results, which indicate that households overweight small probabilities when selecting a deductible or coverage limit. The horizontal axis shows flood damage as a percent of the home's replacement cost, ordered from a 100 percent loss to a 0 percent loss (as rank dependent utility models order outcomes from worst to best). The vertical axis shows the cumulative probability. The lines show the results using the flood probabilities for a specific representative household whose claim rate, loss distribution parameters, and replacement cost are approximately the sample medians. The red line shows the objective probability; the blue line shows the probability distortions derived from the deductible decision, and the green line shows the probability distortions derived from the coverage limit decision. Model parameter values are reported in Table 5.

According to likelihood ratio tests, the RDU CRRA models fit the data significantly better, at the 1 percent level, than the Yaari models for both the deductible and coverage limit decisions. The CRRA rank dependent utility model correctly identifies 64 percent of households' deductible

\footnotetext{
${ }^{32}$ Decreasing marginal utility of wealth is equivalent to increasing sensitivity to losses for typical expected utility models. Let $x$ in the CRRA model (Equation 3) represent initial wealth $w_{0}$ minus losses, $x=w_{0}-l$. For $\rho \neq 1$, the first and second derivative with respect to $l$ are $\partial u / \partial l=-\left(w_{0}-l\right)^{-\rho}$ and $\partial^{2} u / \partial l^{2}=-\rho\left(w_{0}-l\right)^{-(1+\rho)}$. The first derivative is negative: utility decreases in losses. The second derivative is positive if $\rho<0$ and negative if $\rho>0$.
} 
choices (versus 62 percent for Yaari and 47 percent for EUT CRRA), and over-predicts households' coverage limits by 2 percentage points (versus 3 for Yaari; EUT CRRA under-predicts coverage limits by 34 percentage points).

For both deductible and coverage limit models, we find overweighting of small probabilities and negative values of $\rho$. The parameters for the deductible model are $\left\{\rho, \beta_{0}, \beta_{1}, \beta_{2}, \sigma\right\}=\{-4.08$, $0.029,6.03,-59.14,0.186\}$, and for the coverage limit model are $\left\{\rho, \beta_{0}, \beta_{1}, \sigma\right\}=\{-0.767$, $0.0077,3.64,0.125\}$ (Table 5). As $\rho$ is negative, these preferences exhibit diminishing sensitivity to losses: households perceive the difference between a $\$ 1,000$ loss and $\$ 2,000$ loss as greater than that between a $\$ 2,000$ and $\$ 3,000$ loss.

Households' demand for insurance is explained by their overweighting of small probabilities in the RDU CRRA models. Diminishing sensitivity to losses complements the overweighting. The median probability-weighted premium load is 0.37 for the coverage limit decision and 0.15 for the deductible decision according to these models. Thus, even risk neutral households would buy the lowest deductibles and fully insure based on these probability-weighted loads since they are below 1 and so the presence of households who choose higher deductibles or partially insure is explained by diminishing sensitivity to losses. ${ }^{33}$ Thus, our findings are consistent with two of the tenets of prospect theory: households 1) overweight small probabilities, and 2) demonstrate diminishing sensitivity to losses (Kahneman and Tversky, 1979).

We compare the probability weighting estimates from our CRRA rank dependent utility models with Chebyshev polynomials to commonly used probability weighting functions from Prelec (1998) and Wu and Gonzalez (1996). The results are very similar across all three approaches to modeling probability weighting. example, Figure 6 compares the probability distortions across weighting functions for the deductible and coverage limit decisions. The horizontal axis shows objective probabilities, and the vertical axis shows transformed probabilities using the parameter results for each probability weighting function. All three models show similar probability distortions for the deductible decision; for the coverage limit, the Prelec and Wu-Gonalez weighting functions are closest to the results for the Chebyshev polynomials when objective

\footnotetext{
${ }^{33}$ While our explanation sequentially discusses probability weights then diminishing sensitivity, the RDU CRRA models jointly estimate the value function and probability distortions and find that the combination of overweighting and diminishing sensitive best explain our data, including over EUT CRRA, Yaari, and other nested models.
} 
probabilities are small, but start to diverge as probabilities grow. Online Appendix A.6 offers additional details of the Prelec and Wu-Gonzalez model results.

Each of these models suggest that households' small and large stakes decisions are characterized by different preferences. For example, suppose that households are CRRA rank dependent utility maximizers with Prelec probability weighting. We find that households overweight the median annual claim rate of 1.33 percent by a factor of 7.4 , acting as if it occurs with a 10 percent annual probability when making a deductible decision. When selecting a coverage limit, they overweight the claim rate by a factor of 2.5 , acting as if it occurs with a 3.3 percent annual probability. The source of differences in small and large stakes preferences is unclear and requires additional research. It could be due to fundamentally different preferences, incorrectly specifying households' utility functions or probability weighting functions, and/or household heterogeneity (in preferences, beliefs, etc.).

Finally, as we find evidence of prospect theory preferences in our CRRA rank dependent utility model, we model cumulative prospect theory and examine its predictions using the parameters provided in Tversky and Kahneman (1992). ${ }^{34}$ Cumulative prospect theory correctly predicts 56 percent of households' deductibles. Interestingly, it predicts that almost no one (3 percent) would choose an intermediate deductible of $\$ 2,000, \$ 3,000$, or $\$ 4,000$ and almost no one (2 percent) does. It predicts that 75 percent of households would choose one of the lowest two deductibles and 22 percent would choose the highest. The model underestimates coverage limits by an average of 16 percentage points. It predicts that 42 percent of households would fully insure (77 percent do), and an additional 20 percent of households would insure at least 80 percent of their replacement cost. While our structural estimates using the CRRA rank dependent utility model more accurately predict households' choices, the cumulative prospect theory predictions are noteworthy because the parameters were derived in another setting (from lotteries in a lab). We conclude that cumulative prospect theory is a helpful starting point for understanding households' insurance decisions in our data.

\footnotetext{
${ }^{34}$ We assume that households' reference point is a state in which they have no insurance and have incurred no flood losses. Thus, any premiums paid or flood losses occur in the loss domain. The parameters for the value function $v(l)=$ $-\lambda(-l)^{\beta}$ and probability weighting function $\Omega\left(\Pi_{i}^{\prime}\right)=\Pi_{i}^{\prime \delta} /\left(\Pi_{i}^{\prime} \delta+\left(1-\Pi_{i}^{\prime}\right)^{\delta}\right)^{1 / \delta}$ in the loss domain are $\{\lambda, \beta, \delta\}=$ $\{2.25,0.88,0.69\}$ (Tversky and Kahneman, 1992, p. 311).
} 

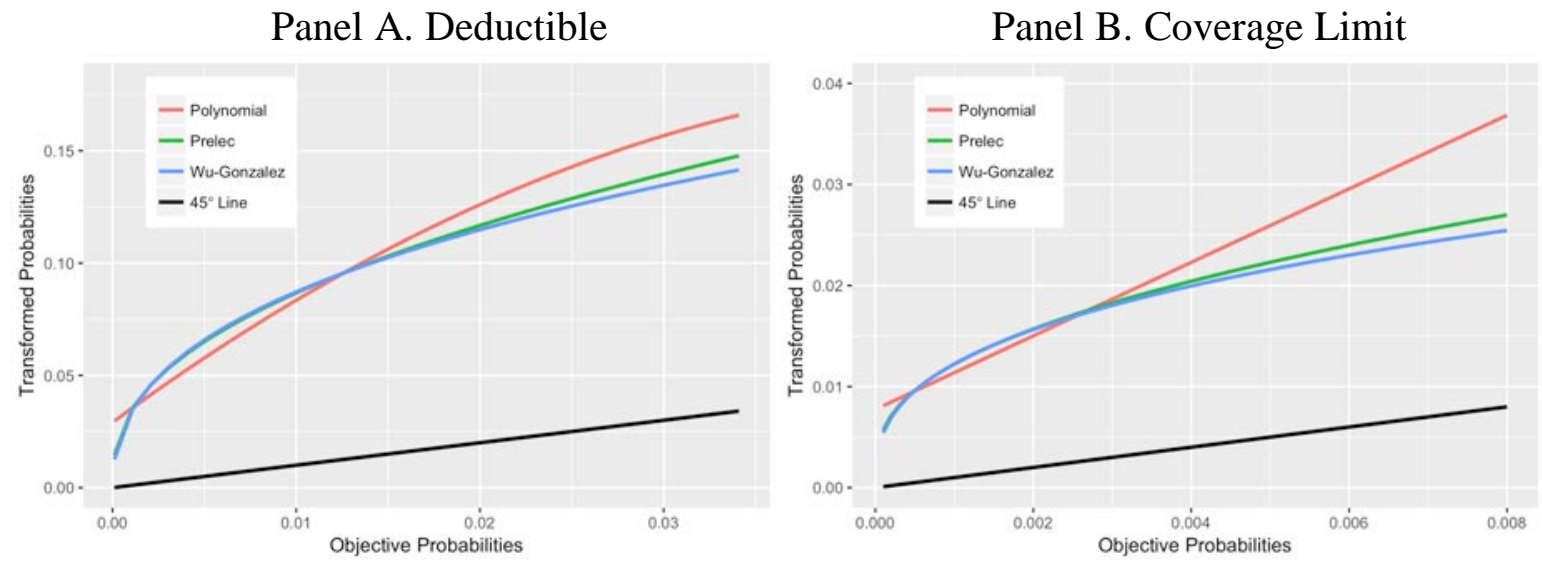

Figure 6 Comparison of Probability Weighting Functions

Note: Figures show probability weighting estimates across several probability weighting functions, modeling distortions using Chebyshev polynomials and weighting functions proposed by Prelec (1998) and Wu and Gonzalez (1996). Panel A shows estimates from deductible decisions; Panel B shows estimates from coverage limit decisions. The 45-degree line shows the one-to-one ratio of objective to transformed probabilities and so illustrates that each of these models find overweighting of small probabilities for both the deductible and coverage limit decisions.

\section{Robustness Tests and Alternative Explanations}

We consider several aspects of the setting and our modeling approach that might interfere with estimating households' preferences from their observed deductible and coverage limits. Specifically, we consider CARA utility, deductible menu defaults, federal requirements that some homeowners insure against flood, and possible state dependence as floods may affect several aspects of a household's finances.

Constant Absolute Risk Aversion. Our results with CARA are like those with CRRA (Table 5). The deductible model finds an absolute risk aversion $r=9.3 \times 10^{-4}$ and correctly predicts 45 percent of households' deductible choices (versus 47 percent for CRRA). For the coverage limit, we find $r=5.5 \times 10^{-5}$, which underestimates coverage limits by an average of 27 percentage points (versus 34 for CRRA). Like the CRRA models, CARA rank dependent utility indicates diminishing sensitivity $(r<0)$ to losses and overweighting of small probabilities. The deductible and coverage limit model parameters are respectively $\left\{r, \beta_{0}, \beta_{1}, \beta_{2}, \sigma\right\}=\{-2.6 \times$ $\left.10^{-4}, 0.0028,7.94,-0.037,0.22\right\}$ and $\left\{r, \beta_{0}, \beta_{1}, \sigma\right\}=\left\{-5.0 \times 10^{-6}, 0.0078,2.40,0.12\right\}$.

Deductible menu defaults. While households' preferences for low deductibles are wellestablished (e.g., Sydnor, 2010), the low default options in our data might increase our deductible risk aversion estimates if households select them because of inattention and inertia (Madrian and Shea, 2001)). Our data includes two deductible defaults: one group has a $\$ 500$ default and another 
a $\$ 1,000$ default. ${ }^{35}$ About 75 percent of households who do not keep their default choose one of the lowest two deductibles (e.g., a household with a $\$ 1,000$ default chooses $\$ 500$ ). We re-estimate our CRRA expected utility models excluding households who adopt the default and find $\rho=108$ (Online Appendix A.7.6). This approach may be conservative as it excludes households whose $\$ 500$ and $\$ 1,000$ default deductibles may reflect their preferences. We also include a household's default in the model of heterogeneous preferences (Online Appendix A.3). We find that being assigned a default of $\$ 1,000$ (rather than the $\$ 500$ default) reduces a households' estimated relative risk aversion by 3.6. In sum, we find a modest effect of deductible menu defaults on our estimates.

Insurance requirements. Households in our baseline sample are required to insure against flood if they have a mortgage from a federally regulated lender. This mortgage requirement is not consistently enforced (Dixon et al., 2006); however, contracts may not reflect household preferences if lenders require households to fully insure. We compare coverage limit selections for our baseline sample with households who live in flood-prone areas not subject to the federal requirement. Their coverage limit selections are remarkably similar, and so would seem to support the assumption that coverage limits reflect households' preferences (Online Appendix A.7.5).

State dependence. Perhaps households have low risk aversion but fully insure because they consider a broad set of consequences of a severe flood (e.g., employment disruptions), some of which are uninsured. ${ }^{36}$ Thus, larger claims payments for home damage could offset other floodrelated expenses. We have two reactions. First, standard risk aversion predicts surprisingly low coverage limits (e.g., $\rho=1$ predicts an average coverage limit of 29 percent of the replacement cost) and so the uninsured disaster portion of the disaster would have to be large. Deryugina (2017) finds that households' disaster exposure is less than was previously appreciated because programs that are not disaster-specific (e.g., unemployment insurance) often provide assistance during catastrophes. Second, and more importantly, standard models do not account for multidimensional risks and our intention is to examine whether these models characterize households' insurance decisions. Large stakes risks rarely occur in a vacuum and so extending models of decision making in this way may be an important topic for future research.

\footnotetext{
${ }^{35}$ Households with the $\$ 1,000$ default deductible have riskier homes with higher premiums and so this default may result from this group's tendency to select higher deductibles. For example, about 6 percent of these households select the highest deductible available $\$ 5,000$ while only 1 percent of households with the $\$ 500$ deductible do so.

${ }^{36}$ Doherty and Schlesinger (1983) note that an expected utility maximizer may want to fully insure an insurable risk if it is positively correlated with an uninsurable background risk.
} 
Additional analyses. We provide additional analyses in Online Appendix A.7 in the interest of space, considering expo-power utility, which can accommodate several combinations of relative and absolute risk preferences; alternative wealth assumptions in our CRRA models; consumption commitments and deductible preferences; mortgage recourse laws and coverage limit decisions; policy tenure and whether contracts reflect households' current preferences, models that exclude overinsuring households, who may misunderstand their insurance contracts; and households in a higher risk flood zone, where claim probabilities are larger than in our baseline data and comparable to previous research on risk preferences and insurance decisions. Ultimately, regarding alternative explanations for our results, we find each possibility compelling, though none seem to provide a straightforward answer for households' choices in our data.

\section{Conclusion}

Explaining households' insurance decisions is difficult with the most common expected utility models. These models assume that households compare a contract's premium to expected value, insuring less as loads increase. Instead, most households choose a low deductible and to fully insure despite paying high loads. For coverage limits, households insure more as premium loads increase. Our models can accommodate households' choices through extreme variation in risk aversion, that households who fully insure must innately differ from those who do not, yet this solution is not a behavioral explanation of households' decisions. Allowing for probability distortions greatly improves model descriptions of households' small and large stakes choices.

Mossin's (1968) discussion of his theoretical result on partially insuring are remarkably prescient, though he may not have anticipated the degree to which expected utility theory misrepresents households' insurance choices in this setting:

Casual empirical evidence seems to contradict the conclusion, however; some of our best friends take full coverage. Several explanations for such behavior can of course be offered, among them: (a) they simply behave irrationally, for example, by not bothering to determine optimal coverage; (b) there may be some uncertainty as to what will be the actual evaluation of the property in case of damage. We have not taken this kind of randomness into account in our theory, but it seems a perfectly reasonable hypothesis that it will lead to a number of observed cases of full (or over-) insurance; (c) they may uniformly overestimate the probability distribution for damage... (p. 558).

We find that households overestimate flood probabilities and over-insure (buying coverage limits greater than their replacement costs) in the way he describes. Also, we understand Mossin's comment that households may "behave irrationally" as a reference to the not-yet-documented 
systematic biases and heuristics individuals use to make choices under risk and uncertainty, including their insurance decisions (e.g., Bhargava, Loewenstein, and Sydnor, 2017; BrotGoldberg et al., 2017; Kunreuther, Pauly, and McMorrow, 2013; Meyer and Kunreuther 2017). For example, beyond our finding that probability distortions help characterize households' decisions, households may anchor on fully insuring their flood risk if they had previously selected to fully insure on their homeowners policy. Advancing model-based approaches to explain how households simplify complex decisions (e.g., Bordalo, Gennaioli, and Shleifer, 2012) is an important area for future research in the insurance domain.

We highlight two limitations of our analyses. First, while we show that the most frequent formulations of expected utility do characterize households' insurance decisions in our data, our study does not intend to evaluate the theory of expected utility, the von Neumann-Morgenstern preference axioms. ${ }^{37}$ Many modifications that follow these axioms might improve our models (e.g., perhaps households consider a broader set of risks or longer time horizons than we have modeled). Second, how our results regarding large stakes preferences generalize to other domains is unclear. Individuals' decisions may more closely align with standard models of expected utility in those settings than ours.

An implication of our findings is that households may not respond to risks in the ways that public policies commonly assume. For example, Cummins and Mahul (2009, p. 10) note that insurance can create "price signals [that] would inform policyholders about their true risk exposure and encourage them to engage in cost-effective mitigation measures." Households may be missing the signal in our setting as they tend to buy as much insurance as they can despite its high price. In other settings, households may also misinterpret incentives to manage, mitigate, or avoid risk when public programs require them to compare alternatives in expected value (e.g., for employment, savings, or health risks). Regarding flood risks, 39 percent of the U.S. population lived in coastal counties in 2010 and the percentage is increasing (NOAA, 2013). Moreover, the geographic size of flood zones is expected to increase by 40 percent by 2100 due to climate change and urbanization (AECOM, 2013). These trends make households' decisions about locating in flood zones, mitigating flood risk, and purchasing flood insurance first order policy considerations.

\footnotetext{
${ }^{37}$ Abdellaoui (2002) shows how these axioms can incorporate rank dependent utility.
} 


\section{References}

Abdellaoui, M. (2002). A Genuine Rank-Dependent Generalization of the Von Neumann-Morgenstern Expected Utility Theorem. Econometrica, 70(2), 717-736.

AECOM (2013). The Impact of Climate Change and Population Growth on the National Flood Insurance Program through 2100. Technical report, Federal Emergency Management Agency.

Aitkin, M. (1987). Modelling variance heterogeneity in normal regression using GLIM. Applied Statistics, 35(3), 332339.

Apesteguia, J., \& Ballester, M. A. (2016). Monotone stochastic choice models: The case of risk and time preferences. Forthcoming in Journal of Political Economy.

Ardia, D., Mullen, K. M., Peterson, B. G., Ulrich, J. (2016). 'DEoptim': Differential Evolution in 'R'. version 2.2-4.

Arrow, K. J. (1971). The theory of risk aversion. Essays in the theory of risk-bearing, 90-120. Markham Publishing Co., Chicago.

Barro, R. J., \& Jin, T. (2011). On the size distribution of macroeconomic disasters. Econometrica, 79(5), 1567-1589.

Barseghyan, L., Molinari, F., O'Donoghue, T., \& Teitelbaum, J. C. (2013). The nature of risk preferences: Evidence from insurance choices. American Economic Review, 103(6), 2499-2529.

Barseghyan, L., Molinari, F., O'Donoghue, T., \& Teitelbaum, J. C. (2016). Estimating risk preferences and risk perceptions in the field. Forthcoming in Journal of Economic Literature.

Barseghyan, L., Prince, J., \& Teitelbaum, J. C. (2011). Are risk preferences stable across contexts? Evidence from insurance data. American Economic Review, 101(2), 591-631.

Berg, J., Dickhaut, J., \& McCabe, K. (2005). Risk preference instability across institutions: A dilemma. Proceedings of the National Academy of Sciences of the United States of America, 102(11), 4209-4214.

Bhargava, S., Loewenstein, G., \& Sydnor, J. (2017). Choose to Lose: Health Plan Choices from a Menu with Dominated Option. The Quarterly Journal of Economics, 132(3), 1319-1372.

Bordalo, P., Gennaioli, N., \& Shleifer, A. (2012). Salience theory of choice under risk. The Quarterly Journal of Economics, 127(3), 1243-1285.

Brot-Goldberg, Z. C., Chandra, A., Handel, B. R., \& Kolstad, J. T. (2017). What does a deductible do? The impact of cost-sharing on health care prices, quantities, and spending dynamics. The Quarterly Journal of Economics, 132(3), 1261-1318.

Braun, M., Fader, P. S., Bradlow, E. T., \& Kunreuther, H. (2006). Modeling the "pseudodeductible" in insurance claims decisions. Management Science, 52(8), 1258-1272.

Cameron, A. C., \& Trivedi, P. K. (2005). Microeconometrics: Methods and Applications. Cambridge University Press.

Cummins, J. D., \& Mahul, O. (2009). Catastrophe risk financing in developing countries: Principles for public intervention. World Bank Publications.

Chetty, R. (2006). A new method of estimating risk aversion. The American Economic Review, 96(5) 1821-1834.

Chetty, R., \& Szeidl, A. (2007). Consumption Commitments and Risk Preferences. The Quarterly Journal of Economics, 122(2), 831-877.

Cohen, A., \& Einav, L. (2007). Estimating risk preferences from deductible choice. The American Economic Review, 97(3), 745-788.

Cohen, A., \& Siegelman, P. (2010). Testing for adverse selection in insurance markets. Journal of Risk and Insurance, 77(1), 39-84.

Dixon, L., Clancy, N., Seabury, S. A., \& Overton, A. (2006). The National Flood Insurance Program's Market Penetration Rate. RAND Corporation. 
Doherty, N. A., \& Schlesinger, H. (1983). Optimal insurance in incomplete markets. Journal of Political Economy, 91(6), 1045-1054.

Dyer, J. S., \& Sarin, R. K. (1982). Relative risk aversion. Management Science, 28(8), 875-886.

Einav, L., Finkelstein, A., \& Levin, J. (2010). Beyond testing: Empirical models of insurance markets. Annual Review of Economics, 2(1), 311-336.

Einav, L., Finkelstein, A., Pascu, I., \& Cullen, M. R. (2012). How general are risk preferences? Choices under uncertainty in different domains. The American Economic Review, 102(6), 2606-2638.

Ericson, K. M., Kircher, P., Spinnewijn, J., \& Starc, A. (2016). Inferring Risk Perceptions and Preferences using Choice from Insurance Menus: Theory and Evidence (No. w21797). National Bureau of Economic Research.

FEMA [U.S. Federal Emergency Management Agency] (2017). Policy Statistics. URL: https://bsa.nfipstat.fema.gov/reports/1011.htm. Last accessed: February 26, 2018.

FEMA [U.S. Federal Emergency Management Agency] (2015). National Flood Insurance Program Community Rating System Coordinator's Manual. URL: http://www.fema.gov/media-library/assets/documents/8768. Last accessed: February 26, 2016.

Friend, I., \& Blume, M. E. (1975). The demand for risky assets. The American Economic Review, 900-922.

Gallagher, J. (2014). Learning about an infrequent event: evidence from flood insurance take-up in the United States. American Economic Journal: Applied Economics, 6(3), 206-233.

GAO [U.S. Government Accountability Office] (2006). Federal Emergency Management Agency: Challenges for the National Flood Insurance Program (25-JAN-06, GAO-06-335T).

Gourinchas, P. O., \& Parker, J. A. (2002). Consumption over the life cycle. Econometrica, 70(1), 47-89.

Harrison, G. W., Humphrey, S. J., \& Verschoor, A. (2010). Choice under uncertainty: evidence from Ethiopia, India and Uganda. The Economic Journal, 120(543), 80-104.

Harrison, G. W., \& Rutström, E. E. (2008). Risk aversion in the laboratory. In Research in Experimental Economics, Vol. 12, ed. James C. Cox and Glenn W. Harrison, 41-196. Bingley, UK: Emerald Group Publishing Limited.

Hey, J. D., \& Orme, C. (1994). Investigating generalizations of expected utility theory using experimental data. Econometrica, 62(6), 1291-1326.

Holt, C. A., \& Laury, S. K. (2002). Risk aversion and incentive effects. American Economic Review, 92(5), 16441655 .

Johnson, E. J., Hershey, J., Meszaros, J., \& Kunreuther, H. Framing, probability distortions, and insurance decisions. Journal of Risk and Uncertainty 7, no. 1 (1993): 35-51.

Kahneman, D., \& Tversky, A. (1979). Prospect theory: An analysis of decision under risk. Econometrica, 47(2), 263291.

Kousky, C., \& Michel-Kerjan, E. (2015). Examining flood insurance claims in the united states: Six key findings. The Journal of Risk and Insurance, DOI: 10.1111/jori.12106

Kousky, C., \& Shabman, L. (2014). Pricing flood insurance: How and why the NFIP differs from a private insurance company. Resources for the Future Discussion Paper 14-37.

Kunreuther, H., Meszaros, J., Hogarth, R. M., \& Spranca, M. (1995). Ambiguity and underwriter decision processes. Journal of Economic Behavior \& Organization, 26(3), 337-352.

Kunreuther, H. C., Pauly, M. V., \& McMorrow, S. (2013). Insurance and behavioral economics: Improving decisions in the most misunderstood industry. Cambridge University Press.

Madrian, B. C., \& Shea, D. F. (2001). The power of suggestion: Inertia in 401 (k) participation and savings behavior. The Quarterly Journal of Economics, 116(4), 1149-1187.

McFadden, D. (1974). The measurement of urban travel demand. Journal of Public Economics, 3(4), 303-328. 
Meyer, R. and Kunreuther, H. (2017). The Ostrich Paradox: Why We Underprepare for Disasters. Wharton Digital Press.

Michel-Kerjan, E. O. (2010). Catastrophe economics: the national flood insurance program. The Journal of Economic Perspectives, 24(4), 165-186.

Michel-Kerjan, E., Lemoyne de Forges, S., \& Kunreuther, H. (2012). Policy tenure under the U.S. National Flood Insurance Program (NFIP). Risk Analysis, 32(4), 644-658.

Mossin, J. (1968). Aspects of rational insurance purchasing. Journal of Political Economy, 76(4), 553-568.

NFIP [National Flood Insurance Program] (2018). Loss Statistics By State. URL: https://bsa.nfipstat.fema.gov/reports/1040.htm. Last accessed: March 1, 2018.

NFIP [National Flood Insurance Program] (2006a). Flood insurance manual, effective May 1, 2006. URL: https://www.fema.gov/flood-insurance-manual-effective-may-1-2006. Last accessed: February 2, 2017.

NFIP [National Flood Insurance Program] (2006b). Transaction record reporting and processing plan for the Write Your Own Program. URL: http://bsa.nfipstat.fema.gov/manuals/manuals.html. Last accessed: March 1, 2016.

NOAA [National Oceanic and Atmospheric Administration] (2013). National coastal population report: Population trends from 1970 to 2020. URL: https://aamboceanservice.blob.core.windows.net/oceanservice-prod/facts/coastalpopulation-report.pdf. Last accessed: February 23, 2018

Orlando, James (2011). Comparison of state laws on mortgage deficiencies and redemption periods. Office of Legislative Research, Research Report. URL: https://www.cga.ct.gov/2010/rpt/2010-R-0327.htm

Prelec, D. (1998). The probability weighting function. Econometrica, 66(3), 497-527.

Preston, M. G., \& Baratta, P. (1948). An experimental study of the auction-value of an uncertain outcome. The American Journal of Psychology, 61(2) 183-193.

Quiggin, J. (1982). A theory of anticipated utility. Journal of Economic Behavior \& Organization, 3(4), 323-343.

Rabin, M. (2000). Risk aversion and expected-utility theory: A calibration theorem. Econometrica, 68(5), 1281-1292.

Rabin, M. \& Thaler, R. H. (2001). Anomalies: risk aversion. Journal of Economic Perspectives, 15(1), 219-232.

Saha, A. (1993). Expo-power utility: A 'flexible' form for absolute and relative risk aversion. American Journal of Agricultural Economics, 75(4), 905-913.

Sydnor, J. (2010). (Over) insuring modest risks. American Economic Journal: Applied Economics, 2(4), 177-199.

Train, K. E. (2009). Logit. Discrete choice methods with simulation. Cambridge university press.

Tversky, A., \& Kahneman, D. (1992). Advances in prospect theory: Cumulative representation of uncertainty. Journal of Risk and Uncertainty, 5(4), 297-323.

Vuong, Q. H. (1989). Likelihood ratio tests for model selection and non-nested hypotheses. Econometrica, 57(2), $307-$ 333.

Wakker, P. P. (2008). Explaining the characteristics of the power (CRRA) utility family. Health Economics, 17(12), 1329-1344.

Western, B., \& Bloome, D. (2009). Variance function regressions for studying inequality. Sociological Methodology, 39(1), 293-326.

Wu, G., \& Gonzalez, R. (1996). Curvature of the probability weighting function. Management science, 42(12), 16761690.

Yaari, M. (1987). The dual theory of choice under risk. Econometrica, 55(1), 95-115. 


\section{FOR ONLINE PUBLICATION}

\section{A Online Appendix}

\section{A.1 Estimating Policyholder Risk}

This appendix describes our claim rate and loss distribution models.

\section{A.1.1 Claim Rates}

We assume that policyholders rely on the same information as the flood insurance program in estimating their flood risk. The included observables are those used in determining flood insurance premiums, which Table 8 lists and defines.

The flood insurance program considers whether a home was built before its flood insurance rate maps (FIRM) were developed. Zoning regulations and building codes intend to reduce vulnerability in designated flood hazard areas and so flood claims and losses may substantially differ depending on whether a home was built pre- or post-FIRM. We model flood risk separately for pre- and post-FIRM dwellings. We estimate the likelihood of a flood using a random effects panel logit for household policy $i$ in community $j$

$$
\begin{aligned}
& I\left(p_{i t}\right)=\beta_{0}+\beta_{1} \text { CRSclass }_{j t}+\beta_{2} I\left(\text { Basement }_{i t}\right)+\beta_{3} D\left(\text { Obstruction }_{i t}\right)+\beta_{5} D\left(\text { Floors }_{i t}\right) \\
& +\beta_{6} I\left(\text { Mobile }_{i t}\right)+\beta_{7} D\left(\text { Elevation }_{i t}\right) \times D\left(\text { Source }_{i t}\right)+\gamma_{i}+\varepsilon_{i t}(A 1)
\end{aligned}
$$

where $I$ is an indicator variable, $D$ describes a dummy set, $\gamma_{i}$ is the random effect, and $\varepsilon_{i}$ an i.i.d. error term. ${ }^{38}$ For example, $D$ (Floors) indicates whether the home has one, two, or three or more floors. The outcome variable $p_{i t}$ equals one if household policy $i$ has a claim in year $t$ and zero otherwise. Only a policyholder's first claim each year is included in the analysis. ${ }^{39}$ Elevation is available for about 40 percent of homes in the baseline sample. The interaction term of elevation and source records missing elevation observations through a dummy variable "Not Indicated." Thus, households without elevation information are grouped together and included in the analysis.

\footnotetext{
${ }^{38}$ We assume random variation in claim rates across years and so do not include an indicator for years. A model wanting to examine the causal effect of these explanatory variables might include such an indicator, but our intention is to estimate each household's flood likelihood irrespective of the year in which it actually incurred a flood.

${ }^{39}$ Focusing on the first claim in a year greatly facilitates modeling the household's decision in Section 4.1 Allowing for more than one claim is computationally prohibitive as it requires accounting for all possible combinations of losses from each flood event. Two percent of policies with claims have a second claim in the same year. If the likelihood of having more than one claim in a year is equal across households, the probability of having at least two claims in a year for the household with the median claim rate is $0.00027(0.0133 \times 0.02=0.00027)$.
} 
Table 9 provides the results of the panel logit model of household claim rates with coefficients reported as log odds ratios. These results are consistent with previous research. For example, Kousky and Michel-Kerjan (2015) find in their assessment of NFIP claims that a community's Community Rating System score, the number of floors in a home, its elevation, and whether it has a basement all significantly influence flood claims and in qualitatively similar ways to our findings.

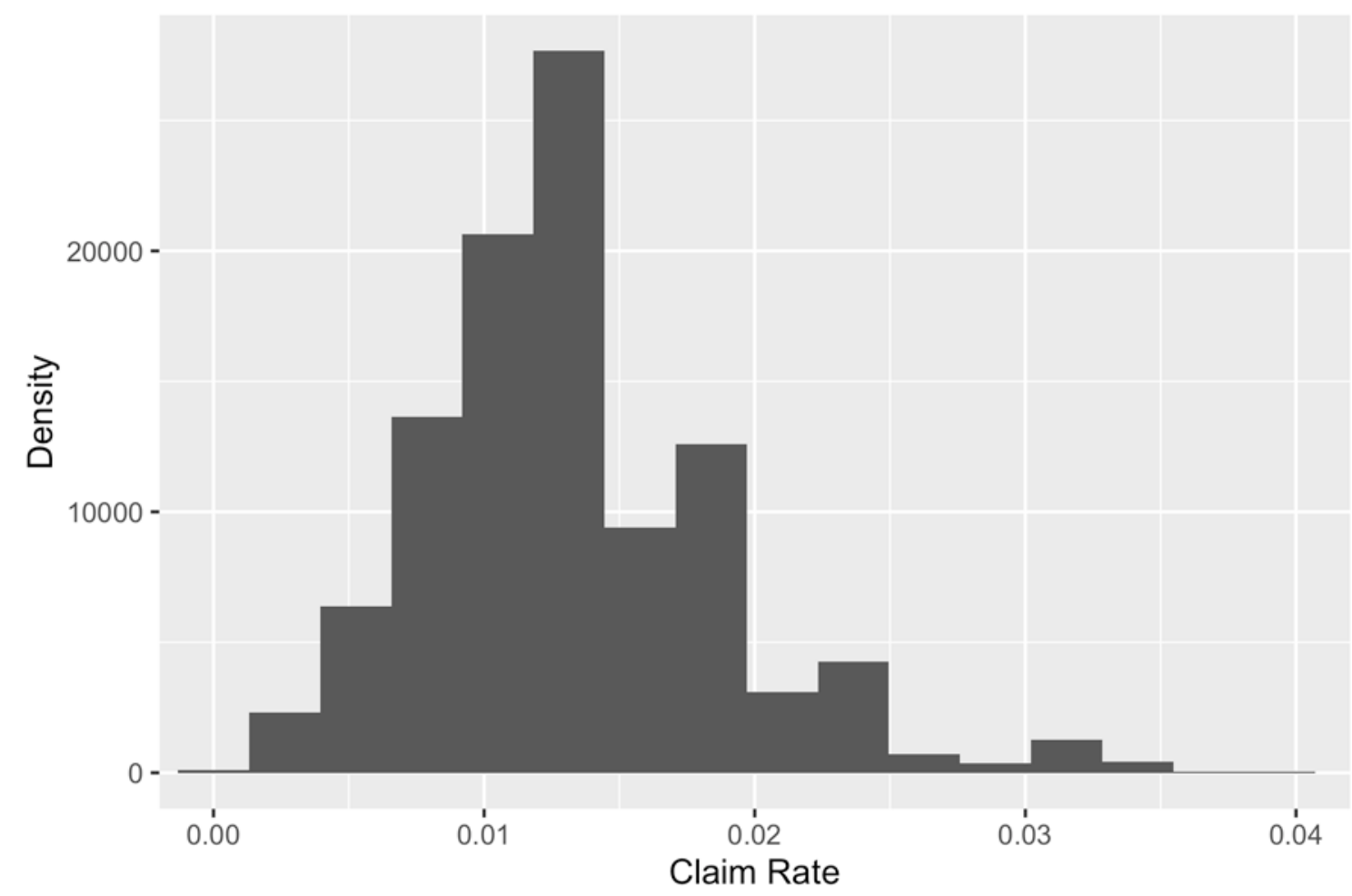

Figure 7 Claim Rate Estimates

Note: Claim rates using random effects panel logit. Baseline sample of 103,080 policies.

Figure 7 shows the histogram of claim rates for our baseline sample. The claim rates bunch around elevation relative to the 100-year flood plain, which FEMA rounds to the nearest foot, taking values from 2 or more feet below the flood plain to 5 or more feet above the flood plain. For example, while the median home in our data has an elevation of 1 foot above the flood plain, none of the homes with estimated claims rates above 3 percent are elevated above the flood plain. 
Table 8. Explanatory Variables Used in Regressions

\section{Explanatory}

variables Description

CRS class

The community's score on the Community Rating System (CRS). The CRS is a voluntary program that rewards communities for taking actions to mitigate flood risk beyond minimum NFIP requirements. Community actions reduce policyholder premiums by up to $45 \%$. CRS class is the associated premium reduction, ranging from 0 to 45 .
Basement Indicates that the property has a basement
Obstruction Indicates that an elevated building has an enclosed area and/or machinery attached to the building below the lowest floor. This variable is not applicable to un-elevated buildings. Thus, it takes three values: 0,1 , not applicable.
Source Indicates that elevation estimates were collected by a contracted engineer. Otherwise, the elevation data are provided by the NFIP and may not have been assessed at the level of the individual home. The source of elevation data is not always reported in the policy database, and in those cases, we record the observation's source as "Not Indicated."

Elevation An estimate of the elevation in feet of a policyholder's home relative to the 100year floodplain. Values are rounded to the nearest foot and bound with the lowest and highest elevation at -2 and 4 feet, respectively.

Mobile Indicates that the structure is a manufactured or mobile home.

Floors

Note: More information can be found on these variables from NFIP (2006). 
ONLINE APPENDIX: Small and Large Stakes Preferences

Table 9. Claim Rate Regressions

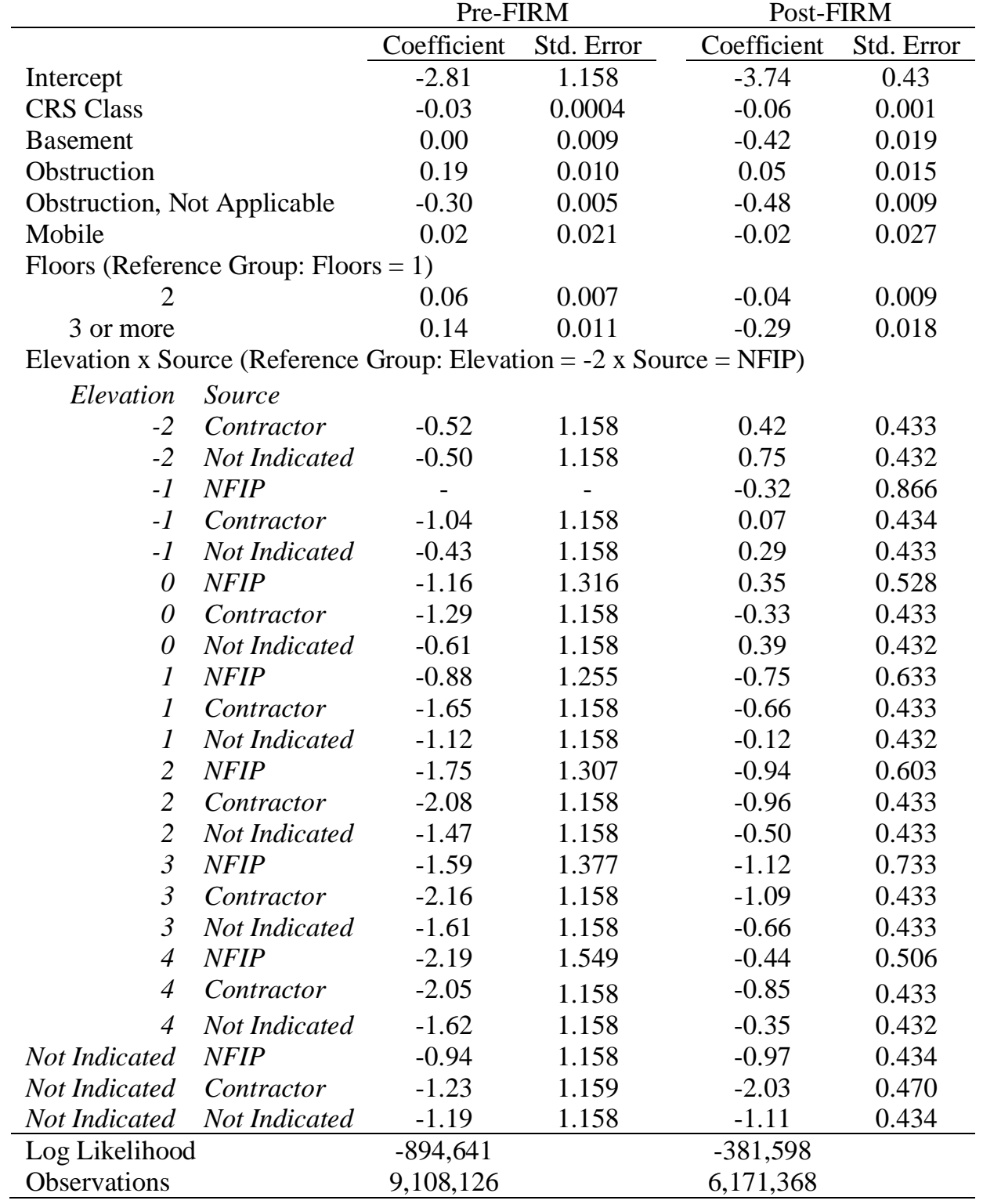

Note: Random effects panel logit panel regression. Coefficients are reported as log odds ratios.

\section{A.1.2 Loss Distributions}

We model household losses beginning with an examination of the loss distribution, considering losses for all households in the same flood risk category concurrently. From this approach, we find that our flood loss distributions are approximately log-normal. Finally, we fit the parameters of the log-normal distribution for each household based on its observables. 


\section{A.1.2.1 Parametric distributions}

This section compares parametric specifications for modeling flood losses. Throughout, we use A zone, pre-FIRM as an example. Given a claim event, the distribution of potential property losses is influenced by the type of event that occurs: events that affect many policyholders result in larger expected losses for each policyholder. We model observations as a mixture of two loss generating processes: (1) isolated loss events, floods affecting an individual or small group of policyholders (e.g., due to unusually heavy, localized rain), or (2) correlated loss events, losses due to a storm, hurricane, etc., affecting many policyholders. We define a correlated loss event as an observation of at least 30 claims with a date of loss on the same day in the same state. That event continues for each consecutive day with at least 30 claims in the same state. The 30 claims threshold is located at the $95^{\text {th }}$ percentile of the distribution of claims by date of loss by state. These criteria create 1,319 correlated loss events out of a total of 635,220 flood insurance claims occurring between 1982 and 2009. All observations that are not associated with a correlated loss event are considered an isolated loss event. Observations from isolated loss events are weighted by

$$
\phi_{h}=\frac{\overline{\pi_{h}}}{n_{h}}
$$

where $\overline{\pi_{h}}$ describes the average across years of the percent of claims generated by isolated loss events and $n_{h}$ indicates the total number of claims generated by isolated loss events $\left(n_{h}=85,075\right)$. On average, 22 percent of claims are generated by correlated loss events. Observations for correlated loss events are weighted by

$$
\phi_{m, j}=\frac{\left(1-\overline{\pi_{h}}\right)}{n_{m} * n_{m, j}}
$$

where $n_{m}$ indicates the total number of correlated loss events and $n_{m, j}$ indicates the total number of claims generated by correlated loss event $j$.

These weights provide empirical loss distributions for the isolated and correlated loss events. No time trends are present in the means and variances of the empirical loss distributions across years: regressing respectively the mean and variance of losses as a percent of the property value by year on time results in non-significant F-statistics of 0.89 and 0.60 .

Using the weighted empirical loss distribution, we fit parametric distributions using maximum likelihood estimation (MLE) and compare models using the Anderson-Darling test, Kolmogorov- 
Smirnov test, and the Akaike Information Criterion (AIC). Comparisons consistently indicate that the log-normal is the best fitting parametric model; this result is consistent across flood zones. Table 10 provides the results for the A zone, Pre-FIRM, correlated loss events distribution for a subset of the tested parametric distributions. ${ }^{40}$

As a sensitivity test, we generate several alternative distributions: (1) defining correlated loss events using a minimum of 10 claims (rather than 30) with the same date of loss in a state, (2) using a minimum of 100 claims, (3) treating all claims as independent and equally weighted. Table 11 shows deciles from the cumulative distributions using these alternative assumptions in Columns 1 through 5; we explain Column 6 in the next section. Excluding the case in which all losses are equally weighted, the distributions are quite similar across approaches. The log-normal results in a slightly thicker right tail than the non-parametric. The equally weighted approach results in the greatest probability of large losses due to severe events.

\section{Table 10. Fit Comparisons Across Parametric Distributions}

\begin{tabular}{lccc} 
& A-D & K-S & AIC \\
\hline Log-normal & 53.41 & 0.060 & -14949.5 \\
Pareto III & 65.61 & 0.064 & -14286.2 \\
Pareto IV & 68.79 & 0.066 & -14364.4 \\
Pareto II & 72.06 & 0.071 & -14322.7 \\
Generalized Extreme Value & 85.10 & 0.063 & -14175.4 \\
Gamma & 143.86 & 0.100 & -13966.1 \\
\hline
\end{tabular}

Note: The results are for the A zone, Pre-FIRM, correlated loss event data. The Anderson-Darling (A-D) and Kolmogorov-Smirnov (K-S) tests and the Akaike Information Criterion suggest that the log-normal is the parametric distribution that best fits the loss data.

${ }^{40}$ Since we model losses in the claims data as a portion of the home's property value, the support for the distribution is on the unit interval, $l \in(0,1]$ and so we might consider a distribution that more closely matches this support (e.g., beta, logit-normal) rather than the log-normal, which has a support of all positive numbers $x \in(0, \infty)$. For example, the support of the logit-normal is $x \in(0,1)$ rather than log-normal. We believe our loss generating process more consistently aligns with a censored distribution: losses are increasing in flood severity, but are capped at the full loss of the home. This censoring process would be expected to result in a probability density function in which flood probabilities tend to decrease in flood severity, but a mass emerges at a full loss. The empirical density of losses shown in Figure 1 illustrates this pattern where the probability of a full loss is several orders of magnitude larger than the probability of a 99 percent loss. In contrast, the logit-normal does not create this discontinuity, but would tend to add probability mass smoothly as flood severity approached a full loss, a feature not observed in the empirical distribution. 
Table 11. Cumulative Distributions for A Zone, pre-FIRM

\begin{tabular}{|c|c|c|c|c|c|c|}
\hline & (1) & (2) & $\begin{array}{l}\text { Homogeneou } \\
\text { (3) }\end{array}$ & (4) & (5) & $\begin{array}{l}\text { Heterogeneous } \\
\text { (6) }\end{array}$ \\
\hline Loss & Log-normal & $\begin{array}{l}\text { Nonparametric } \\
\text { (30 claims) }\end{array}$ & $\begin{array}{l}\text { Nonparametric } \\
\text { (10 claims) }\end{array}$ & $\begin{array}{l}\text { Nonparametric } \\
\text { (100 claims) }\end{array}$ & $\begin{array}{l}\text { Nonparametric, } \\
\text { equally weighted }\end{array}$ & Log-normal \\
\hline 10.0 & 53.1 & 55.3 & 58.0 & 51.9 & 40.6 & 50.6 \\
\hline 20.0 & 73.8 & 71.7 & 73.9 & 68.5 & 55.4 & 69.0 \\
\hline 30.0 & 83.3 & 80.3 & 82.1 & 77.6 & 64.5 & 78.0 \\
\hline 40.0 & 88.4 & 86.5 & 87.9 & 84.3 & 71.8 & 83.5 \\
\hline 50.0 & 91.6 & 90.8 & 91.6 & 89.0 & 77.6 & 87.1 \\
\hline 60.0 & 93.6 & 93.5 & 94.0 & 92.2 & 81.9 & 89.6 \\
\hline 70.0 & 95.0 & 95.4 & 95.7 & 94.3 & 85.3 & 91.5 \\
\hline 80.0 & 96.0 & 96.7 & 97.0 & 96.0 & 88.2 & 92.8 \\
\hline 90.0 & 96.8 & 97.9 & 98.0 & 97.4 & 91.2 & 93.9 \\
\hline
\end{tabular}

Note: Alternative specifications of the cumulative distribution for losses. Losses are measured as a percent of the structure's value. The parametric distributions use the correlated loss event definition of 30 claims. Columns 1 through 5 report deciles assuming a homogeneous loss distribution across all policyholders in the A zone, pre-FIRM. Column 1 reports deciles for the log-normal distribution. Columns 2 through 4 report for nonparametric distributions for which weights are based on definitions of the correlated loss events. Columns 2, 3, and 4 respectively use definitions of a correlated loss event as a minimum of 30, 10, and 100 claims in the same state on the same day. Column 5 reports deciles for the nonparametric distribution using equal weights for all observations. Column 6 reports deciles using the median log-normal parameter $\mu$ and $\sigma$ estimates fit for each household based on observables.

\section{A.1.2.2 Household-level loss distributions}

We develop loss distribution estimates for each policyholder using the log-normal distribution and our assumption that the loss generating process is a mixture of isolated and correlated loss events. Our approach is similar to that of Aitkin (1987) and Western and Bloome (2009). Aitkin proposes modeling variance heterogeneity to address heteroscedasticity. Western and Bloome note that the estimations of these variance models may themselves be of interest for research related to withingroup differences and so adapt Aitkin's approach to study income inequality. They propose an iterative MLE. We use this approach to fit parameters $\mu$ and $\sigma$ of the log-normal distribution. Consider the two-equation model

$$
\begin{gathered}
\mathrm{E}\left[\log l_{i}\right]=\boldsymbol{x}_{\boldsymbol{i}}^{\prime} \boldsymbol{\beta} \\
\log \sigma_{i}^{2}=\boldsymbol{x}_{\boldsymbol{i}}^{\prime} \boldsymbol{\lambda}
\end{gathered}
$$

where $l_{i} \in(0,1]$ is the flood loss as a proportion of the home value for policyholder $i, \boldsymbol{x}_{\boldsymbol{i}}$ is a vector of policyholder observables, and $\sigma_{i}^{2}$ is the estimated variance in losses for each policyholder. We fit the model using an iterative MLE approach:

1. Estimate $\widehat{\boldsymbol{\beta}}$ using a Tobit model, which is right censored at 0 , as $\log l_{i} \in(-\infty, 0]$. Save the residuals, $e_{i}=\log l_{i}-\boldsymbol{x}_{\boldsymbol{i}}^{\prime} \widehat{\boldsymbol{\beta}}$. 
2. Estimate $\hat{\lambda}$ with a gamma regression of the squared residuals $e^{2}$, using a log link function. Save the fitted values, $\widehat{\sigma^{2}}=\exp \left(\boldsymbol{x}_{\boldsymbol{i}}^{\prime} \hat{\boldsymbol{\lambda}}\right)$.

3. Estimate $\widehat{\boldsymbol{\beta}}$ using a Tobit model with weights $1 / \widehat{\sigma}^{2}$ and update the residuals.

4. Repeat steps 2 and 3 until the log likelihood converges.

This iterative approach (1) addresses heteroscedasticity in the mean model by weighting observations based on the fitted variance, and (2) corrects the standard errors in the variance model by increasing the precision of the coefficient estimates from the mean model (Western and Bloome, 2009).

Fixed effects in these regressions account for correlated loss events. We order correlated loss events by the number of claims for each event and bin the events every 5 percentiles, creating twenty fixed effects across the distribution of correlated loss events (i.e., vigintiles). For example, a fixed effect is included for all correlated loss events for which the number of claims is below the fifth percentile, another one for events with claims from the fifth and to tenth percentiles, etc.

We follow the estimation equation A1 that we use in our claim rate regressions, though some minor differences exist in our claims and policy data. For example, these regressions do not include a households Community Rating System score. Table 12 shows the output of the mean and variance models for our baseline sample (Zone A). Its results are also qualitatively consistent with the findings of Kousky and Michel-Kerjan (2015) with respect to explanatory variables such as elevation, whether the home has a basement, and whether the home is permanent or a mobile home.

Loss observations are associated with a specific event; however, we are attempting to estimate each policyholder's loss distribution across all possible events. That is, for each household, we would like the expected loss given the explanatory variables and the occurrence of a loss event $\mathrm{E}\left[l_{i} \mid l_{i}>0 \cap \boldsymbol{x}_{\boldsymbol{i}}\right]$ but the fixed effects model provides an observation given specific event $m_{j}, \mathrm{E}\left[l_{i} \mid l_{i}>0 \cap \boldsymbol{x}_{\boldsymbol{i}} \cap m_{j}\right]$. To address this in our probability estimates, we weight each event by its probability in these data. For example, the model of log losses can be written as

$$
\log l_{i}=\alpha+\boldsymbol{x}_{\boldsymbol{i}}^{\prime} \boldsymbol{\beta}+\boldsymbol{F} \boldsymbol{E}^{\prime} \boldsymbol{\gamma}+\epsilon_{\boldsymbol{i}}
$$

where $\boldsymbol{\gamma}$ is the vector of coefficients on the fixed effects $\boldsymbol{F} \boldsymbol{E}$. The probability from this equation can then be written as

$$
\mathrm{E}\left[\log l_{i} \mid l_{i}>0 \cap \boldsymbol{x}_{\boldsymbol{i}}\right]=\overline{\pi_{h}} \alpha+\left(1-\overline{\pi_{h}}\right)(\alpha+\gamma)^{\prime} \boldsymbol{\pi}_{\boldsymbol{F} \boldsymbol{E}}+\boldsymbol{x}_{\boldsymbol{i}}^{\prime} \boldsymbol{\beta}
$$


where $\overline{\pi_{h}}$ is the probability that an observed loss is generated from an isolated loss event (rather than a correlated loss event), and $\boldsymbol{\pi}_{\boldsymbol{F} E}$ are the probabilities for each fixed effect event. In this case, each quantile has a 5 percent probability, given that a correlated loss event occurs. The term $\overline{\pi_{h}} \alpha+$ $\left(1-\overline{\pi_{h}}\right)(\alpha+\gamma)^{\prime} \pi_{F E}$ is a constant and provides the intercept for the predictive model and so can be used to estimate fitted values for each household. The same approach is taken for the variance model. The mean and variance estimates for each household are then used to fit parameters of the log-normal distribution. Table 11 provides the cumulative loss distribution for the median policyholder at each decile following this approach in Column 6. The median of these loss distributions results in a slightly higher probability of a total loss than the group-level log-normal (Column 1) and the weighted nonparametric distributions (Columns 2-4) but a lower probability than the distribution in which all observations are equally weighted (Column 5). Figure 1 illustrates the result: the triangles correspond with Column 2, the squares with Column 5, and the circles with Column 6.

\section{A.2 Premium Formula and Loads}

The formula used by the flood insurance program that determines premiums $p$ for home $i$ in community $k$ is

$$
p_{i}=\left(\left(\min \left(c_{i}, 50,000\right) r_{1, i}+\max \left(c_{i}-50,000,0\right) r_{2, i}\right) \delta_{i}+a_{1, i}\right) C R S_{k}+a_{2, i} .
$$

Households' choices affect premiums through the household's selected coverage limit $c_{i}$ and a multiplier $\delta_{i} \in[0.75,1.10]$ that depends on the selected deductible, with smaller multipliers for larger deductibles (e.g., a household choosing between a $\$ 1,000$ and $\$ 5,000$ deductible may have $\delta=1.0$ versus $\delta=0.785$, respectively). The characteristics of the home (e.g., its elevation relative to the 100-year flood plain) determine the coverage rate: $r_{1, i}$ is the rate per dollar of coverage limit on the first $\$ 50,000$ of coverage limit (mean $=0.0072$, s.d. $=0.00355) ; r_{2, i}$ is the rate for coverage limits in excess of $\$ 50,000($ mean $=0.0030$, s.d. $=0.00249)$. These parameters differ, among other reasons, depending on whether a home was built before federal flood maps were developed for its location. For example, premiums for homes built before the flood maps do not penalize low-lying properties to the extent that they do for homes built afterward. Parameter $a_{1, i}$ addresses the cost of bringing a flood-damaged home up to current building codes (mean = 44.75, s.d. =29.59). Actions taken by the community to reduce flood vulnerability can reduce households' premiums through 
a FEMA program called the "Community Rating System," $C R S_{k} \in[0.65,1] .{ }^{41}$ Finally, $a_{2, i} \in$ $\{30,35\}$ is a policy administration fee. The flood insurance program provides tables to calculate a policyholder's parameters (e.g., $r_{1}$ and $r_{2}$ ) for the premium calculation (NFIP, 2006a). We calculated premiums manually from these formulas to confirm that all the policies in our data were priced using this structure.

Loads in our baseline sample tend to be higher than that for the program. First, we only model a household's preferences from its contract choices at the time of its first claim, excluding the policy afterward and so reducing the influence of properties with frequent losses on our load statistics. The U.S. Government Accountability Office (GAO, 2006) estimates that one percent of the properties insured "account for 25 to 30 percent of all claims losses." Our baseline sample also differs in that it is limited to homes in Zone $\mathrm{A}$ and valued at $\$ 250,000$ or less (the maximum allowable coverage limit in the program, Section 3.2). Both criteria may lead to different contract loads in the baseline sample than those for the entire program. Second, loads in our baseline sample are within the range that previous research identifies for sub-populations in the program. For example, Michel-Kerjan (2010) examines the ratio of NFIP premiums collected to claims paid by state over the period 1978 to 2008 (in 2008 dollars). The ratio varies substantially by state with a maximum of 15.1 in Colorado and minimum of 0.2 in Mississippi. Finally, loads in our baseline sample are within the range of some private catastrophe insurance markets. For example, Kunreuther et al. (1995) survey insurance underwriters regarding loads for a hypothetical catastrophe insurance contract. The geometric mean of their loads ranges from 1.6 to 3.4 depending on the level of uncertainty about the risk (the geometric mean for our baseline sample is 2.7). For uncertain liability risks, they find a geometric mean load over 5.5.

Several common misperceptions about the program (e.g., that the average participating household pays actuarially advantageous rates) motivate a brief discussion of its pricing. Like private insurance markets, the flood insurance program includes expense loads to cover program and insurance agent costs; however, the program differs from private insurance pricing in two significant ways. First, flood premiums do not include capital costs (e.g., reinsurance and reserving due to uncertainty about the underlying risk). Instead, the NFIP sets premiums so that, net of expense loads, collected premiums will cover losses in the "average historical loss year." In years

\footnotetext{
${ }^{41}$ Community actions include maintaining and disseminating flood maps of the community, preventing building in floodplains, developing flood warning systems, improving community drainage systems, etc. (see FEMA, 2015).
} 
when losses exceed the program's accrued earnings, the NFIP borrows from the U.S. Treasury. Second, premium ratings are less sensitive to risk than those a private insurer would likely charge, e.g., due to grandfathering for homes built before flood maps were developed. The program's rules have resulted in substantial cross-subsidization (discussed below and in Kousky and Shabman, 2014).

\section{A.3 Modeling Heterogeneous Preferences}

We estimate a household's coefficient of risk aversion in our structural model using the regression equation

$$
\rho_{i}=\lambda_{j}+\delta_{t}+\eta_{1} \text { PropertyValue }_{i}+\eta_{2} \text { Age }+\eta_{3} I\left(\text { DefaultDeductible }_{i}=\$ 1,000\right)
$$

where $\lambda_{j}$ and $\delta_{t}$ are respectively region, using the nine U.S. Census Bureau divisions, and year fixed effects. Age is the age of the home. The property value serves as a proxy for wealth as well as other aspects of the household such as educational attainment may affect its risk preferences but are not included in the utility function. Property value and age are standardized (i.e., values are subtracted from the mean and divided by the standard deviation). Their coefficients show how a one standard deviation change in these variables affects risk aversion. Table 13 provides the regression results. 
Table 12. Models of Flood Loss as a Percent of Home Value

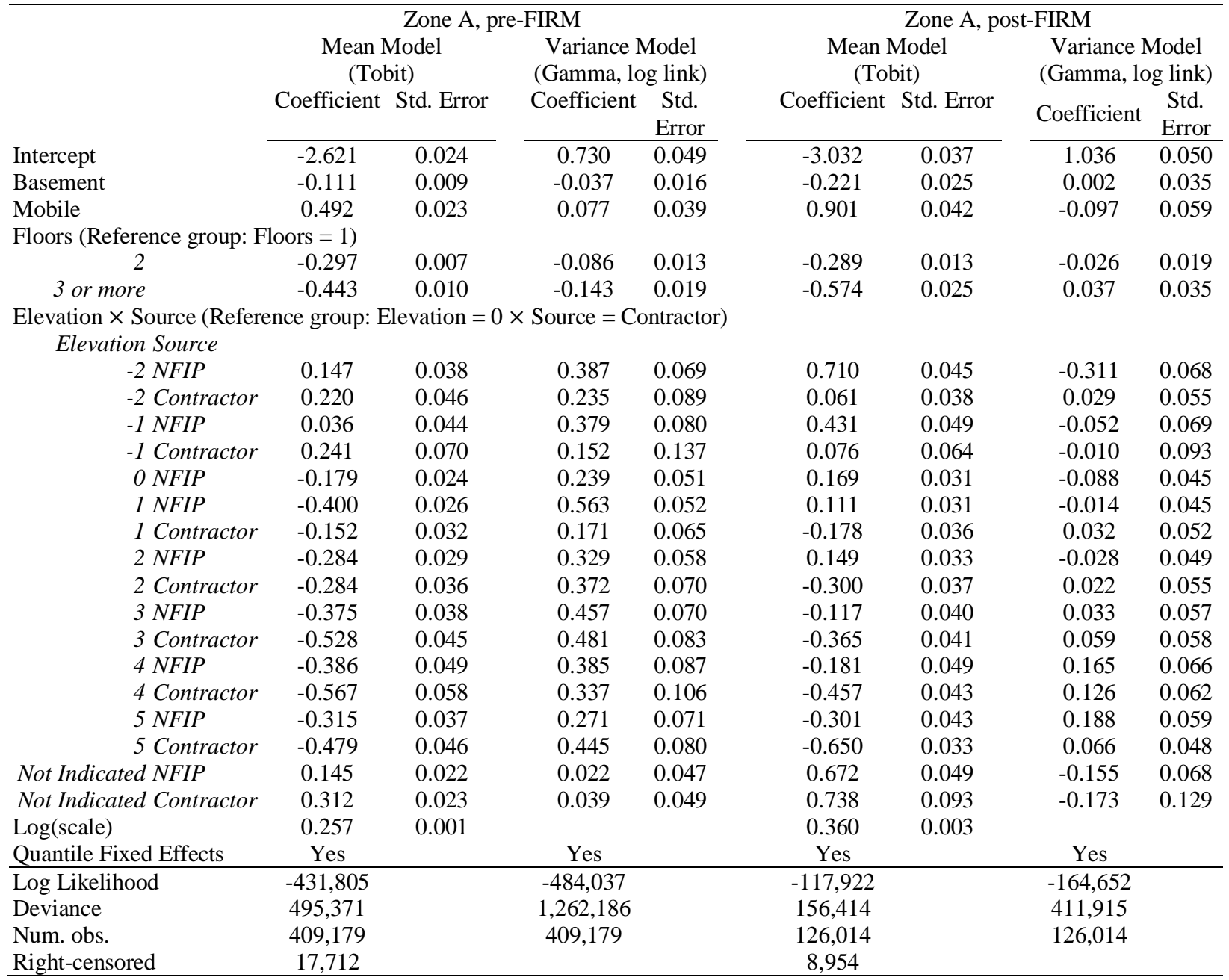

Note: Standard errors in parentheses. Models predict the mean and variance of flood loss for A zone, pre-FIRM and A zone, post-FIRM. We model flood losses between 1982 and 2009. The mean and variance models are fit using an iterative maximum likelihood approach proposed by Aitkin (1987). The mean model is a Tobit with a dependent variable of $\log (\operatorname{loss})$ where loss is measured as a proportion of the structure's value. The variance model uses the squared residuals of the mean model as a dependent variable. In turn, the inverse of the predicted value of the variance model is used to weight observations in the mean model. Quantile fixed effects describe a set of dummies we include to account for major storms. 
Table 13 Coefficient Estimates for CRRA Expected Utility Models Assuming Heterogeneous Preferences

\begin{tabular}{|c|c|c|c|c|}
\hline & \multicolumn{2}{|c|}{ Deductible } & \multicolumn{2}{|c|}{ Coverage Limit } \\
\hline & Coefficient & Standard errors & Coefficient & Standard Errors \\
\hline Intercept & 112.84 & 0.037 & 3.42 & 0.029 \\
\hline Property Value & 39.23 & 0.022 & 0.25 & 0.015 \\
\hline Age of Home & -3.41 & 0.044 & -0.14 & 0.013 \\
\hline $\mathrm{I}($ Default Deductible $=\$ 1,000)$ & -4.38 & 0.019 & -0.32 & 0.029 \\
\hline \multicolumn{5}{|c|}{ Region (Reference Group: East North Central) } \\
\hline I(East South Central) & -21.88 & 0.254 & -0.38 & 0.021 \\
\hline I(Middle Atlantic) & 36.92 & 1.572 & 0.10 & 0.020 \\
\hline I(Mountain) & 19.16 & 9.301 & -0.08 & 0.099 \\
\hline I(New England) & 24.72 & 0.783 & 0.68 & 0.070 \\
\hline $\mathrm{I}($ Other $)$ & -30.51 & 0.022 & -0.39 & 0.052 \\
\hline I(Pacific) & 60.49 & 3.342 & 0.17 & 0.040 \\
\hline I(South Atlantic) & 31.75 & 0.950 & -0.04 & 0.016 \\
\hline I(West North Central) & -20.94 & 0.734 & -0.31 & 0.032 \\
\hline I(West South Central) & -1.17 & 0.500 & -0.44 & 0.012 \\
\hline \multicolumn{5}{|l|}{ Year (Reference Group: 2008) } \\
\hline $\mathrm{I}(2003)$ & -17.47 & 0.226 & -0.44 & 0.019 \\
\hline $\mathrm{I}(2004)$ & -0.34 & 0.057 & -0.37 & 0.036 \\
\hline $\mathrm{I}(2005)$ & -7.90 & 0.696 & -0.19 & 0.011 \\
\hline $\mathrm{I}(2006)$ & 2.86 & 0.494 & -0.20 & 0.027 \\
\hline $\mathrm{I}(2007)$ & 8.96 & 1.608 & 0.10 & 0.023 \\
\hline Scale & 0.31 & 0.002 & 0.18 & 0.001 \\
\hline Log Likelihood & $-164,935$ & & $-297,756$ & \\
\hline AIC & 329,908 & & 595,549 & \\
\hline $\mathrm{BIC}$ & 330,090 & & 595,730 & \\
\hline Observations & 183,080 & & 183,080 & \\
\hline
\end{tabular}

Note: Table shows the effects of a household's characteristics on its relative risk aversion based on its deductible and coverage limit decisions. Regressions follow Equation (A2). Property value and the age of the home are standardized variables (i.e., values are subtracted from the mean and divided by the standard deviation). Default deductible indicates whether households have a $\$ 500$ or $\$ 1,000$ default deductible. Region uses U.S. Census Bureau Divisions where "other" applies to U.S. territories such as Puerto Rico.

\section{A.4 Boundary Analysis, Agreement Across Deductible and Coverage Limit Choices}

We examine whether at least one value of relative risk aversion could explain both a household's deductible and coverage limit decision. Specifically, define the "deductible interval" $\mathrm{P}_{d}$ as the range of values from the lower bound to upper bound of relative risk aversion implied by the household's deductible decision, $\mathrm{P}_{d, i} \equiv\left[\rho_{d, i}^{-}, \rho_{d, i}^{+}\right]$, likewise for the "coverage limit interval," $\mathrm{P}_{c, i} \equiv\left[\rho_{c, i}^{-}, \rho_{c, i}^{+}\right]$. We examine whether these intervals intersect, $\mathrm{P}_{d, i} \cap \mathrm{P}_{c, i}$, and conclude that they "overlap" if they are not disjoint sets. For example, a household in our data selects a $\$ 1,000$ deductible and partially insures, selecting a coverage limit that equals 90 percent of its home's replacement cost. This household's deductible interval is 10 to 26 and its coverage limit interval 
is 10 to 11 . These intervals intersect so that a relative risk aversion coefficient in the range of 10 to 11 could explain both the deductible and coverage limit decisions of this household.

Table 14 shows the percent of households whose deductible and coverage limit intervals overlap. It also describes the minimum relative risk aversion values that explain both the deductible and coverage limit decisions for households whose intervals overlap. This minimum value from the above example is 10 . For ease of exposition, we have collapsed partial insurers into a single group (in contrast Table 7 in which we subdivide them).

For fully insuring households, the risk aversion intervals overlap 85 percent of the time. As noted in Table 7, only lower bound risk aversion is identified for fully insuring households; we treat their upper bound as infinite and so conclude that the intervals overlap if the upper bound of the deductible decision exceeds the lower bound of the coverage limit decision. About 41 percent of households select the lowest deductible and fully insure; their risk aversion intervals always overlap as both have an infinite upper bound. The intervals overlap for 76 percent of households who select the $\$ 1,000$ deductible and 17 percent who select the $\$ 5,000$ deductible. While the intervals of fully insuring households overlap frequently, the minimum relative risk aversion required to explain both the deductible and coverage limit choices is high with a median of 186.

In contrast, the intervals of partially insuring households overlap infrequently, 12 percent of the time, but the minimum risk aversion for these households with overlap is often in the single digits with a median of 3 . In total, about 2.6 percent of households in our data have both overlapping intervals and a lower bound risk aversion below 10.

Finally, we consider the 23 percent of households who deviate from the default deductible as it is possible that these households might be more actively engaged in the choice process than households who select the menu default. Deviating households have a median lower bound risk aversion of 65 from their deductible. Also, 27 percent of these deviating households partially insure and so depart from the norm on both choices. The deductible and coverage limit choices of these households overlap 7.7 percent of the time (508 households in total) and indicate a median lower bound of 3 when they do. 
Table 14 Comparison of Relative Risk Aversion Estimates from Deductible and Coverage Limit Decisions

\begin{tabular}{|c|c|c|c|c|c|c|c|c|c|c|}
\hline \multirow[b]{3}{*}{ Coverage Limit } & \multirow[b]{3}{*}{ Deductible } & \multirow[b]{3}{*}{ Obs. } & \multirow[b]{3}{*}{ Overlap (\%) } & \multicolumn{7}{|c|}{ Min. Risk Aversion for Households with Overlap } \\
\hline & & & & \multirow[b]{2}{*}{ Mean } & \multirow[b]{2}{*}{ St. Dev. } & \multicolumn{5}{|c|}{ Percentiles } \\
\hline & & & & & & $1 \%$ & $10 \%$ & $50 \%$ & $90 \%$ & $99 \%$ \\
\hline \multirow[t]{4}{*}{ Full } & 500 & 40,395 & 100 & 278.1 & 229.7 & 27 & 72 & 211 & 579 & 1,110 \\
\hline & 1,000 & 35,722 & 76 & 208.4 & 155.7 & 21 & 70 & 157 & 422 & 752 \\
\hline & 5,000 & 2,404 & 17 & 36.0 & 32.8 & -11 & 1 & 31 & 74 & 146 \\
\hline & All Deductibles & 80,145 & 85 & 247.7 & 205.8 & 22 & 69 & 186 & 514 & 1,008 \\
\hline \multirow[t]{4}{*}{ Partial } & 500 & 7,682 & 6 & 10.7 & 35.5 & 0 & 1 & 2 & 10 & 204 \\
\hline & 1,000 & 13,184 & 15 & 5.6 & 14.7 & 0 & 1 & 3 & 8 & 56 \\
\hline & 5,000 & 1,520 & 9 & 5.3 & 5.8 & 0 & 2 & 3 & 11 & 30 \\
\hline & All Deductibles & 22,935 & 12 & 6.5 & 19.8 & 0 & 1 & 3 & 8 & 101 \\
\hline All Coverage Limits & All Deductibles & 103,080 & 69 & 238.8 & 207.1 & 2 & 55 & 179 & 505 & 1,002 \\
\hline
\end{tabular}

Note: Table uses the lower and upper bounds of relative risk aversion implied by a household's deductible and coverage limit decisions. "Overlap" indicates that a household's risk aversion interval from its deductible intersects the risk aversion interval from its coverage limit. For households with overlapping intervals, we report the minimum risk aversion value that could explain both the deductible and coverage limit decisions.

\section{A.5 Modeling Probability Distortions}

We allow for probability weighting of the cumulative probability distribution following Quiggin (1982). While a variety of probability weighting functions have been proposed (e.g., Tversky \& Kahneman, 1992; Prelec, 1998; Wu and Gonzalez, 1996), the probabilities in our data are small relative to the values tested in those studies. Therefore, we take a more flexible approach and model probability weights using a Chebyshev polynomial expansion, following Barseghyan et al. (2013). For example, a third-degree Chebyshev polynomial would lead to

$$
\begin{aligned}
T_{0}(\Pi) & =1 \\
T_{1}(\Pi) & =\Pi \\
T_{2}(\Pi) & =2 \Pi^{2}-1 \\
T_{3}(\Pi) & =4 \Pi^{3}-3 \Pi \\
\Omega=\alpha_{0} T_{0}+\alpha_{1} T_{1} & +\alpha_{2} T_{2}+\alpha_{3} T_{3}
\end{aligned}
$$

where $\Pi$ is a vector of cumulative probabilities, $\Omega$ is the transformed probabilities, $T_{m}$ is the Chebyshev polynomial of order $m$, and $\alpha_{j}$ represent a set of coefficients to be estimated. We impose a penalty in our maximum likelihood estimations that prevents negative probabilities and 
the sum of distorted flood probabilities from exceeding 1. For ease of interpretation, we simplify the presentation of our results through substitution, rewriting Equation $A 3$ as

$$
\begin{aligned}
\Omega & =\alpha_{0}-\alpha_{2}+\left(\alpha_{1}-3 \alpha_{3}\right) \Pi+2 \alpha_{2} \Pi^{2}+4 \alpha_{3} \Pi^{3} \\
& =\beta_{0}+\beta_{1} \Pi+\beta_{2} \Pi^{2}+\beta_{3} \Pi^{3}
\end{aligned}
$$

where $\beta_{0}=\alpha_{0}-\alpha_{2}$ and $\beta_{1}=\alpha_{1}-3 \alpha_{3}$, etc.

Table 15 shows the model results using increasingly higher polynomial expansions for a random sample of 10,000 households from our data. For Row 1, the case in which we assume that households do not distort probabilities, we set $\beta_{0}, \beta_{2}, \beta_{3}=0$ and $\beta_{1}=1$ and use MLE to fit $\rho$. For Row 2, we set $\beta_{0}, \beta_{2}, \beta_{3}=0$, and use MLE to fit $\rho$ and $\beta_{1}$, etc. Our estimates of $\rho$ for each model are quite stable across higher order polynomial expansions of probability distortions. Most probability distortion models assume that probabilities pass through the origin $\left(\beta_{0}=0\right)$. We find that this assumption changes our estimates of risk aversion very little relative to the other distortion models (compare the second row for the deductible and coverage limits to higher rows), but our model fit is notably improved by allowing for an intercept. The best fitting models, those that minimize the Bayesian Information Criterion (BIC) and Akaike Information Criterion (AIC) values, are shown in bold type - a second-degree polynomial for the deductible and a first-degree polynomial for the coverage limit. 
Table 15 Estimates of CRRA Across Probability Distortion Approximations

\begin{tabular}{cccccccccc} 
& & & & \multicolumn{5}{c}{ Log } \\
& $\rho$ & $\beta_{0}$ & $\beta_{1}$ & $\beta_{2}$ & $\beta_{3}$ & $\sigma$ & Likelihood & AIC & BIC \\
\hline Deductible & 145 & & & & & 0.368 & $-16,368$ & 16,372 & 32,754 \\
& -0.209 & & 8.73 & & & 0.194 & $-10,361$ & 10,367 & 20,750 \\
& -4.19 & 0.0288 & 5.44 & & & 0.189 & $-10,091$ & 10,099 & 20,219 \\
& $\mathbf{- 4 . 1 1}$ & $\mathbf{0 . 0 2 8 8}$ & $\mathbf{5 . 9 8}$ & $\mathbf{- 5 9 . 6 3}$ & & $\mathbf{0 . 1 8 5}$ & $\mathbf{- 1 0 , 0 8 0}$ & $\mathbf{1 0 , 0 9 0}$ & $\mathbf{2 0 , 2 0 6}$ \\
& -4.17 & 0.0288 & 6.06 & -62.25 & 1.71 & 0.185 & $-10,079$ & 10,091 & 20,213 \\
Coverage Limit & 2.78 & & & & & 0.180 & $-29,035$ & 29,039 & 58,088 \\
& -2.59 & & 19.30 & & & 0.111 & $-25,303$ & 25,309 & 50,634 \\
& $-\mathbf{0 . 7 7 7}$ & $\mathbf{0 . 0 0 7 5}$ & $\mathbf{3 . 8 3}$ & & & $\mathbf{0 . 1 2 7}$ & $\mathbf{- 2 3 , 9 6 1}$ & $\mathbf{2 3 , 9 6 9}$ & $\mathbf{4 7 , 9 5 9}$ \\
& -0.777 & 0.0075 & 3.83 & -0.0013 & & 0.127 & $-23,961$ & 23,971 & 47,968 \\
& -0.777 & 0.0075 & 3.83 & -0.0012 & 0.0000 & 0.127 & $-23,961$ & 23,973 & 47,977 \\
\hline
\end{tabular}

Note: Table compares models of probability distortions derived from household deductible and coverage limit decisions using a CRRA utility model where $\rho$ is the coefficient of relative risk aversion. The best fitting models, those that minimize the Bayesian Information Criterion (BIC) and Akaike Information Criterion (AIC) values, are shown in bold type. Parameters $\boldsymbol{\beta}$ show probability distortions $\Omega=\beta_{0}+\beta_{1} \Pi+$ $\beta_{2} \Pi^{2}+\beta_{3} \Pi^{3}$ where $\Pi$ is the objective probability. Parameters in the table left blank are omitted from the MLE. When $\beta_{0}, \beta_{2}$, and $\beta_{3}$ are omitted, they are assumed to equal 0 ; when $\beta_{1}$ is omitted, it is assumed to equal 1. Random sample of 10,000 households from the baseline data.

\section{A.6 Comparison of Probability Weighting Functions}

Here, we compare the probability weighting estimates from our CRRA rank dependent utility models with Chebyshev polynomials to commonly used probability weighting functions from Prelec (1998) and Wu and Gonzalez (1996). Table 16 provides the results. For comparison, the first rows ("Polynomial") repeat our results described above (Section 6.2) in which we model probability distortions using Chebyshev polynomials (labelled "RDU CRRA" in Table 5). The remaining rows show the estimates using the Prelec and Wu-Gonzalez probability weighting functions. The Prelec results and $\mathrm{Wu}-$ Gonzalez results are almost identical. Both indicate a $\rho$ coefficient of about -8.7 for the deductible and about -0.83 for the coverage limit. These coefficients are smaller (more negative) than those for the polynomial model, but qualitatively similar in that they indicate diminishing sensitivity to losses. These models correctly predict 66 percent of households' deductible choices (versus 64 for the polynomial model) and coverage limits by an average of 2 percentage points (like the polynomial model). 
Table 16 Comparing Probability Weighting Functions for CRRA Rank Dependent Utility

\begin{tabular}{|c|c|c|c|c|c|c|c|c|c|}
\hline & & $\rho$ & & & & $\sigma$ & $\begin{array}{c}\text { Log } \\
\text { Likelihood }\end{array}$ & AIC & BIC \\
\hline \multirow[t]{2}{*}{ Polynomial } & Deductible & $\begin{array}{c}-4.08 \\
(0.059)\end{array}$ & $\begin{array}{c}\beta_{0} \\
0.029 \\
(0.014)\end{array}$ & $\begin{array}{c}\beta_{1} \\
6.03 \\
(0.023)\end{array}$ & $\begin{array}{c}\beta_{2} \\
-59.14 \\
(0.014)\end{array}$ & $\begin{array}{c}0.186 \\
(0.000074)\end{array}$ & $-103,865$ & 103,875 & 207,788 \\
\hline & Coverage Limit & $\begin{array}{c}-0.767 \\
(0.0088)\end{array}$ & $\begin{array}{c}0.00774 \\
(0.000034)\end{array}$ & $\begin{array}{c}3.64 \\
(0.027)\end{array}$ & & $\begin{array}{c}0.125 \\
(0.00049)\end{array}$ & $-244,469$ & 244,477 & 488,984 \\
\hline
\end{tabular}

\begin{tabular}{|c|c|c|c|c|c|c|c|}
\hline \multirow{3}{*}{ Prelec } & \multirow{2}{*}{ Deductible } & -8.62 & $\begin{array}{c}v \\
0.728\end{array}$ & $\begin{array}{c}\psi \\
0.794\end{array}$ & 0.194 & \multirow{2}{*}{$-103,317$} & \multirow{2}{*}{$103,325206,680$} \\
\hline & & $(0.13)$ & $(0.0022)$ & $(0.0021)$ & $(0.00084)$ & & \\
\hline & Coverage Limit & $\begin{array}{l}-0.837 \\
(0.013)\end{array}$ & $\begin{array}{c}1.51 \\
(0.0021)\end{array}$ & $\begin{array}{c}0.554 \\
(0.00069)\end{array}$ & $\begin{array}{c}0.130 \\
(0.00052)\end{array}$ & $-245,094$ & $245,102490,234$ \\
\hline
\end{tabular}

\begin{tabular}{|c|c|c|c|c|c|c|c|}
\hline \multirow[t]{3}{*}{ Wu-Gonzalez } & Deductible & -8.83 & $\begin{array}{c}\delta \\
0.709\end{array}$ & $\begin{array}{c}\gamma \\
0.436\end{array}$ & $\begin{array}{c}0.195 \\
(0.00082)\end{array}$ & $-103,353$ & $103,361206,752$ \\
\hline & Coverage Limit & $\begin{array}{l}(0.11) \\
-0.824\end{array}$ & $\begin{array}{c}(0.0076) \\
0.146\end{array}$ & $\begin{array}{c}(0.0026) \\
0.357\end{array}$ & $\begin{array}{c}(0.00082) \\
0.131\end{array}$ & $-245,290$ & $245,298490,626$ \\
\hline & & $(0.018)$ & $(0.005)$ & $(0.0043)$ & $(0.00053)$ & & \\
\hline
\end{tabular}

Note: Standard errors are in parentheses. Table compares probability weighting functions with CRRA rank dependent utility for households' deductible and coverage limit decisions. The first model repeats results from Table 5, where they are labeled "RDU CRRA." The models use maximum likelihood estimation to fit model parameters. The parameter $\sigma$ describes the scale of errors in the random utility model. Parameters $\boldsymbol{\beta}$ show probability distortions $\Omega=$ $\beta_{0}+\beta_{1} \Pi^{\prime}+\beta_{2} \Pi^{\prime 2}$ where $\Pi$ is the rank-ordered cumulative objective probability. Negative values for the coefficient of relative risk aversion $\rho$ indicate diminishing sensitivity to losses. The $\beta_{2}$ parameter is assumed to equal 0 in the coverage limit model based on the analysis in Online Appendix A.4. Baseline sample of 103,080 policies.

\section{A.7 Robustness Tests and Alternative Explanations}

In this section, we consider aspects of the setting and our modeling approach that might interfere with estimating households' preferences from their observed deductible and coverage limits. Our analysis also builds on previous research regarding insurance decisions and risk preferences from Cohen and Einav (2007), Sydnor (2010), Barseghyan, Prince, and Teitelbaum (2011), Barseghyan et al. (2013), and others, and each of those papers provides a thoughtful discussion of alternative explanations that often also apply to our setting.

\section{A.7.1 Expo-Power Utility}

The expo-power utility function (Saha, 1993) can accommodate a variety of combinations of relative and absolute risk preferences (e.g., DARA, DRRA, etc.). It takes the form

$$
u(x)=-\exp \left(-\tau x^{\psi}\right)
$$

with restrictions $\tau \neq 0, \psi \neq 0$, and $\tau \psi>0$. Holt and Laury (2002) posit that expo-power utility might reconcile households' small and large stakes preferences and find supporting evidence in their lab experiments. CARA is nested in expo-power utility, when $\psi=1$. 
Table 17 provides the results. Expo-power preferences provide an improvement over CRRA in explaining both households' deductible and coverage limit preferences according to the AIC and BIC. A Vuong test leads to a similar conclusion, resulting in a fit that is significantly better at the 1 percent level in each case. The deductible parameters are $\{\tau, \psi, \sigma\}=\{1.8 \times$ $\left.10^{-4}, 1.14,0.20\right\}$, which a combination of increasing absolute risk aversion (IARA) and increasing relative risk aversion (IRRA) for the deductible model. The coverage limit model parameters are $\{\tau, \psi, \sigma\}=\left\{5.05 \times 10^{-5}, 1.00,0.21\right\}$, indicating a combination of IRRA and constant absolute risk aversion. That is, expo-power collapses to the CARA model in explaining households' coverage limit decisions.

The limitations of CRRA expected utility also apply to expo-power. Expo-power preferences correctly predict households' deductible choices at rates similar to CRRA (46 percent versus 47 percent for CRRA). Expo-power predict that households would choose much smaller coverage limits than what they do: expo-power underestimates households' coverage limit ratios choices by an average of 27 percentage points (versus 34 for CRRA). Like CRRA preferences, expo-power preferences result in substantially different model parameters for households' deductible and coverage limit decisions. For example, the $\tau$ parameter is over three times larger for the deductible decision.

While these tests of expo-power do not exhaust the many possible utility functions that might be employed in expected utility models, they further illustrate the difficulty of explaining households' small and large stakes insurance preferences with common applications of expected utility theory. 
Table 17 Expected Utility, Expo-Power Preferences Model Results

\begin{tabular}{lcccccc} 
& $\tau$ & $\psi$ & $\sigma$ & Log Likelihood & AIC & BIC \\
\hline Deductible & $1.8 \mathrm{e}-04$ & 1.14 & 0.202 & $-152,867$ & 305,740 & 305,769 \\
& $(3.3 \mathrm{e}-06)$ & $(0.0015)$ & $(0.0014)$ & & & \\
Coverage Limit & $5.5 \mathrm{e}-05$ & 1.00 & 0.208 & $-294,245$ & 588,496 & 588,525 \\
& $(7.3 \mathrm{e}-07)$ & $(0.00079)$ & $(0.0012)$ & & & \\
\hline
\end{tabular}

Note: Standard errors are in parentheses. Table compares utility models describing households' deductible and coverage limit decisions, comparing outcomes using the Akaike information criterion (AIC) and the Bayesian information criterion (BIC). For the AIC and BIC, lower values indicate better fit. The remaining models use maximum likelihood estimation to fit model parameters. Baseline sample of 103,080 policies.

\section{A.7.2 Household Wealth}

Perhaps households are considering a much lower or higher level of wealth than what we assume, affecting our risk preference estimates. We analyze the sensitivity of our findings to our wealth assumptions using a random sample of 10,000 policies from the baseline sample. We set wealth equal to varying proportions of the replacement cost $R C$, ranging from 5 percent to 10 times its value, using scalar $\alpha$. To illustrate, we rewrite the coverage limit problem (Equation 2), replacing wealth $w$ with $\alpha R C$

$$
\max _{c \in[c, \bar{c}]} \int_{0}^{d^{*}} u(\alpha h-p(c)-l) \omega(l)+\int_{d^{*}}^{c} V\left(\alpha h-p(c)-d^{*}\right) \omega(l)+\int_{c}^{, \bar{c}} V\left(\alpha h-p(c)-d^{*}-l+c\right) \omega(l) \quad d l
$$

where $d^{*}$ is the deductible that the household selects, $p$ the premium, $l$ losses with $l \in[0, R C]$, and $\omega(l)$ the household's transformation of loss probabilities. As before, we set a lower bound so that wealth never falls below $\$ 1$. The average replacement cost is $\$ 107,177$ in our data, and so similar to Sydnor (2010), these wealth assumptions range from an average of about $\$ 5,000$ to $\$ 1$ million across values of $\alpha$. Rather than the replacement cost, the final column uses the home's property as reference wealth (average value: $\$ 112,387$ ). Property value and replacement cost have a Pearson correlation of 0.58 .

Across wealth assumptions, our findings are qualitatively consistent with the main findings that our structural models consistently estimate much higher risk aversion in the deductible models than in the coverage limit models. Table 18 shows the results. For the deductible, relative risk aversion follows the expected pattern: for a given insurance contract, estimates of risk aversion increase in household wealth. For the coverage limit, we observe that risk aversion decreases in wealth until around 50 percent of the replacement cost, then increases. The increase in risk aversion for low values of $\alpha$ results from households selecting large coverage limits relative to their assumed wealth. The deductible and coverage limit risk aversion estimates diverge as reference 
wealth grows. For example, assuming that household wealth is 10 times its replacement cost (on average about $\$ 1$ million in absolute terms) leads to risk aversion estimates of $\rho_{\text {Deductible }}=1,378$ and $\rho_{\text {CoverageLimit }}=56$.

While not typically applied in classical utility theory, the table also shows that deductible and coverage limit preferences could be reconciled by allowing households to select different reference wealth for each decision. For example, a reference wealth of about 5 percent of the replacement cost in the deductible decision and around 200 percent of the replacement cost in the coverage limit decision would seem to result in similar relative risk aversion coefficients. However, the expected utility models for coverage limits continue to under-predict households' coverage limit selections. For example, the CRRA expected utility model with $\rho=9.33, \sigma=0.149$, and wealth as 200 percent of the home's replacement cost predict an average coverage limit ratio of 70 percent while the actual average is 93 percent.

Finally, using property value as reference wealth results in similar relative risk aversion estimates as using replacement cost (with $\alpha=1$ in both cases), though the relative risk aversion from the coverage limit is slightly higher (3.7 versus 2.6).

\section{Table 18. Relative Risk Aversion Estimates Across Wealth Assumptions}

\begin{tabular}{|c|c|c|c|c|c|c|c|c|c|c|c|}
\hline & \multirow[b]{3}{*}{$\alpha$} & \multicolumn{5}{|c|}{ Deductible } & \multicolumn{5}{|c|}{ Coverage Limit } \\
\hline & & \multicolumn{3}{|c|}{ Std. } & \multirow{2}{*}{$\begin{array}{c}\text { Std. } \\
\text { Error }\end{array}$} & \multirow{2}{*}{$\begin{array}{c}\text { Log } \\
\text { Likelihood }\end{array}$} & \multicolumn{3}{|c|}{ Std. } & \multirow{2}{*}{$\begin{array}{l}\text { Std. } \\
\text { Error }\end{array}$} & \multirow{2}{*}{$\begin{array}{c}\text { Log } \\
\text { Likelihood }\end{array}$} \\
\hline & & $\rho$ & Error & $\sigma$ & & & $\rho$ & Error & $\sigma$ & & \\
\hline \multirow[t]{8}{*}{ Replacement Cost } & 0.05 & 7.56 & 0.229 & 0.399 & 0.007 & $-15,199$ & 1.42 & 0.002 & 0.121 & 0.002 & $-26,578$ \\
\hline & 0.10 & 15.4 & 0.303 & 0.355 & 0.008 & -15 & 1.29 & 0.002 & 0.11 & 0.001 & $-25,358$ \\
\hline & 0.25 & 38.1 & 0.564 & 0.334 & 0.008 & -15, & 1.16 & 0.002 & 0.145 & 0.002 & $-25,654$ \\
\hline & 0.50 & 62.5 & 0.206 & 0.372 & 0.009 & $-16,2$ & 1.12 & 0.003 & 0.206 & 0.003 & $-27,546$ \\
\hline & 1 & 145 & 2.193 & 0.368 & 0.010 & $-16,368$ & 2.62 & 0.035 & 0.230 & 0.007 & $-29,095$ \\
\hline & 2 & 278 & 4.134 & 0.355 & 0.009 & $-16,280$ & 9.33 & 0.057 & 0.149 & 0.003 & $-28,276$ \\
\hline & 5 & 689 & 10.347 & 0.346 & 0.009 & $-16,222$ & 26.8 & 0.163 & 0.147 & 0.003 & $-28,103$ \\
\hline & 10 & 1,378 & 19.835 & 0.343 & 0.009 & $-16,204$ & 55.7 & 0.322 & 0.146 & 0.003 & $-28,057$ \\
\hline Property Value & 1 & 141 & 0.77 & $0.31-$ & 0.008 & $-16,120$ & 3.71 & 0.057 & 0.312 & 0.006 & $-30,194$ \\
\hline
\end{tabular}

Note: Table shows estimated relative risk aversion for households' deductible and coverage limit decisions using CRRA expected utility models. In the rows labeled "Replacement Cost" (the first eight rows), $\alpha$ is multiplied by the replacement cost so that, for example, the first row shows a risk aversion of $\rho=7.56$ from the deductible decision when household wealth is assumed to be 5 percent of the replacement cost (around $\$ 5,000$ in these data). The final row assumes that household wealth is the home's property value rather than the replacement cost. Random sample of 10,000 policies from the baseline sample.

\section{A.7.3 Consumption Commitments}

Households' decisions may reflect budget or liquidity constraints. For example, Chetty and Szeidl's (2007) theory of consumption commitments posits that large shocks lead to adjustments 
in fixed liabilities (e.g., housing costs); however, such adjustments can be costly so small shocks are fully born by discretionary consumption. We exploit variation in property values in our data to assess for empirical evidence that households' preferences for low deductibles are explained by consumption commitments.

While Chetty and Szeidl's (2007) describe consumption commitments as a percent of income, all households in our data face the same deductible menu. As a household's income grows, the utility loss of paying an insurance deductible (of say \$500) would be expected to decrease because it represents a smaller proportion of the household's discretionary consumption. This argument predicts that (risk averse) households with higher incomes would select higher deductibles in this program. Instead, we find that households with higher property values (a proxy for income) are slightly more likely to select a low deductible.

Figure 8 shows households' property values (as a proxy for income) and their deductible choices. We do not observe a consistent relationship; households with high and low property values prefer low deductibles. We estimate an ordered logit, regressing the deductible choice on property values (in $\$ 10,000$ ) for household $i$

$$
\text { Deductible }_{i}=\alpha_{j t}+\beta \text { PropertyValue }_{i}+\varepsilon_{i}
$$

where $\alpha_{j t}$ are County $\times$ Year fixed effects. We find a statistically significant, negative relationship between property values and deductible choices, an odds ratio of $\beta=0.986$ (s.e. $=$ 0.0013, $p<0.01$ ). We conclude that such commitments may influence the decisions of some households in our data, but our results do not seem to be explained by consumption commitments. 

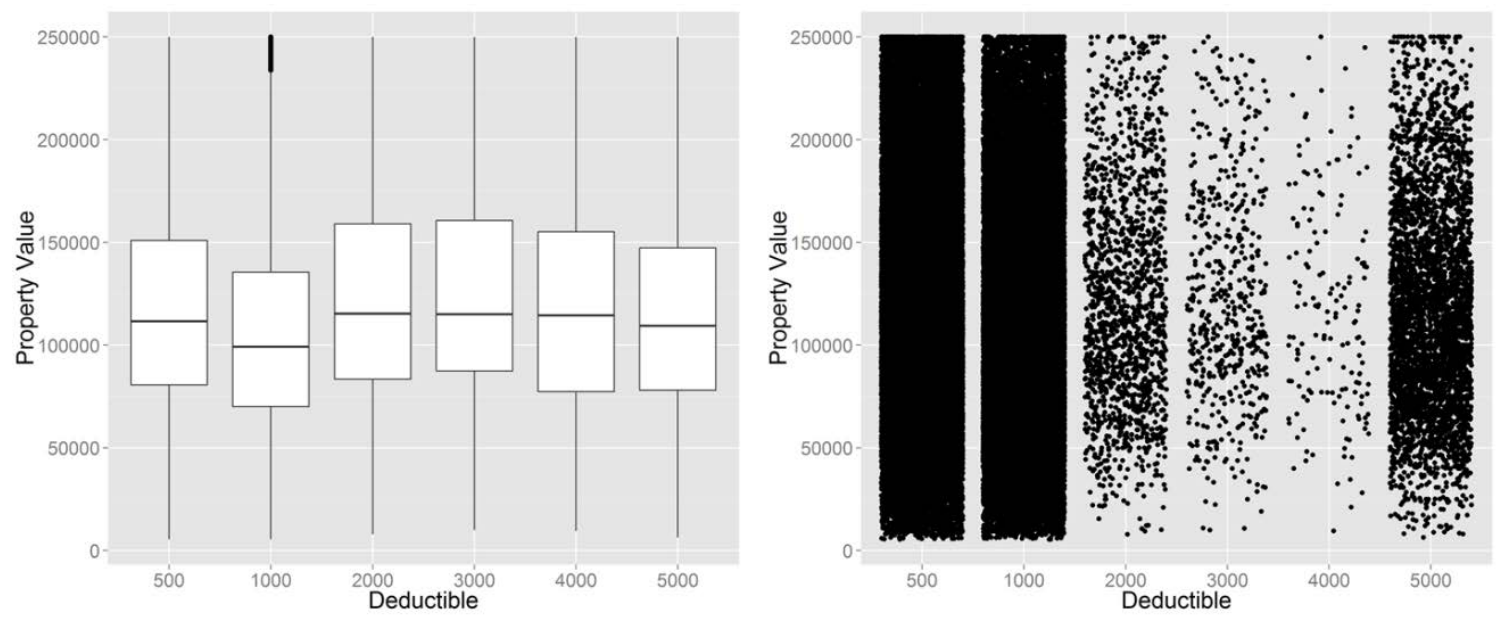

Figure 8 Boxplot and Jitter Plot of Households' Deductible Choices and Property Values

Note: The left figure provides a boxplot of household deductible choices and property values. The solid line in the center of each box shows the median property value, the upper and lower edges of the box provide $25^{\text {th }}$ and $75^{\text {th }}$ percentiles, and the solid lines extend to 1.5 times the interquartile range, the distance between the $25^{\text {th }}$ and $75^{\text {th }}$ percentiles. Dots outside of these lines identify individual outliers. The right figure shows individual observations of deductible choices and property values. Baseline sample of 103,080 policies.

\section{A.7.4 Mortgages and Strategic Non-repayment}

The differences in households' preferences across low and high stakes might be explained by their use of mortgages: homeowners may be unconcerned about losses beyond their equity. By modeling households' potential loss as the total value of the home, we would overestimate their exposure and conclude that households selecting low coverage limits are less risk aversion than they actually are. If households are insuring based on their limited liability for damage to the home, we would expect them to select lower coverage limits relative to their replacement costs in "nonrecourse" states, where lenders' ability to collect on defaulted mortgages is limited. ${ }^{42} \mathrm{We}$ find a small difference in recourse and non-recourse states, as shown in Figure 9. For example, 75 percent of households in non-recourse states fully insure compared to 78 percent of households in recourse states. The magnitude of this difference on our preference estimates is negligible and cannot explain households' coverage limit choices.

\footnotetext{
${ }^{42}$ Non-recourse laws prevent lenders from seeking a deficiency judgment when the sale from a foreclosure is insufficient to cover the homeowner's liability on a defaulted mortgage. Orlando (2011) identifies Alaska, Arizona, California, Hawaii, Minnesota, Montana, North Dakota, Oklahoma, Oregon, and Washington as non-recourse states during the same time period as our data.
} 


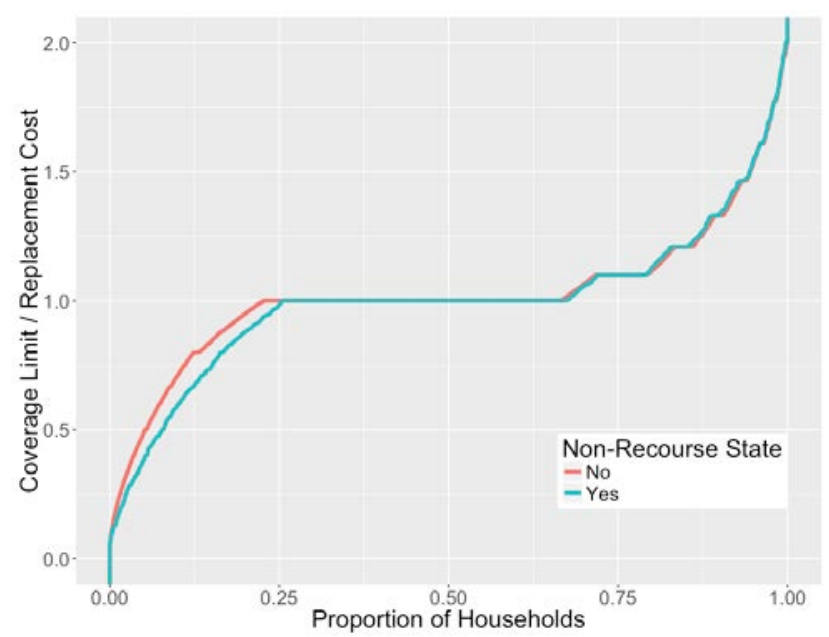

Figure 9 Coverage Limits Selected in Recourse and Non-Recourse States

Note: The figure compares coverage limit selections for households that live "non-recourse" states versus other states. Orlando (2011) identifies Alaska, Arizona, California, Hawaii, Minnesota, Montana, North Dakota, Oklahoma, Oregon, and Washington as non-recourse states during the same time period as our data.

\section{A.7.5 Program Requirements}

Households in our baseline sample are required to insure against flood if they have a mortgage from a federally regulated lender. This mortgage requirement does not seem to be consistently enforced (Dixon et al., 2006); however, contracts may not reflect household preferences if, say, lenders determined coverage limits (e.g., required that households fully insure their homes). We compare coverage limit selections for our baseline sample with households that participate in the program but live in a zone not subject to the federal requirement. Figure 10 compares the distribution of coverage limits for our core sample (labeled "Federal Requirement") and the less vulnerable group (labeled "No Requirement"). About 78 percent of households fully insure in the baseline sample versus 80 percent fully insure in the zone where flood insurance is not required (Online Appendix A.7.5). The similar coverage limit distribution for these two groups suggests that the federal requirement has little effect on the coverage limit choices that insured households select. 


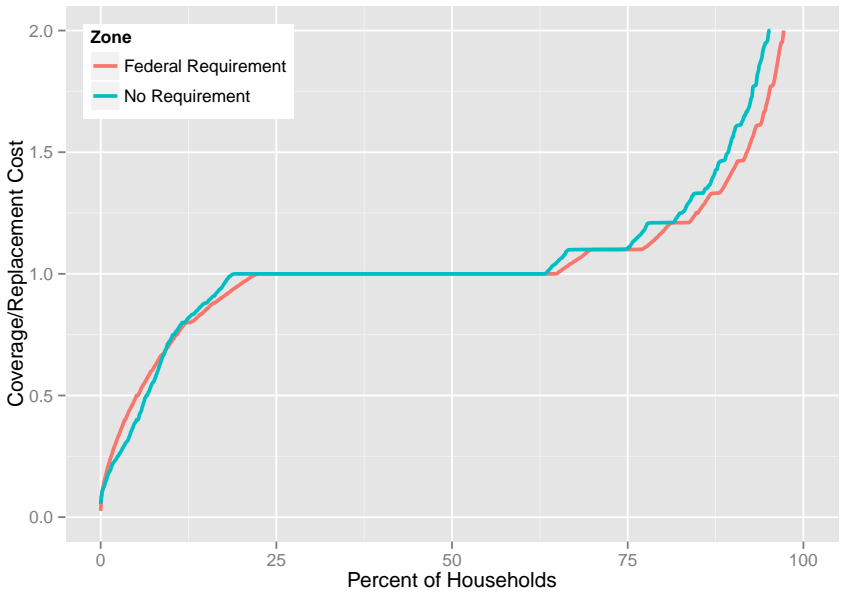

Figure 10 Coverage Limits Selected in Zones Where Insurance is Sometimes Required vs. Voluntary

Note: The figure compares coverage limit selections for households that live in a zone in which the federal government requires that households with federally backed mortgages insure with a zone in which households are not required to insure.

\section{A.7.6 Policy Tenure}

Previous research identifies that households often maintain the same financial contract terms despite changes over time that would be expected to lead them to update their contracts. For example, Sydnor (2010) finds that while new customers frequently select one of the lowest deductible options for their homeowners insurance in his data, households with longstanding policies (e.g., 15 years) are even more likely to have a low deductible. In this context, households' insurance contract decisions may result from inertia rather than current risk preferences. Like Michel-Kerjan, de Forges, and Kunreuther (2012), we find that the mean flood insurance policy tenure during this time is four years (the median is two years), reducing concerns that the households' contract choices reflect severely outdated preferences. We find a small effect of contract duration on households' choices. For example, 44 percent of households with policy tenures in the first quartile (1 year or less) selected the lowest deductible while 46 percent of households with policy tenures in the fourth quartile (5 years or greater) did so. Households with first quartile policy durations fully insured their homes 73 percent of the time while those with fourth quartile policy durations did so 78 percent of the time. 


\section{A.7.7 Deductible Menu Defaults}

Households are influenced by program default options in many contexts (e.g., Madrian and Shea, 2001). Most households (77 percent) select the default deductible option in our data, which might indicate inattention or that the defaults are judiciously chosen to match households' risk preferences. Our baseline sample includes two deductible defaults: one group has a $\$ 500$ default and another a $\$ 1,000$ default. Households with the $\$ 1,000$ default deductible have riskier homes with higher premiums and so this default may result from this group's tendency to select higher deductibles. For example, about 6 percent of these households select the highest deductible available $\$ 5,000$ while only 1 percent of households with the $\$ 500$ deductible do so.

We find a modest effect of deductible menu defaults on our estimates. First, we re-estimate our models excluding households who adopted the default option. Table 19 provides the results, labeled "Active Choosers." We re-estimate our CRRA expected utility models excluding households who adopted the default option and find risk aversion estimates of $\rho_{\text {Deductible }}=108$ and $\rho_{\text {Coverage Limit }}=2.6$. As we are omitting households based on their deductible choices, we observe larger differences in the parameter estimates from households' deductible decisions. For example, we estimate relative risk aversion of 108 for these households versus 139 for our baseline sample. Second, we include a household's assigned default deductible in the model of heterogeneous preferences (Online Appendix A.3). While standard models predict that a household's assigned default deductible would not influence the preferences inferred from its contract choices, we find that being assigned a default of $\$ 1,000$ (rather than the $\$ 500$ default) reduces a households' relative risk aversion by 4.38 in the deductible model, after controlling for other factors such as the age and property value of the home. Finally, our boundary analysis indicates that households who deviate from the default deductible make a deductible choice that requires a median lower bound risk aversion of 65 (Online Appendix A.4).

\section{A.7.8 Misunderstandings About the Insurance Coverage Limit}

A large group of households (35 percent) purchased coverage limits that were higher than their replacement costs. We tend to agree with Mossin's (1968) explanation that households may buy too much insurance to address the risk that their replacement cost is higher than anticipated; however, perhaps instead these households did not understand the contract that they were purchasing, thinking that they could receive larger payments than the replacement cost. Our 
models, which account for the contract structure, may not correctly estimate the risk preferences of households that misunderstood it. Given this possibility, we re-estimate our model excluding these households. Table 19 provides the results, labeled "No Over-Insurers," which are similar to our estimates with the baseline sample (e.g., $\rho_{\text {Deductible }}=147$ and $\rho_{\text {Coveragelimit }}=2.5$ ).

Table 19 Estimates for Households That Did Not Select Their Default Deductible and Households That Did Not Over-Insure

\begin{tabular}{lcccccc}
\multicolumn{1}{l}{} & $\rho$ & $\sigma$ & Log Likelihood & AIC & BIC \\
\hline $\begin{array}{lccccc}\text { Active Choosers } \\
\text { EUT CRRA }\end{array}$ & Deductible & 108 & 2.78 & $-43,169$ & 86,342 & 86,360 \\
& $(3.46)$ & $(0.153)$ & & & \\
\multicolumn{1}{c}{ Coverage Limit } & 2.56 & 0.188 & $-69,907$ & 139,818 & 139,836 \\
& $(0.0115)$ & $(0.00231)$ & & & \\
\multicolumn{2}{l}{$\begin{array}{l}\text { No Over-Insurers } \\
\text { EUT CRRA Deductible }\end{array}$} & 147 & 0.44 & $-110,901$ & 221,806 & 221,824 \\
& $(0.807)$ & $(0.00461)$ & & & \\
& Coverage Limit & 2.48 & 0.159 & $-184,929$ & 369,862 & 369,880 \\
& $(0.00638)$ & $(0.0011)$ & & & \\
\hline
\end{tabular}

Note: See Section A.7.6 and Section A.7.8 for details. Number of observations: 24,193 ("Active Choosers") and 66,732 ("No Over-Insurers").

\section{A.7.9 Events with Small Probabilities}

We also test our main results in an area with a higher probability of flooding. A great deal of research on risk preferences, especially lab research, considers events with likelihoods greater than the average annual claim rate of 1.3 percent in our data. Perhaps our preference estimates are an anomalous byproduct of examining relatively rare events.

Our data also include a population that is vulnerable to inundation as well as wave damage (dwellings located directly on the coast, in FEMA-defined V zones) and their average annual claim rate is 4.1 percent, over three times higher than that of our core sample. This claim rate is similar to Sydnor (2010) and Barseghyan, Prince, and Teitelbaum (2011) who examine homeowners insurance deductibles. We analyze the coverage limit selections for 7,113 households in this higher risk zone.

Premiums are much higher in this zone, with a mean of \$1,497 (and median of \$1,201), almost 3 times the average in the baseline sample of $\$ 540$ (Table 1). Households in this zone choose higher deductibles: 78 percent choose one of the lowest two deductibles (versus 94 percent in the 
baseline sample) and 12 percent choose the highest deductible of $\$ 5,000$ (versus 3.8 percent in the baseline sample). Eighty percent of these households fully insure.

Table 20 provides the results. For comparability to the coverage limit, we restrict the probability weighting model to a second order polynomial for the deductible decision. We find qualitatively similar risk aversion estimates in the CRRA expected utility models to those in our baseline sample. Rank dependent utility models continue to show overweighting of small probabilities and diminishing sensitivity to losses.

Table 20 Parameter Estimates Across Models for High Risk Zone

\begin{tabular}{|c|c|c|c|c|c|c|c|c|}
\hline & & $\rho$ & $\beta_{0}$ & $\beta_{1}$ & $\sigma$ & $\begin{array}{c}\text { Log } \\
\text { Likelihood }\end{array}$ & AIC & BIC \\
\hline \multirow[t]{2}{*}{ EUT CRRA } & Deductible & $\begin{array}{l}139 \\
(3.3)\end{array}$ & & & $\begin{array}{c}1.24 \\
(0.064)\end{array}$ & $-12,525$ & 25,054 & 25,068 \\
\hline & Coverage Limit & $\begin{array}{c}3.58 \\
(0.035)\end{array}$ & & & $\begin{array}{c}0.135 \\
(0.0047)\end{array}$ & $-21,084$ & 42,172 & 42,186 \\
\hline \multirow[t]{2}{*}{ RDU CRRA } & Deductible & $\begin{array}{l}-10.2 \\
(0.24)\end{array}$ & $\begin{array}{c}0.087 \\
(0.0015)\end{array}$ & $\begin{array}{c}4.2 \\
(0.042)\end{array}$ & $\begin{array}{c}0.401 \\
(0.0065)\end{array}$ & $-10,318$ & 20,644 & 20,671 \\
\hline & Coverage Limit & $\begin{array}{l}-0.681 \\
(0.026)\end{array}$ & $\begin{array}{c}0.0382 \\
(0.0004)\end{array}$ & $\begin{array}{l}0.778 \\
(0.12)\end{array}$ & $\begin{array}{c}0.127 \\
(0.0017)\end{array}$ & $-15,486$ & 30,980 & 31,007 \\
\hline
\end{tabular}

Note: Standard errors are in parentheses. Table compares utility models describing households' deductible and coverage limit decisions. The models use maximum likelihood estimation to fit model parameters. The parameter $\sigma$ describes the scale of errors in the random utility model. Parameters $\boldsymbol{\beta}$ show probability distortions $\Omega=\beta_{0}+\beta_{1} \Pi^{\prime}$ where $\Pi^{\prime}$ is the rank-ordered cumulative objective probability. Expected utility theory (EUT) assumes that households weight outcomes based on their objective probabilities and so these models fix $\beta_{0}=0$ and $\beta_{1}=1$. We allow for probability distortions using rank dependent utility (RDU, Quiggin, 1982). Positive values for $\beta_{0}$ and $\beta_{1}>1$ indicate overweighting of the small probabilities in our data. Negative values for the coefficient of relative risk aversion $\rho$ indicate diminishing sensitivity to losses. Number of observations: 7,113. 